\title{
Heterogeneity of gut microbial responses in healthy household dogs transitioning from an extruded to a mildly cooked diet
}

\author{
Jirayu Tanprasertsuk ${ }^{1}$, Justin Shmalberg ${ }^{1,2}$, Heather Maughan ${ }^{1,3}{ }^{,}$, Devon E Tate ${ }^{1}$, LeeAnn M Perry ${ }^{1}$, Aashish R Jha \\ 1,4 , Ryan W Honaker ${ }^{\text {Corresp. } 1}$ \\ ${ }^{1}$ NomNomNow Inc, Nashville, Tennessee, United States of America \\ 2 Department of Comparative, Diagnostic, and Population Medicine, College of Veterinary Medicine, University of Florida, Gainesville, Florida, United \\ States \\ 3 Ronin Institute, Montclair, New Jersey, United States of America \\ 4 Genetic Heritage Group, Program in Biology, New York University Abu Dhabi, Abu Dhabi, United Arab Emirates \\ Corresponding Author: Ryan W Honaker \\ Email address: ryan.honaker@nomnomnow.com
}

Background: The gut microbiota (GM) is associated with canine health and can be impacted by diet. Dog owners in the U.S. have increasingly shown an interest in feeding their dogs a mildly cooked (MC) diet. However, its impact on canine GM and health remains largely unknown.

Methods: Healthy household dogs were tracked upon switching from various brands of extruded to MC diets for four weeks. A health assessment was completed and stool samples were collected by each owner before (day 0) and after the diet transition (day 28). Shotgun metagenomic sequencing was performed at both time points to characterize the GM.

Results: Dogs completed the study by either completing the health assessments $(n=31)$ or providing stool samples at both time points $(n=28)$. All owners reported either better or no change in overall health at the end of the study ( $61 \%$ and $39 \%$, respectively), and none reported worse overall health. Defecation frequency was also reported to be lower (58\%) or about the same (35\%). Principal coordinate (PCo) analysis showed a significant shift $(p=0.004)$ in the $\beta$-diversity of the GM upon diet transition $(34.2 \%$ and $10.3 \%$ explained by the first two axes). The abundances of 70 species increased after the diet change (adjusted $p<0.05$ ), $67 \%$ and $24 \%$ of which belonged to the Lactobacillales and the Enterobacterales orders respectively. The abundances of 28 species decreased (adjusted $p<0.05$ ), 46\%, 18\%, and 11\% of which belonged to the Clostridiales, Bacillales, and Bacteroidales orders, respectively. Lower Lactobacillales and Enterobacterales, and higher Bacteroidales at baseline were associated with a greater shift along the PCol axis. Protein content of the baseline diet was correlated with the shift along the PCol axis $(\rho=0.67, p=0.006)$.

Conclusion: Owners reported either improvement or no change in health in dogs transitioning from extruded kibble to MC diets for 4 weeks, but this report of health perception requires further exploration in a controlled trial. Diet change also led to a significant shift in the GM profile of healthy dogs. The magnitude of shift was associated with baseline GM and dietary protein, and warrants further examination of individualized responses and personalized nutrition in companion dogs. These results also support future investigation of the impact of a MC diet on health maintenance given its increasing popularity. 


\section{Title}

2 Heterogeneity of gut microbial responses in healthy household dogs transitioning from an extruded

3 to a mildly cooked diet

4

\section{Running title}

6 Dog gut microbiome upon diet change

7

\section{Authors}

9 Jirayu Tanprasertsuk, $\mathrm{PhD}^{1}$, Justin Shmalberg, DVM, DACVN, DACVSMR ${ }^{1,2}$, Heather Maughan, $\mathrm{PhD}^{1,3}$, Devon E. Tate, MNSP ${ }^{1}$, LeeAnn M. Perry, $\mathrm{MS}^{1}$, Aashish R. Jha, $\mathrm{PhD}^{1,4}$, Ryan W. Honaker, $11 \mathrm{PhD}^{1}$

13 Affiliation

$14{ }^{1}$ NomNomNow Inc, Nashville, Tennessee, USA

152 Department of Comparative, Diagnostic, and Population Medicine, College of Veterinary 16 Medicine, University of Florida, Gainesville, Florida, USA

$17{ }^{3}$ Ronin Institute, Montclair, New Jersey, USA

$18{ }^{4}$ Genetic Heritage Group, Program in Biology, New York University Abu Dhabi, Abu Dhabi, 19 UAE

20

\section{Corresponding author}

22 Ryan W. Honaker, $\mathrm{PhD}^{1}$

23 NomNomNow Inc, 
242223 Whites Creek Pike,

25 Nashville, TN 37207, USA

26 ryan.honaker@nomnomnow.com

27

28

29

30

31

32

33

34

35

36

37

38

39

40

41

42

43

44

45

46

Peer] reviewing PDF | (2021:03:58917:1:2:NEW 18 May 2021) 


\section{$47 \quad$ Abstract}

48 Background: The gut microbiota $(\mathrm{GM})$ is associated with canine health and can be impacted by diet. Dog owners in the U.S. have increasingly shown an interest in feeding their dogs a mildly

50

$67 \mathrm{p}=0.006)$.

68 Conclusion: Owners reported either improvement or no change in health in dogs transitioning cooked (MC) diet. However, its impact on canine GM and health remains largely unknown.

Methods: Healthy household dogs were tracked upon switching from various brands of extruded to $\mathrm{MC}$ diets for four weeks. A health assessment was completed and stool samples were collected by each owner before (day 0) and after the diet transition (day 28). Shotgun metagenomic sequencing was performed at both time points to characterize the GM.

Results: Dogs completed the study by either completing the health assessments $(n=31)$ or providing stool samples at both time points $(n=28)$. All owners reported either better or no change in overall health at the end of the study (61\% and 39\%, respectively), and none reported worse overall health. Defecation frequency was also reported to be lower $(58 \%)$ or about the same (35\%). Principal coordinate $(\mathrm{PCo})$ analysis showed a significant shift $(\mathrm{p}=0.004)$ in the $\beta$-diversity of the GM upon diet transition (34.2\% and $10.3 \%$ explained by the first two axes). The abundances of 70 species increased after the diet change (adjusted $\mathrm{p}<0.05$ ), $67 \%$ and $24 \%$ of which belonged to the Lactobacillales and the Enterobacterales orders respectively. The abundances of 28 species decreased (adjusted $\mathrm{p}<0.05$ ), 46\%, 18\%, and $11 \%$ of which belonged to the Clostridiales, Bacillales, and Bacteroidales orders, respectively. Lower Lactobacillales and Enterobacterales, and higher Bacteroidales at baseline were associated with a greater shift along the PCo1 axis. Protein content of the baseline diet was correlated with the shift along the PCo1 axis $(\rho=0.67$, from extruded kibble to $\mathrm{MC}$ diets for 4 weeks, but this report of health perception requires further 
70 exploration in a controlled trial. Diet change also led to a significant shift in the GM profile of

71 healthy dogs. The magnitude of shift was associated with baseline GM and dietary protein, and

72 warrants further examination of individualized responses and personalized nutrition in companion

73 dogs. These results also support future investigation of the impact of a MC diet on health

74 maintenance given its increasing popularity.

75

76

77

78

79

80

81

82

83

84

85

86

87

88

89

90

91

92 


\section{List of abbreviations}

94 AAFCO

$95 \mathrm{BCS}$

96 DESeq2

$97 \quad \mathrm{FC}$

98 FDR

99 GI

100 GLM

101 GM

102 HR

$103 \mathrm{IQR}$

104 KEGG

$105 \mathrm{KO}$

106 LAB

107 LR

$108 \mathrm{MC}$

109 MR

110 PAM

111 PCo

112 PCoA

113 PERMANOVA
American Association Feed Control Officials

body condition score

differential expression analysis for sequence count data version 2

fold change

false discovery rate

gastrointestinal

generalized linear model

gut microbiome

high-responder

interquartile range

Kyoto Encyclopedia of Genes and Genomes

KEGG Orthology

lactic acid bacteria

low-responder

mildly cooked

mid-responder

Partitioning Around Medoids

principal coordinate

principal coordinate analysis

permutational multivariate analysis of variance

114

115 


\section{Introduction}

117 For several millennia humans and dogs coevolved, sharing food and shelter (Axelsson et al., 2013).

118 However, extruded dry food, commonly known as kibble, remains the most common form of

119 feeding pet dogs in the United States. Extrusion cooking refers to a process where a mixture of 120 ingredients is steam conditioned, compressed, and forced through the die of an extruder (Tran, 121 Hendriks \& van der Poel, 2008). Mildly cooked (MC) diets, composed of ingredients that are 122 cooked without extrusion, have been gaining in popularity in recent years among dog owners in 123 the U.S. (PRWeb, 2015; Algya et al., 2018). Commercial MC canine diets are increasingly 124 available, and must conform with the American Association Feed Control Officials (AAFCO) 125 nutrient profiles or have been tested in feeding trials for the labeled life stages when complete and balanced. The nutritional profile of a MC diet may or may not differ significantly from dried and extruded pet food. Compared to dried and extruded food, MC diets have higher moisture content, higher digestibility of fats and protein, and dogs fed a MC diet for 28 days had lower levels of triglycerides (Algya et al., 2018; Oba et al., 2020; Do et al., 2021). Additionally, positive health perception was reported by dog owners after feeding their dogs a veterinarian-formulated MC diet (Johnson et al., 2016). However, the nutritional contents of MC diets and their effect on overall canine health remain understudied compared to other types of commercial dog foods.

134 Dietary changes are generally accompanied by alterations of the gut microbiota (GM) (Wernimont et al., 2020), which can have profound impact on canine health and disease (Redfern, Suchodolski

136 \& Jergens, 2017; Pilla \& Suchodolski, 2019). Many studies have shown microbiome composition

137 changes upon switching to raw food diets, which are often higher in protein and fat and lower in 138 carbohydrates (including fiber) than kibble diets (reviewed in (Wernimont et al., 2020)). These 
139 studies have shown that raw food diets lead to increased levels of certain Fusobacteria and

140 Proteobacteria (Sandri et al., 2017; Algya et al., 2018; Schmidt et al., 2018). Similarly, MC diets

141 have been associated with higher levels of certain Bacteroidetes, Fusobacteria and Proteobacteria,

142 and lower levels of certain Actinobacteria and Firmicutes as compared to an extruded kibble diet

143 (Algya et al., 2018; Do et al., 2021). However, these studies were conducted in only a small group

144 of dogs under a laboratory setting. Thus, to what extent does MC influences the gut microbiomes

145 of real world pet dogs with heterogeneous characteristics such as age, breeds, living conditions,

146 and body size remains unexplored.

147

148 An investigation of the effect of dietary transition to a MC diet on GM and owner-reported 149 subjective health metrics in healthy dogs was carried out to improve understanding of the effects 150 of this increasingly popular diet type. Dogs switched from an extruded kibble to a MC diet for four

151 weeks were assessed for changes relative to baseline in: 1) the gut microbiome by profiling the 152 taxonomic and functional compositions of feces; and 2) perceived health outcomes using an 153 owner-reported survey. Due to the variety of differences between diets, we hypothesized we would 154 observe a shift in the diversity and abundance of GM upon diet change. Enrolled dogs were healthy 155 at recruitment, however we aimed to determine if any additional positive impacts were reported 156 by owners, including outcomes likely to change based on the literature for similar diets (e.g fecal 157 output).

\section{Materials and methods}

160

Dog owners gave electronic informed consent to the use of their dog's non-identifying data for 162 scientific study prior to study enrollment. All dog owners willingly underwent diet transition 
163 regardless of study participation. As previously explained (Tanprasertsuk et al., 2021), since fecal

164 samples were collected non-invasively by the dog owners, no institutional animal ethical review 165 was required.

166

167

\subsection{Animals and study design}

168

A total of 4,978 dog owners were contacted via email to gauge interest in study participation (Fig. 169

1). All owners were incoming customers of Nom Nom (a direct-to-consumer pet food and health company in Nashville, TN, USA), who intended to switch their dog's diet to a MC diet regardless of study participation. A total of 850 dogs of various breeds were screened using an online questionnaire; 54 dogs met the inclusion criteria described below and were enrolled in the study.

Dogs were eligible to participate in the study if they met the following owner-assessed criteria at enrollment: aged 1-14 years, body condition score (BCS) of 4-6 on the 9-point scale (Laflamme, 1997), currently feeding two meals per day exclusively of an extruded kibble diet with treats comprising $\leq 10 \%$ of overall caloric intake, absent of gastrointestinal (GI) issues (including chronic diarrhea/vomiting or diarrhea/vomiting within the previous 30 days), absent of any infections or major chronic diseases (pancreatitis, diabetes, kidney disease or failure, liver disease, heart disease, cancer, severe GI issues when young [ $<6$ months old]), and not pregnant or lactating). Only one 181 dog per household was permitted to enroll. Dogs were not eligible to participate if they had consumed any prebiotics, probiotics, cultured foods, or antibiotics within the last three months, had a significant change in their diet within the last month, or had surgery within the previous three months. The criteria were similar to those previously described (Tanprasertsuk et al. 2021). 
186 Participants were asked to provide the brand and formula of the baseline extruded kibble diet, and 187 guaranteed analysis of nutrients was assembled when possible. Online health assessments were 188 administered and stool samples were collected by owners one day before the diet transition (day 189 0) and again four weeks after the diet transition (day 28). On day 1, dogs began the transition from 190 their previous extruded diet to a MC diet. An email reminder was sent out to all dog owners weekly 191 to ensure adherence to the study diet and maintenance of baseline habits (supplements, medication, 192 and exercise), as well as provide owners with the opportunity to report any observed adverse 193 effects.

194

195

196

\subsection{Dietary interventions}

Dog owners chose one to four commercially-available Nom Nom recipes as their study MC diet 197 (Beef, Chicken, Pork, Turkey). Mildly cooking includes cooking techniques designed to reach 198 internal temperatures for reduction of pathogens but without canning or extrusion, and the term is used to describe similar diets in a previous study (Algya et al., 2018). However, unlike the MC diet in the referenced paper, the protein sources were not ground and emulsified, but mixed into a homogenous blend with vitamin and mineral supplements. After cooking, the diets were then 202 refrigerated or frozen and thawed prior to feeding. Dietary information for participants who completed the study is summarized in Supplemental Fig. 1. The ingredients and guaranteed 204 nutrient analysis of each recipe are available in Table 1. All recipes were formulated to meet AAFCO standards for all life stages. All dog owners were instructed to feed two MC meals daily 206 from day 1 to the completion of the study on day 28. The meal portion for each dog was calculated

207 using a proprietary custom-portioning algorithm which takes owner-reported ideal body weight 
208 and physical activity level into account. The amount of food not consumed was also reported at 209 the end of the study to account for dietary adherence.

210

\section{$211 \quad 2.3$ Health assessment}

212 An online health assessment was completed by each owner prior to diet transition (day 0 ). The 213 assessment was composed of five broadly targeted questionnaires containing questions about 214 signalment, overall wellness, diet and lifestyle, medical history, oral health, and behavior, and was 215 previously used in a research study (Jha et al., 2020). Questions included single-choice checkbox, 216 multiple-choice radio-button, dropdown, and fill-in-the-blank questions. A second set of online 217 assessment questions was administered to assess change in health outcomes from baseline as 218 perceived by the owner on day 28. The questions are written verbatim in Supplemental Table 1. 219 A visual stool chart was used to assess the fecal quality (Lewis \& Heaton, 1997), and a previously 220 validated 9-point system was used to assess the BCS (Laflamme, 1997).

221

222

\subsection{Stool sample collection and DNA extraction}

223 Stool samples from each dog were collected by owners with Nom Nom Plus Microbiome Testing 224 Kits (NomNomNow, Inc., TN, USA) at baseline (day 0) and four weeks after the diet transition 225 (day 28). The kits were previously used in research studies (Jha et al. 2020; Tanprasertsuk et al. 226 2021). All stool samples were processed and sequenced in a single batch at Diversigen, Inc. (MN, 227 USA). DNA extraction and library construction protocols were performed as previously described 228 (Johnson et al. 2019; Tanprasertsuk et al. 2021), with the exception that DNA was extracted using 229 the Zymogen Quick-DNA Fecal/Soil Microbe 96 Mag Bead kit (Zymo Research, CA, USA) using 230 Powerbead Pro (Qiagen, CA, USA) plates with $0.5 \mathrm{~mm}$ and $0.1 \mathrm{~mm}$ ceramic beads. Extraction 
231 controls included a no template control (water) and a characterized homogenized stool. All

232 samples were quantified with Quant-iT Picogreen dsDNA Assay (Invitrogen, CA, USA).

233 Subsequently, DNA amplification and library construction were performed with the Nextera XT

234 DNA Library Preparation Kit (Illumina Inc, CA, USA).

235

236

\subsection{GM shotgun metagenomic sequencing and annotation}

237 Whole genome shotgun sequence reads used for this study are available on the NCBI Short Read 238 Archive associated with the NCBI BioProject PRJNA714112. Shotgun metagenomic sequencing 239 was performed at Diversigen, Inc. (MN, USA) using their Boostershot shallow metagenomic 240 sequencing service (2 million reads/sample), as previously described (Johnson et al., 2019). For 241 quality control, single-end shotgun reads were trimmed and processed using Shi7 (Al-Ghalith et 242 al., 2018). The sequences were then aligned to the NCBI RefSeq representative prokaryotic 243 genome collection at 97\% identity using BURST with default settings (Al-Ghalith \& Knights, 244 2017). A filtering step was performed to remove taxa present in $<5 \%$ of the samples and those 245 belonging to unknown phyla. The resulting taxonomy table was also aggregated at higher 246 taxonomy levels (for example, species, genus, family). After filtering, a total of 959 taxa were used 247 for the analysis (Supplemental Fig. 2). The average sequencing depth was 2,481,073 $\pm 909,748$, 248 and the depth per sample ranged from 476,329 to 4,819,202 reads. It has been shown that this 249 particular method of low-depth metagenomic sequencing can reach species-level taxonomic 250 assignment and allows for the assessment of functional profiles (Hillmann et al., 2018).

251

$252 \quad 2.6$ Functional annotation 
253 Sequenced reads were matched directly using alignment at 97\% identity to the Kyoto Encyclopedia

254 of Genes and Genomes Orthology groups (KEGG KOs) derived from the NCBI RefSeq 255 representative prokaryotic genome collection. A filtering step was performed to remove KO terms 256 present in $<5 \%$ of the samples and those whose absolute count was $\leq 1$. After $401 \mathrm{KO}$ terms were 257 removed, 4,216 terms were used in subsequent analyses.

258

259

\subsection{Statistical analysis}

260 Continuous variables are expressed as mean $\pm \mathrm{SD}$, unless specified as mean $\pm \mathrm{SEM}$. GM relative 261 abundances are expressed as median (IQR). Categorical variables are presented as count (\%). All 262 analyses were performed using R Studio version 1.2.5033. Statistical significance level was set at $263 \alpha=0.05$.

264 265

\subsubsection{Analysis of health outcomes}

266

267 268 269 270 271 of responses.

272

273

274 Similar to the approach previously described (Jha et al. 2020), species richness and Shannon's 275 diversity indices were computed by rarefying the samples to various depths starting from 10,000- 
276470,000 sequences per sample by increasing the sequencing depth by 10,000 reads. One hundred

277 iterations were performed at each depth and mean values were used as the estimate of these

278 measures in each sample. Wilcoxon signed rank test was used to compare changes of alpha

279 diversity metrics (evenness, diversity indices) from baseline to week 4.

280

281 The non-rarefied count data were log-transformed and principal coordinate analysis (PCoA) was 282 performed using Bray-Curtis dissimilarity calculated with the vegan package at the species level 283 (Oksanen et al. 2014; Tanprasertsuk et al. 2021). Using the vegan package, permutational 284 multivariate analysis of variance (PERMANOVA) was performed using Bray-Curtis dissimilarity 285 with 10,000 randomizations by including timepoints to assess the differences in community 286 composition (Oksanen et al., 2014). Partitioning around the medoids (PAM) Clustering was also 287 performed to investigate the dissimilarity of bacterial profiles in samples collected at two different 288 time points using the cluster package (Maechler et al., 2015). Fisher's exact test was performed to 289 investigate the association between the cluster membership and timepoint. Kruskal-Wallis test 290 with Dunn's post hoc test, Wilcoxon signed rank test, and McNemar's Chi-squared test were 291 performed to compare various measures among different groups as specified throughout the 292 manuscript.

293

294 Differential abundances of bacterial taxa between timepoints were assessed at each taxonomic 295 level using a negative binomial generalized linear model (GLM), using the differential expression 296 analysis for sequence count data version 2 package (DESeq2) (Love et al. 2014; Jha et al. 2020). 297 Taxa with absolute $\log _{2}$ (fold change $\left.[\mathrm{FC}]\right)>2$ and FDR-adjusted p-values $<0.05$ were considered 298 significant. 
300 To investigate the dissimilarity of bacterial profiles among subjects at baseline, we utilized the 301 same statistical methods described above (PCoA using Bray-Curtis dissimilarity, PAM Clustering, 302 negative binomial GLM with DESeq2). Additionally, random forest classifiers were constructed 303 using repeated k-fold cross validation and random search implemented in the R-package caret 304 (Khun, 2014). As previously described (Jha et al. 2020), the data were randomly divided into 305 training and validation sets containing $70 \%$ and $30 \%$ of the samples, respectively, and bacterial 306 species were used as the predictors. The models were trained by optimizing the tuning parameters 307 using 10-fold cross validation repeated 3 times, and accuracy was used to select the optimal model. 308 The performance of the classifiers was assessed by generating area under the receiver operating 309 characteristic curves using the R-package ROCR (Sing et al., 2005).

311 Similarly, the non-rarefied count data of KO terms were log-transformed and PCoA was performed 312 using the Bray-Curtis dissimilarity as described above. A negative binomial GLM using the 313 DESeq2 was performed to identify differentially abundant $\mathrm{KO}$ terms between the two time points.

314 The identified KO terms were used for KEGG pathway mapping against the PATHWAY database 315 (Kanehisa \& Sato, 2020).

\section{$317 \quad$ 2.7.3 Correlation analysis}

318 Correlation analysis was performed to investigate the relationship between: 1) the PCo1 score and 319 the abundance of Enterobacterales and Lactobacillales at baseline; and 2) the PCo1 score and the macronutrient composition in the baseline extruded diet. Spearman's correlation coefficients are

321 reported. 


\section{3. Results}

324

\subsection{Cohort description}

325 Of 54 dogs initially enrolled, 13 did not complete the study due to the following reasons: vomiting $326(n=1)$, diarrhea $(n=1)$, loss to follow-up $(n=3)$, and owners' personal reasons not related to dog 327 health $(\mathrm{n}=8)$ (Fig. 1). No major adverse effect was reported. Eight cases (14.8\%) of diarrhea and 328 nine cases $(16.7 \%)$ of vomiting were reported in those who enrolled, regardless of study 329 completion. The rates of diarrhea and vomiting were 1 case per 27 dog-weeks and 1 case per 24 330 dog-weeks, respectively.

332 The remaining 41 participants completed the study by either filling out the online health 333 assessment, collecting a stool sample, or both. Among those who completed the study, three dogs

334 missed $>6$ meals of the study diet and five dogs changed their medication habit. These included 335 four cases of antibiotic use (two cases of urinary tract infection, one case of diarrhea, one case of common cold) and one case of Prednisone use (to treat a physical injury not related to the study). After the exclusion of these eight dogs, data for 33 dogs were available for subsequent analyses ( $\mathrm{n}=5$ only completed the online health assessment, $\mathrm{n}=2$ only provided fecal samples, $\mathrm{n}=26$ provided both). In other words, of the 33 dogs that completed the study, we included 31 dogs for health data analysis and 28 for the microbiome data analysis.

\section{$342 \quad 3.2$ Subject characteristics}

343 Characteristics of the 31 dogs with the health assessment data and the 28 dogs with fecal samples

344 are described in Table 2. The wide distribution of body weights reflect the diversity of breeds. 
345 Age, sex, weight, and breed information for each individual dog is available in Supplemental

346 Table 2. The baseline extruded kibble diets were diverse in terms of ingredients and nutrient

347 profiles (data not shown). Reported fecal consistency scores were on average between 3 (sausage-

348 shaped with cracks on surface) and 4 (sausage-shaped or snake like, smooth and soft).

349

$350 \quad 3.3$ Health outcomes

351 Dog owners' perceptions of changes in health outcomes 28 days after the diet transition are listed

352 in Table 3. Of 31 dog owners, 19 (61\%) reported better overall health, 15 (48\%) reported higher

353 physical activity, 15 (48\%) reported improved coat condition, and 19 (61\%) reported higher

354 appetite. Post-hoc pairwise comparisons showed the proportion of owners that reported no change

355 in these outcomes was not significantly different from those that reported an improvement. None

356 of the dog owners reported worsened overall health, coat condition, or lower physical activity level

357 after transitioning from extruded kibble to MC diet. Furthermore, 18 (58\%) reported lower

358 defecation frequency. Fecal score showed a small decrease from $3.0 \pm 1.3$ to $2.5 \pm 0.9$ after diet

359 transition but it was not statistically significant $(\mathrm{p}=0.091)$. Body weight on average was maintained

360 throughout the study period.

361

3623.4 Gut microbiome

363 3.4.1 Diversity

364 To investigate the effect of diet transition on GM a-diversity, we calculated two standard a-

365 diversity measures, species richness and Shannon's diversity index. A rarefaction curve generated

366 for sequencing depth 10,000-470,000 reads demonstrated sufficient sequencing depth to assess the

367 alpha diversity (Supplemental Fig. 3A and 3B). Using sequencing depth at 470,000 reads, these 
368 a-diversity measures were not significantly different between baseline and four weeks after diet

369 change ( $\mathrm{p}>0.05$, Wilcoxon signed rank test).

370

371 PCoA was performed to investigate changes in $\beta$-diversity. The first two axes (PCo1 and PCo2),

372 which respectively explained $34.2 \%$ and $10.3 \%$ of variation at the species level (Fig. 2A.)

373 Eigenvalues for the first 25 PCo axes are displayed in Supplemental Fig. 4. Spatial separation

374 between the two timepoints along the first two PCo axes was demonstrated ( $p=0.004$,

375 PERMANOVA Bray-Curtis dissimilarity matrices). A shift in PCo1 score, but not PCo2-5 scores,

376 was also observed after 4 weeks of diet change ( $p=1.72 \mathrm{E}-04$, Wilcoxon signed rank test, Fig. 2B).

377

378 Using PAM Clustering analysis to investigate changes in $\beta$-diversity, the 56 samples (2 samples

379 from each of the 28 dogs) could be partitioned into 2 clusters (Supplemental Fig. 5). The first

380 cluster (C1) consisted primarily of baseline samples (15 samples collected at baseline and 5

381 samples collected at week 4), while the second cluster (C2) consisted of 13 samples collected at

382 baseline and 23 samples collected at week 4. A significantly higher proportion of subjects had their

383 baseline samples assigned to $\mathrm{C} 1$ and their week 4 samples assigned to $\mathrm{C} 2$ than the null hypothesis

$384(\mathrm{p}=0.009$, McNemar's Chi-squared test $)$. This result further confirms a significant shift in GM

385 composition occurred due to dietary shift from extruded kibble to MC in these participants,

386 although the presence of 13 baseline samples in C2 also indicates heterogeneous responses to diet

387 change. 
389

390

391

392

393

394 395

396

397

398

399

400

401

402

403

404

405

406

407

408

409

410

\subsubsection{Relative abundances}

Four phyla, Firmicutes, Proteobacteria, Actinobacteria, and Bacteroidetes, dominated the GM

(Fig. 3, 28 subjects are displayed in three separate rows based on the magnitude of MB response as explained in section 3.5.1). No significant changes in relative abundances were observed between the timepoints at phylum or class levels after diet change (adjusted $p>0.05$, negative binomial GLM with DESeq2). The relative abundance of the order Micrococcales significantly increased after the diet change (Supplemental Table 3). At the family level, the relative abundances of four families significantly increased at week 4 (Leuconostocaceae, Hafniaceae, Lactobacillaceae, and Morganellaceae), while four families significantly decreased after 4 weeks of diet change (Prevotellaceae, Sutterellaceae, Atopobiaceae, and Microbacteriaceae).

The effect of diet change was more pronounced at the genus and species levels. Relative abundances of 16 genera increased and 12 genera decreased significantly after the diet change (Supplemental Table 3). Of the genera that increased, 9 (56\%) belong to the Enterobacterales order (Hafnia, Raoultella, Morganella, Proteus, Edwardsiella, Erwinia, Lelliottia, Yersinia, Leclercia), and 7 (44\%) belong to the Lactobacillales order (Leuconostoc, Tetragenococcus, Lactobacillus, Weissella, Carnobacterium, Pediococcus, Lactococcus). Half of the 12 decreasing genera were in the Bacillales order (Rummeliibacillus, Brevibacillus, Aneurinibacillus, Thermobacillus, Lysinbacillus, Bacillus). The relative abundances of 70 bacterial species significantly increased after the diet change (Fig. 4, Table 4). Among these species, 47 (67\%) belong to the Lactobacillales order (also known as lactic acid bacteria or LAB), and 17 (24\%) belong to the Enterobacterales order. Meanwhile, the relative abundances of 28 species 
411 significantly decreased, $13(46 \%)$ of which belong to the Clostridiales order, $5(18 \%)$ of which

412 belong to the Bacillales order, and 3 (11\%) of which belong to the Bacteroidales order.

413

$414 \quad$ 3.4.3 Gut microbiome functionality

415 A total of 4,617 KO terms from all samples were identified, and after filtering 4,216 remained for 416 subsequent analyses. PCoA was performed to investigate changes between time points. Fig. 5A 417 shows the first two principal coordinate axes (which respectively explain $67.1 \%$ and $11.3 \%$ of the 418 variation) and the eigenvalues for the first 25 axes are shown in Supplemental Fig. 6. Spatial 419 separation between the two timepoints along the first two PCoA axes was demonstrated $(p=0.007$, 420 PERMANOVA using the Bray-Curtis dissimilarity matrices). A significant shift in the PCo1 score 421 after 4 weeks of diet change was observed ( $p=0.013$, Wilcoxon signed rank test, Fig. 5B). As listed 422 in Table 5, a significant increase in the abundances of $14 \mathrm{KO}$ terms was observed using a negative 423 binomial GLM, while the abundances of $11 \mathrm{KO}$ terms significantly decreased. Pathway mapping 424 demonstrated differential abundances of pathways including the biosynthesis of secondary metabolites (ko01110: K02203, K13548, K16011), amino sugar and nucleotide sugar metabolism 426 (ko00520: K13019, K16011, K17716), O-antigen nucleotide sugar biosynthesis (ko00541: K13019, K16011, K17716), and microbial metabolism in diverse environments (ko01120: 428 K00385, K02203, K16165).

429

\subsection{Differential gut microbiome responses to diet transition}

431

432 433

\subsubsection{Identification of high-, mid-, and low-responders}

While a significant shift in PCo1 score $(0.16 \pm 0.20)$ was observed across all subjects over the four week period, there were interindividual differences in the magnitude of the shift along PCo1 (Fig. 
434 2C). Given this wide range of responses, subjects were further divided into tertiles based on the 435 magnitude of PCo1 score change to examine the differential response. Those with the highest 436 magnitude of positive change were termed high-responders $(H R, n=9)$, those in the second tertile 437 mid-responders (MR, $n=9)$, and those in the third tertile low-responders ( $\mathrm{R}, \mathrm{n}=10)$. PCo1 score 438 was significantly different among HR, MR, and LR at baseline ( $p=0.017$, Kruskal-Wallis test), but 439 not at week 4 ( $p=0.082$, Kruskal-Wallis test). PCo1 score at baseline in HR was significantly lower 440 than that of MR (FDR-adjusted $p=0.035$, Dunn's post hoc test) and LR (FDR-adjusted $p=0.025$, 441 Dunn's post hoc test).

443 To better understand the observed differences in the GM composition among the differential 444 response groups (HR, MR, and LR), the abundances at the species level of the 28 samples collected 445 at baseline were further analyzed. PCoA was performed and the first two axes (PCo1 and PCo2) 446 explained $37.4 \%$ and $10.0 \%$ of the variation. Spatial separation among HR, MR, LR along the first 447 two PCo axes was demonstrated ( $p=0.022$, PERMANOVA Bray-Curtis dissimilarity matrices) 448 (Supplemental Fig. 7). PAM Clustering analysis revealed two clusters. GM clusters using Bray449 Curtis dissimilarity matrices and a MDS ordination assigned $8 \mathrm{HR}, 2 \mathrm{MR}$, and $2 \mathrm{LR}$ samples to 450 one cluster (C1), while $94 \%$ of samples assigned to the other cluster (C2) contained samples from 451 MR or LR ( $p=0.004$, Fisher's exact test). In other words, a significantly higher proportion of HR 452 samples were assigned to $\mathrm{C} 1$ and a significantly higher proportion of MR and LR samples were 453 assigned to $\mathrm{C} 2$. We also ran a Random Forest classification model on the samples collected at 454 baseline (70\% of the samples used as a training data set and $30 \%$ used as a validation data set), 455 which was able to differentiate between the two classes (HR vs MR/LR) with 78\% accuracy. 456 Classification error for $\mathrm{HR}$ and $\mathrm{MR} / \mathrm{LR}$ were $33 \%$ and $17 \%$ respectively; AUC $=0.94$. These 
457 results collectively demonstrate that the magnitude of GM response to diet change along the PCo1 458 axis was dependent on the initial gut microbiota.

459

460

3.5.2 Gut microbiome relative abundance at baseline in high- and low-responders

461

The relative abundances at the phylum level are displayed for HR, MR, and LR (Fig. 3).

462

Comparisons of species abundances demonstrate a distinctive pattern between HR and LR at

463

baseline (Table 6, Fig. 6A). Species belonging to the order Bacteroidales were observed to have

464

higher, and never lower, abundances in HR as compared to LR (Supplemental Fig. 8A). On the

465

contrary, species belonging to the Enterobacterales or the Lactobacillales order were observed to

466

have lower, and never higher, abundances in HR as compared to LR, with a single exception of

467

Streptococcus minor (Lactobacillales order).

468

469

Bacteroidales and Clostridiales dominated the gut of high-responders. Among 40 bacterial 470 species whose abundance were higher in HR, 20 (50\%) belonged to the Bacteroidales order (Table

6, Supplemental Fig. 8A). They included 9 Bacteroides species and 7 Prevotella species. Seven species (18\%) of the Clostridiales order and 5 Megamonas species (13\%) were also observed to dominate the gut of the HR at baseline.

474

475

Enterobacterales and Lactobacillales dominated the gut of low-responders. On the other hand, 476 97 species had lower abundances in the guts of HR as compared to LR dogs (Table 6, Supplemental Fig. 8A). Forty seven of these species (48\%) were in the Enterobacterales order.

478 Species in the Lactobacillales order were also underrepresented in the guts of HR and accounted 479 for $35 \%$ of the 97 species. It is worth noting that the abundances of many Enterobacterales and 
480 Lactobacillales species increased as a result of diet change when all subjects were included in the 481 analysis (Table 4).

482

483 Given the enrichment of Enterobacterales and Lactobacillales in LR as compared to HR, 484 correlative analysis was performed in all dogs. The read counts and the relative abundances of 485 total Enterobacteriales were negatively correlated with the magnitude of PCo1 change (read count: 486 Spearman's $\rho=-0.74, p=6.66 \mathrm{E}-06$, relative abundance: Spearman's $\rho=-0.69, p=6.77 \mathrm{E}-05)$. 487 Significant correlation was not observed with total Lactobacillales.

488

489

3.5.3 Changes in the gut microbiome abundance from baseline to week 4 in high- and low490 responders

491 Not only was the GM of HR and LR different at baseline, HR and LR also responded differently 492 to the diet transition (Supplemental Table 4, Fig. 7A and 7B).

493

494

Enterobacterales and Lactobacillales increased predominantly in high-responders. Over the 4 495 week period in HR the abundances of 97 species of Enterobacterales increased and none decreased 496 (Supplemental Table 4 and Fig. 7A). Whereas in LR no increase in abundance of any 497 Enterobacterales species was observed, but rather seven Enterobacterales species were reduced 498 (Fig. 7B). Similarly, the abundances of 77 species in the Lactobacillales order significantly 499 increased and none decreased at week 4 in HR, whereas only five species of Lactobacillales 500 increased and one decreased in LR.

501 
502 Clostridiales and Bacteroidales had distinctive responses in high- vs low-responders. A

503 distinctive pattern of change in the Clostridiales and Bacteroidales orders was also noted between

504 HR and LR. In HR, the abundances of 17 species of Clostridiales were reduced whereas there were

505 increased abundances of five species (three of which were members of the genus Clostridium)

506 (Supplemental Table 4 and Fig. 7A). In LR the abundances of only three species of Clostridiales

507 increased and one species decreased (Fig. 7B). Additionally, the abundance of any Bacteroidales

508 did not significantly change in LR, while seven species of Bacteroidales (six of which were in the 509 genus Prevotella) were reduced in HR.

510

511 3.5.4 Gut microbiome relative abundance at week 4 in high- and low-responders

512 Consistent with a distinctive GM profile at baseline and differential changes between HR and LR,

513 the microbial profiles of HR and LR at week 4 also differed (Table 7, Fig. 6B). A summary of 514 overall GM profile and changes in the abundance of Bacteroidales, Clostridiales, Lactobacillales, 515 and Proteobacteria is also provided in Table 8.

516

517 Enterobacterales and Lactobacillales dominated the gut of high-responders. Among 68 bacterial

518 species whose abundances were higher in HR, 38 (56\%) were Enterobacterales (Table 7,

519 Supplemental Fig. 8B). No Enterobacterales species was observed to be higher in LR at week 4.

520 This was the opposite of baseline GM where 47 species of Enterobaterales were higher in LR

521 (Table 6). For Lactobacillales, five species were enriched in the gut of HR while two species were

522 enriched in the gut of LR at week 4.

523 
524 Clostridiales in the gut of high-and low-responders. Nine (13\%) out of 68 species with higher

525 abundances among HR were in the Clostridiales order, while six (50\%) out of 12 species with

526 higher abundances among LR were in the Clostridiales order (Table 7, Supplemental Fig. 8B).

527

528

Bacteroidales was no longer different in high-vs low-responders. The 20 species in the

Bacteroidales order observed to have higher abundances in HR at baseline were no longer different

530 between HR and LR at week 4 (Table 7, Supplemental Fig. 8B).

531

532

\subsubsection{Protein content of the baseline diet associated with the magnitude of PCo1 change}

In addition to baseline GM, the magnitude of PCol change was also associated with baseline diet composition. Data on the baseline extruded kibble diets were assembled; however, guaranteed nutrient analysis could only be determined for 15 dogs whose specific formula was provided (Supplemental Table 5). Protein content of the baseline diet statistically differed among HR, MR, and LR, when expressed as either $\%$ dry matter $(\mathrm{p}=0.040)$ or gram per $1000 \mathrm{kcal}$ diet $(\mathrm{p}=0.027$, Kruskal-Wallis test). In addition, \% protein dry matter was also negatively correlated with PCo1 score at baseline (Spearman's $\rho=-0.54, p=0.039$ ) (Supplemental Fig. 9A), and positively correlated with PCo1 score change over the 4 week (Spearman's $\rho=0.67, p=0.006$ ) (Supplemental

Fig. 9B). A similar finding was seen when protein content was expressed as g/1000 kcal 542 (Spearman's $\rho=-0.59, p=0.024$ for correlation with PCo1 score at baseline; Spearman's $\rho=0.78$, 543 p=9.9E-04 for correlation with PCo1 score change) (Supplemental Fig. 9C, 9D). No association 544 with PCo1 score was observed for fat, fiber, or calorie density. Changes in PCo1 score were also 545 not associated with any of the four different recipes of the intervention diet. 
547 3.5.6 Subject characteristics and $\alpha$-diversity in high-, mid-, and low-responders

548 Other subject characteristics among the HR, MR, and LR are summarized in Supplemental Table

549 6A. Age, sex, body weight, BCS and other subject characterisitics at baseline were not

550 significantly different among the groups. Likewise, health outcomes reported at week 4 were also

551 not associated with the magnitude of PCo1 score change (Supplemental Table 6B). Additionally,

552 no measure of $\alpha$-diversity was different among HR, MR, and LR at baseline or at week 4 at the 553 sequencing coverage of 470,000 reads (Supplemental Table 7).

554

555 3.6 Gut microbiome and change in overall health

556 To investigate the association between changes in the microbial profile and overall health, the GM

557 of dogs with reported "better" $(n=19)$ and "no change" $(n=12)$ in overall health were compared at

558 the species level at week 4 (Table 3, Table 9, Fig. 8). Dogs whose owners reported improved

559 health had higher abundances of 35 species, $24(69 \%)$ of which are in the Lactobacillales order 560 and two of which are in the Enterobacterales order. Five (14\%) species of the Erysipelotrichaceae

561 family were also higher in dogs reported as having better overall health. Two species, both

562 Bacteroides, were lower in those reported as having better overall health.

563

564 Since the overall health status at baseline was comparable between these two groups of dogs, as a 565 control the same analysis was performed on the sample collected at baseline. Only 8 species were 566 identified to be differentially present between the two groups (Supplemental Table 8). None of 567 the identified species were a Lactobacillales, an Enterobacterales, or an Erysipelotrichaceae.

568 
569 The magnitude of change in PCo1 score was not significantly different between dogs reported as

570 having improved versus no change in overall health. Species evenness, richness, and Shannon's

571 diversity index were not different between these two groups at baseline at the sequencing coverage

572 of 470,000 reads. At week 4, however, the species evenness in those reported improved overall

573 health was significantly higher than those reported no change in overall health $(0.59 \pm 0.10 \mathrm{vs}$

$5740.52 \pm 0.11, \mathrm{p}=0.023$, Kruskal-Wallis test). Likewise, Shannon's diversity index at week 4 was

575 higher in those reported to have improved overall health $(2.39 \pm 0.39$ vs $2.10 \pm 0.44, p=0.023$, 576 Kruskal-Wallis test).

577

578 4. Discussion

579 We describe GM composition and owner-reported health perception of dogs switching from 580 various brands of kibble to commercial MC diets. To our knowledge, this is the first MC diet study 581 performed in household dogs, including male and female dogs of various breeds across a broad 582 age range. As a result of this diverse and free-living study population these findings may be more 583 generalizable to the dog population than other studies that focus on a single breed or a single diet.

584 Two previously published studies using a similar diet comparison were conducted, however they 585 consisted of eight and 12 Beagles in a laboratory setting (Algya et al., 2018; Do et al., 2021). Dogs 586 in the present study maintained their body weight throughout the study period, therefore changes 587 in health and GM were independent of weight change. Finally, the characterization of gut bacteria 588 in this study was performed with metagenomic sequencing, a powerful technique enabling 589 enhanced taxonomic resolution and accuracy, as well as increased detection of diversity and 590 functional genes, a technique that has not yet been widely used in canine research (Ranjan et al., 
591 2016; Salas-Mani et al., 2018; Xu et al., 2019; Alessandri et al., 2019; Connelly et al., 2019; Do et 592 al., 2021).

593

594 All dogs were perceived by their owners as having either better or no change in overall health after 595 diet transition. It is possible that this observation could be subject to bias and may not directly 596 correlate to more objective health outcomes, but as argued by Yeates and Main (Yeates \& Main, 597 2009), owner-reported health assessment is a separate and independent outcome that is especially 598 important in this type of research study. A chance of bias may also derive from the willingness of 599 participants to report the health impact associated with the diet transition, and the observation that 600 a significant portion of participants (24\%) did not complete the study. However the association 601 between a MC diet and positive health perception has been previously reported using a survey 602 administered to a group of dog owners after a veterinarian formulated MC diets for the dogs 603 (Johnson et al., 2016). Dogs accepted MC diets well and remained healthy in two additional 604 feeding trials (Algya et al., 2018; Do et al., 2021).

605

606 Incidents of vomiting and diarrhea were recorded over the four weeks after diet transition.

607 Currently there is not much data on the prevalence and frequency of these symptoms in household 608 dogs, regardless of diet transition. A 2005 survey collecting responses from 772 dog owners in 609 England found that the rate of spontaneous vomiting and diarrhea was one case per 10.6 dog-weeks 610 and one case per 13.4 dog-weeks, respectively (Hubbard et al., 2007). A diet change was suggested 611 to be a cause of diarrhea in some dogs. These are slightly higher than the rates in this present study. 612 Likewise, $27 \%$ of dogs experienced diarrhea within seven weeks after boiled minced beef replaced $61375 \%$ of the calories in an extruded diet (one case per 25.6 dog-weeks) (Herstad et al., 2017, 2018). 
614 Other diet transition studies using a raw or MC diet did not report cases of diarrhea or vomiting

615 (Sandri et al., 2017; Algya et al., 2018; Do et al., 2021). Therefore, the rates of vomiting and

616 diarrhea appear to be consistent with data available from other household dog populations.

617

618 Fifty eight percent of owners reported lower defecation frequency upon diet transition in this study, 619 although this proportion was not significantly different from those reporting no change. Fecal 620 output has been reported to be significantly lower in dogs fed MC diets compared to extruded 621 diets, despite dogs maintaining the same body weight on different diets (Oba et al., 2020; Do et 622 al., 2021). The extremely high nutrient and energy digestibility of MC diets is suggested to be the 623 main driver of the reduction in fecal output (Do et al., 2021). There was also a non-significant 624 trend towards firmer stool when dogs switched to the test diets in our study. In studies using 625 veterinarian-assessed data or an objective analysis of fecal moisture, fecal consistency was 626 reported to be firmer (Sandri et al., 2017; Bermingham et al., 2017) or comparable (Algya et al., 627 2018; Schmidt et al., 2018; Do et al., 2021) among healthy dogs fed MC or raw diets compared to 628 those fed a traditional extruded diet.

629

630 The intervention diet in this study consisted of many nutrients and dietary components that may 631 have an influence on both health and GM composition, including water (Cameron et al., 2011; 632 Deng et al., 2014; Alexander, Colyer \& Morris, 2014), prebiotic fibers (Middelbos et al., 2010; 633 Panasevich et al., 2015; Alexander et al., 2018; Eisenhauer et al., 2019), omega-3 fatty acids 634 (Bauer, 2011), carotenoids, and polyphenols (Kolchin et al., 1991; Kim et al., 2000; Chew et al., 635 2000; Massimino et al., 2003; Hall et al., 2006; Carrera-Quintanar et al., 2018; Lyu et al., 2018), 636 although high-quality extruded diets may include these nutrients and compounds as well. Nutrient 
637 and energy digestibility has also been observed to be different between extruded kibble and MC 638 diets (Algya et al., 2018), and it may facilitate differential impacts on health and GM. Due to the 639 study design, it is impossible to pinpoint which component(s) of the MC diets contributed to the 640 change in health and GM profile. Similarly, the MC diets were different in nutrient and in 641 ingredient composition, adding an additional confounding factor.

642

643 Changes in $\alpha$-diversity in response to dietary interventions have varied between studies, likely at

644 least partially dependent on the diets being compared. Similar to Do et al. (Do et al., 2021), we did 645 not observe any change in the GM $\alpha$-diversity between kibble and MC diets. A cross-sectional 646 study performed in household dogs also reported no differences in $\alpha$-diversity between those fed 647 raw and extruded diets (Schmidt et al., 2018). However these findings contrast with previous 648 reports that demonstrate reduced $\alpha$-diversity upon transitioning to a MC diet in 8 or 11 dogs 649 (Herstad et al., 2017; Algya et al., 2018), or increased $\alpha$-diversity upon transitioning to a raw food 650 diet in eight dogs (Sandri et al., 2017). a-Diversity was also higher in six household dogs fed raw 651 diets as compared to five household dogs fed commercial extruded diets (Kim et al., 2017). Herstad 652 et al. argued that decreased $\alpha$-diversity with a cooked beef diet may be due to higher fat content 653 inducing bile production (Herstad et al., 2017), which has been shown to be antimicrobial (Yokota 654 et al., 2012; Herstad et al., 2017). As the fat and protein content in the baseline extruded diets were 655 not statistically different from the intervention diet in this present study, it is possible that the lack 656 of macronutrient composition difference is responsible for the lack of a change in $\alpha$-diversity. The 657 variety of baseline diets and the utilization of four different MC recipes may also mask the effect 658 of diet transition on $\alpha$-diversity. Often, the $\alpha$-diversity is observed to be lower in diseased 659 populations (Wernimont et al., 2020). In this study the Shannon's diversity index in a subgroup of 
660 dogs whose overall health reported to be improved at week four was significantly higher than those

661 that remained unchanged. However, the use of $\alpha$-diversity and its clinical importance have been

662 recently challenged (Moya \& Ferrer, 2016).

663

664 Consistent with previous shotgun metagenomic sequencing studies in household dogs (Alessandri 665 et al., 2019; Jha et al., 2020), four phyla, Firmicutes, Proteobacteria, Actinobacteria, and 666 Bacteroidetes, dominated the GM. A variety of taxonomic differences in the microbiome were 667 observed after dietary transition, including increased abundances of many LAB. The abundances 668 of the Lactobacillaceae and Leuconostocaceae families and the Lactobacillus genus were similarly 669 reported to be higher in dogs fed a raw diet compared to a kibble diet (Bermingham et al., 2017; 670 Schmidt et al., 2018). On the contrary, Do et al. reported lower levels of Lactobacillus in dogs fed 671 MC diets compared to an extruded kibble (Do et al., 2021), but the kibble contained an $L$. 672 acidophilus fermentation product and high chicory content which were postulated to contribute to 673 the growth of LAB (Do et al., 2021). In many mammals LAB have been suggested to be 674 allochthonous, meaning they are ingested through their natural occurrence on food rather than 675 being true habitants of the distal part of the host GI tract (Walter, 2008). Owing to their 676 demonstrated ability to improve GI health (Grześkowiak et al., 2015; Jensen \& Bjørnvad, 2019), 677 selective LAB are often included in probiotic food or supplements. We also observed a significant 678 association between increased abundances of Lactobacillales and dogs reported as having better 679 health after four weeks of the intervention diet.

680

681 An increase of Enterobacterales was also observed with diet transition. Similar increases were 682 previously observed in healthy dogs fed either a MC or a raw diet (Sandri et al., 2017; Algya et 
683 al., 2018; Schmidt et al., 2018). While there are pathogens within this order, many species of

684 Enterobacterales, such as Salmonella and E. coli, are also members of the healthy human and

685 canine GM, and only opportunistically cause disease in humans, for instance, when an immune

686 system is compromised (Moon et al., 2018). Frequently, only specific strains are pathogenic. It is

687 unknown whether some species of Enterobacterales are also associated with increased disease risk

688 in dogs, particularly since some known human pathogens (e.g. Escherichia/Shigella spp. (Sandri

689 et al., 2017), $\beta$-lactamase producing E. coli (Baede et al., 2015), Salmonella (Reimschuessel et al.,

690 2017), and Campylobacter spp. (Bojanić et al., 2017)) are present in the GI tract of healthy dogs.

691 Additionally, Enterobacterlaes are diverse and have a considerably wide range of abundances in

692 the present study. A wide range of Proteobacteria, whose members predominantly include

693 Enterobacterales, have been previously reported in other cohorts of healthy dogs using

694 metagenomic sequencing (IQR: 3\%-52\% in (Jha et al., 2020)) or 16S rRNA sequencing (range:

695 0\%-22\% in (Hand et al., 2013), range: 0\%-17\% in (Garcia-Mazcorro et al., 2012)). Therefore the

696 impact of an increased abundance of Enterobacterales on canine health remains to be determined.

697

698 Switching to the MC diet also resulted in reduced abundances of some taxa, including species in

699 the order Clostridiales and certain genera, including Blautia, Prevotella, Peptostreptococcus, and

700 Faecalibacterium. This result shares some similarities with previous reports with a transition from

701 an extruded kibble to a raw diet (Sandri et al., 2017; Bermingham et al., 2017; Algya et al., 2018;

702 Schmidt et al., 2018). A MC diet also decreased Prevotella in dogs switching from an extruded

703 kibble diet (Do et al., 2021), but not Clostridium, Blautia, or Faecalibacterium. Many of these

704 bacteria are present in a healthy human GI tract, but their relevance is unknown in dogs. $F$.

705 prausnitzii, which was lower after the intervention diet, was also shown to be lower in dogs fed 
706 minced beef than those fed an extruded diet (Herstad et al., 2017). This bacterium is thought to be

707 beneficial because of its ability to produce butyrate, a short-chain fatty acid that serves as an energy

708 source for colonocytes (Louis \& Flint, 2009; Donohoe et al., 2011). However, its reduced

709 abundance in MC diets may be due to other butyrate-producing bacteria becoming more abundant

710 (e.g. Firmicutes (Macfarlane \& Macfarlane, 2003)), as has been shown with increased levels of

711 Roseburia and butyrate in dogs fed minced beef (Herstad et al., 2017), but not in the previous trial

712 (Do et al., 2021), or in the present study. This is further supported by the observation that the KO

713 terms related to short-chain fatty acid metabolism remained unchanged upon diet transition in this

714 study.

715

716 Our results indicate a differential microbiomic response to dietary transition based on the 717 magnitude of change in $\beta$-diversity (i.e. HR, MR, and LR). While similar analytical approaches

718 have been adopted in human research (Salonen et al., 2014; Mills et al., 2019), to our knowledge

719 this is the first study to report distinct varied microbial responses in dogs in response to diet change.

720 Using assorted multivariate analyses, the GM at baseline was demonstrated to be different among

721 HR, MR, and LR. Specifically, HRs had lower abundances of Lactobacillales and

722 Enterobacterales, and higher abundances of Bacteroidales than the LRs, and they responded to the

723 MC diet differently and more robustly. We hypothesize that the niche occupied by Bacteroidales

724 at baseline becomes more favorable for Enterobacterales and LAB growth upon diet transition.

725 This may explain why the lower abundance of Enterobacterales at baseline was associated with

726 greater PCo1 score change. Moreover, the protein content of the baseline diet was positively

727 correlated with the magnitude of PCo1 change, although we acknowledge the small sample size

$728(\mathrm{n}=15)$ as well as a previous analysis of 750 commercial dry pet foods demonstrating $1.6 \%$ 
729 difference between the guaranteed and actual analysis of crude protein (Hill et al., 2009). Given

730 that the protein content of the baseline and the intervention diets were statistically comparable, and

731 that Enterobacterlaes are able to thrive on proteins, carbohydrates, or lipids (Moon et al., 2018),

732 the observed correlation may be explained by the change in the ingredients despite an unmodified

733 macronutrient profile. For example, replacing chicken with whole cricket meal led to a small

734 change in the GM profile in dogs (Jarett et al., 2019), and replacing cellulose and brewer's rice

735 with potato fiber up to $6 \%$ also led to an increase of Faecalibacterium (Panasevich et al., 2015).

736 Such associative findings between baseline characteristics and magnitude of responses to the

737 intervention can serve as a basis for future studies that aim to construct predictive models, and

738 ultimately, dietary plans tailored to each individual based on existing microbiome composition and

739 function for optimized health outcomes (Zmora et al., 2018).

740

741 Changes in GM function characterized by KEGG were detected with a multivariate analysis

742 (PCoA), but remained less defined with univariate analysis (negative binomial GLM with

743 DESeq2) in this study. The univariate method is inferior in terms of its ability to capture small

744 changes cumulatively. GM functional redundancy under different dietary environments has been

745 demonstrated (Moya \& Ferrer, 2016), and changes in GM profile in healthy dogs may not reflect

746 a drastic change in the functionality as compared to those with improved or worsened health status

747 after an intervention (Guard et al., 2015). Thus the lack of any drastic change in functionality is

748 likely at least partially reflective of dogs being healthy at both baseline and week 4 . Availability

749 of data from other platforms such as transcriptional profiling or targeted metabolomics may

750 complement metagenomic sequencing in capturing finer changes in GM functionality. 
752 In conclusion, we have demonstrated significant changes in the GM profile of healthy dogs

753 transitioning from a variety of kibble diets to MC diets. The magnitude of shift is associated with

754 baseline GM profile and protein content of the baseline diet. The test diets were well accepted

755 throughout the study, and the majority of dog owners report an improvement or no change in

756 specific health outcomes. Despite its novelty, there are some limitations to the study. A control

757 group where dogs remained on the baseline diet for four weeks was not included, thus any direct

758 causal relationship cannot be established between diet transition and outcomes. However, observed

759 changes in the GM were likely to be caused by diet change as minimal changes were expected if

760 baseline diets were maintained for four weeks. While the four different MC diet recipes may have

761 dampened the signal, most dogs were on a mixed-recipe diet and a wide variety of baseline diets

762 may have provided an opportunity to investigate the wide range of diets and responses among

763 subjects. Finally, while no clinical measures were available, the health data do reflect the owner's

764 perceptions of health

765

766 5. Acknowledgements

767 The authors are grateful for support from Jessica Siasoco with participant recruitment. We are also

768 grateful to our participants who helped make this study possible. We would like to thank Jan

769 Suchodoski, $\mathrm{PhD}$ and Kelly Swanson, $\mathrm{PhD}$ for their thoughtful consideration and helpful

770 discussion regarding data analysis and interpretation.

771

772 Figures

773 Figure 1. Trial flowchart. 
775 Figure 2. Species level principal coordinate analysis (PCoA). (A) PCo1 (Axis 1) and PCo2 (Axis 776 2) respectively explain $34.2 \%$ and $10.3 \%$ of species abundance variance (56 samples from 28 777 dogs). PERMANOVA using Bray-Curtis distance shows significant spatial separation between 778 baseline (red) and week 4 (blue) $(\mathrm{p}=0.004)$. (B) A significant shift along the PCo1 axis from 779 baseline (red) to week 4 (blue) is observed ( $\mathrm{p}=1.72 \mathrm{E}-04$, Wilcoxon signed rank test). (C) Varying 780 degrees of shift along the PCo1 axis are observable from baseline to week 4. Subjects were divided 781 into tertiles based on the degree of PCo1 changes between baseline and week 4, with subjects in 782 the first tertile labeled high-responders (HR, maximal PCo1 score increase, red, $n=9$ ), those in the 783 second tertile mid-responders (MR, blue, $n=9)$, and those in the third tertile low-responders (LR, 784 PCo1 score decrease or minimal PCo1 score increase, gray, $\mathrm{n}=10$ ).

785

786 Figure 3. Relative abundances at phylum level at baseline and week 4. The phyla Firmicutes 787 (baseline: 59.18 [36.39 - 77.09]\%, week 4: 49.59 [31.00 - 77.05]\%), Proteobacteria (baseline: 2.12 $788[0.06-46.75] \%$, week 4: $33.67[11.35-61.92] \%$ ), Actinobacteria (baseline: $12.59[0.34-19.35] \%$, 789 week 4: $1.67[0.05-9.23] \%$ ), and Bacteroidetes (baseline: 0.39 [0.03 - 3.79]\%, week 4: 0.05 [0.00 $790-0.88] \%$ ) dominated the GM at baseline and at week 4. Data are displayed separately for high791 (HR, n=9), mid- (MR, n=9), and low-responders (LR, $n=10)$ (see section 3.5.1 for the definition 792 of HR, MR, and LR).

793

794 Figure 4. Volcano plot demonstrating fold-change (FC) in species abundance at week 4 compared 795 to baseline. Vertical dashed lines represent $\log _{2} \mathrm{FC}$ at 1 and -1 (i.e. FC at 2 and -2), horizontal 796 dashed line adjusted $\mathrm{p}=0.05$. Adjustments of $\mathrm{p}$ values were performed with false discovery rate. 797 Points are colored by phylum. 
798

799 Figure 5. Principal coordinate analysis (PCoA) of the Kyoto Encyclopedia of Genes and Genomes 800 Orthology (KO) terms. (A) PCo1 (Axis 1) and PCo2 (Axis 2) respectively explain 67.1\% and $801 \quad 11.3 \%$ of abundance variance (56 samples from 28 dogs). PERMANOVA using Bray-Curtis 802 distance shows significant spatial separation between baseline (red) and week 4 (blue) $(\mathrm{p}=0.007)$. 803 (B) A significant shift along the PCo1 axis from baseline (red) to week 4 (blue) is observed $804(\mathrm{p}=0.013$, Wilcoxon signed rank test).

805

806 Figure 6. Volcano plots demonstrating fold-change (FC) of species abundance between high807 responders $(\mathrm{HR}, \mathrm{n}=9)$ and low-responders $(\mathrm{LR}, \mathrm{n}=10)$ at $(\mathrm{A})$ baseline and $(\mathrm{B})$ week 4 . FC is 808 calculated from HR/LR. Vertical dashed lines show $\log _{2} \mathrm{FC}$ at 1 and -1 (i.e. FC at 2 and -2 ). 809 Horizontal dashed line shows adjusted $p=0.05$. Adjustment of $p$ values is performed with false 810 discovery rate. Points are colored by phylum.

811

812 Figure 7. Volcano plots demonstrating fold-change (FC) of species abundance between week 4 813 and baseline in (A) high-responders $(n=9)$ and $(B)$ low-responders $(n=10)$. Vertical dashed lines 814 show $\log _{2} \mathrm{FC}$ at 1 and -1 (i.e. FC at 2 and -2). Horizontal dashed line shows adjusted p $=0.05$. 815 Adjustment of $\mathrm{p}$ values is performed with false discovery rate. Points are colored by phylum.

816

817 Figure 8. Volcano plot demonstrating fold-change (FC) of species abundance between week 4 and 818 baseline in those reporting better overall health $(n=16)$ compared to those reporting about the same 819 overall health $(\mathrm{n}=10)$. Vertical dashed lines show $\log _{2} \mathrm{FC}$ at 1 and -1 (i.e. FC at 2 and -2 ). 
820 Horizontal dashed line shows adjusted $p=0.05$. Adjustment of $p$ values is performed with false 821 discovery rate. Points are colored by phylum.

822

823 References

824 Alessandri G, Milani C, Mancabelli L, Mangifesta M, Lugli GA, Viappiani A, Duranti S,

825 Turroni F, Ossiprandi MC, van Sinderen D, Ventura M. 2019. Metagenomic dissection of 826 the canine gut microbiota: insights into taxonomic, metabolic and nutritional features.

827 Environmental microbiology 21:1331-1343. DOI: 10.1111/1462-2920.14540.

828 Alexander JE, Colyer A, Morris PJ. 2014. The effect of reducing dietary energy density via the 829 addition of water to a dry diet, on body weight, energy intake and physical activity in adult 830 neutered cats. Journal of nutritional science 3:e21. DOI: 10.1017/jns.2014.22.

831 Alexander C, Cross T-WL, Devendran S, Neumer F, Theis S, Ridlon JM, Suchodolski JS, de

832 Godoy MRC, Swanson KS. 2018. Effects of prebiotic inulin-type fructans on blood

833 metabolite and hormone concentrations and faecal microbiota and metabolites in

834 overweight dogs. The British journal of nutrition:1-10. DOI:

$835 \quad$ 10.1017/S0007114518001952.

836 Al-Ghalith GA, Hillmann B, Ang K, Shields-Cutler R, Knights D. 2018. SHI7 is a self-learning 837 pipeline for multipurpose short-read DNA quality control. mSystems 3. DOI:

$838 \quad 10.1128 / \mathrm{mSystems.00202-17.}$

839 Al-Ghalith G, Knights D. 2017. BURST enables optimal exhaustive DNA alignment for big data.

840 DOI: $10.5281 /$ zenodo.3779009.

841 Algya KM, Cross T-WL, Leuck KN, Kastner ME, Baba T, Lye L, de Godoy MRC, Swanson KS.

842 2018. Apparent total-tract macronutrient digestibility, serum chemistry, urinalysis, and fecal 
843 characteristics, metabolites and microbiota of adult dogs fed extruded, mildly cooked, and 844 raw diets1. Journal of Animal Science 96:3670-3683. DOI: 10.1093/jas/sky235.

845 Axelsson E, Ratnakumar A, Arendt M-L, Maqbool K, Webster MT, Perloski M, Liberg O, 846 Arnemo JM, Hedhammar A, Lindblad-Toh K. 2013. The genomic signature of dog 847 domestication reveals adaptation to a starch-rich diet. Nature 495:360-364. DOI: $848 \quad 10.1038 /$ nature11837.

849 Baede VO, Wagenaar JA, Broens EM, Duim B, Dohmen W, Nijsse R, Timmerman AJ, Hordijk 850 J. 2015. Longitudinal study of extended-spectrum- $\beta$-lactamase- and AmpC-producing $851 \quad$ Enterobacteriaceae in household dogs. Antimicrobial agents and chemotherapy 59:3117852 853

Bauer JE. 2011. Therapeutic use of fish oils in companion animals. Journal of the American 854 Veterinary Medical Association 239:1441-1451. DOI: 10.2460/javma.239.11.1441.

Bermingham EN, Maclean P, Thomas DG, Cave NJ, Young W. 2017. Key bacterial families 856 (Clostridiaceae, Erysipelotrichaceae and Bacteroidaceae) are related to the digestion of protein and energy in dogs. PeerJ 5:e3019. DOI: 10.7717/peerj.3019.

858

859

860

861

862 863

864 865

Bojanić K, Midwinter AC, Marshall JC, Rogers LE, Biggs PJ, Acke E. 2017. Isolation of Campylobacter spp. from client-owned dogs and cats, and retail raw meat pet food in the Manawatu, New Zealand. Zoonoses and public health 64:438-449. DOI: 10.1111/zph.12323.

Cameron KM, Morris PJ, Hackett RM, Speakman JR. 2011. The effects of increasing water content to reduce the energy density of the diet on body mass changes following caloric restriction in domestic cats. Journal of animal physiology and animal nutrition 95:399-408. DOI: $10.1111 / \mathrm{j} .1439-0396.2010 .01107 . x$. 
866 Carrera-Quintanar L, López Roa RI, Quintero-Fabián S, Sánchez-Sánchez MA, Vizmanos B, 867 Ortuño-Sahagún D. 2018. Phytochemicals that influence gut microbiota as prophylactics 868 and for the treatment of obesity and inflammatory diseases. Mediators of inflammation 869 2018:9734845. DOI: 10.1155/2018/9734845.

870 Chew BP, Park JS, Wong TS, Kim HW, Weng BB, Byrne KM, Hayek MG, Reinhart GA. 2000.

871 Dietary beta-carotene stimulates cell-mediated and humoral immune response in dogs. The 872 Journal of nutrition 130:1910-1913. DOI: 10.1093/jn/130.8.1910.

873 Connelly S, Fanelli B, Hasan NA, Colwell RR, Kaleko M. 2019. Low dose oral beta-lactamase 874 protects the gut microbiome from oral beta-lactam-mediated damage in dogs. AIMS public 875 health 6:477-487. DOI: 10.3934/publichealth.2019.4.477.

876 Deng P, Iwazaki E, Suchy SA, Pallotto MR, Swanson KS. 2014. Effects of feeding frequency 877 and dietary water content on voluntary physical activity in healthy adult cats. Journal of 878 animal science 92:1271-1277. DOI: 10.2527/jas.2013-7235.

879 Donohoe DR, Garge N, Zhang X, Sun W, O’Connell TM, Bunger MK, Bultman SJ. 2011. The 880 microbiome and butyrate regulate energy metabolism and autophagy in the mammalian $881 \quad$ colon. Cell metabolism 13:517-526. DOI: 10.1016/j.cmet.2011.02.018.

882 Do S, Phungviwatnikul T, de Godoy MRC, Swanson KS. 2021. Nutrient digestibility and fecal 883 characteristics, microbiota, and metabolites in dogs fed human-grade foods. Journal of 884 animal science 99. DOI: 10.1093/jas/skab028.

885 Eisenhauer L, Vahjen W, Dadi T, Kohn B, Zentek J. 2019. Effects of brewer's spent grain and 886 carrot pomace on digestibility, fecal microbiota, and fecal and urinary metabolites in dogs 887 fed low or high protein diets. Journal of animal science. DOI: 10.1093/jas/skz264.

888 Garcia-Mazcorro JF, Dowd SE, Poulsen J, Steiner JM, Suchodolski JS. 2012. Abundance and 

1:340-347. DOI: 10.1002/mbo3.36.

891 Grześkowiak Ł, Endo A, Beasley S, Salminen S. 2015. Microbiota and probiotics in canine and 892 feline welfare. Anaerobe 34:14-23. DOI: 10.1016/j.anaerobe.2015.04.002.

893 Guard BC, Barr JW, Reddivari L, Klemashevich C, Jayaraman A, Steiner JM, Vanamala J, 894 Suchodolski JS. 2015. Characterization of microbial dysbiosis and metabolomic changes in 895 dogs with acute diarrhea. PloS one 10:e0127259. DOI: 10.1371/journal.pone.0127259.

896 Hall JA, Picton RA, Finneran PS, Bird KE, Skinner MM, Jewell DE, Zicker S. 2006. Dietary 897 antioxidants and behavioral enrichment enhance neutrophil phagocytosis in geriatric 898 Beagles. Veterinary immunology and immunopathology 113:224-233. DOI: $899 \quad$ 10.1016/j.vetimm.2006.03.019.

900 Hand D, Wallis C, Colyer A, Penn CW. 2013. Pyrosequencing the canine faecal microbiota: 901 breadth and depth of biodiversity. PloS one 8:e53115. DOI: 10.1371/journal.pone.0053115. 902 Herstad KMV, Gajardo K, Bakke AM, Moe L, Ludvigsen J, Rudi K, Rud I, Sekelja M, Skancke 903 E. 2017. A diet change from dry food to beef induces reversible changes on the faecal 904 microbiota in healthy, adult client-owned dogs. BMC veterinary research 13:147. DOI: 10.1186/s12917-017-1073-9.

Herstad KMV, Rønning HT, Bakke AM, Moe L, Skancke E. 2018. Changes in the faecal bile 907 acid profile in dogs fed dry food vs high content of beef: a pilot study. Acta veterinaria 908 Scandinavica 60:29. DOI: 10.1186/s13028-018-0383-7.

909 Hill RC, Choate CJ, Scott KC, Molenberghs G. 2009. Comparison of the guaranteed analysis 910 with the measured nutrient composition of commercial pet foods. Journal of the American 911 Veterinary Medical Association 234:347-351. DOI: 10.2460/javma.234.3.347. 
912 Hillmann B, Al-Ghalith GA, Shields-Cutler RR, Zhu Q, Gohl DM, Beckman KB, Knight R,

913 Knights D. 2018. Evaluating the information content of shallow shotgun metagenomics.

914 mSystems 3. DOI: 10.1128/mSystems.00069-18.

915 Hubbard K, Skelly BJ, McKelvie J, Wood JLN. 2007. Risk of vomiting and diarrhoea in dogs.

916 The Veterinary record 161:755-757. DOI: 10.1136/vr.161.22.755.

917 Jarett JK, Carlson A, Rossoni Serao M, Strickland J, Serfilippi L, Ganz HH. 2019. Diets with

918 and without edible cricket support a similar level of diversity in the gut microbiome of dogs.

919 PeerJ 7:e7661. DOI: 10.7717/peerj.7661.

920 Jensen AP, Bjørnvad CR. 2019. Clinical effect of probiotics in prevention or treatment of

921 gastrointestinal disease in dogs: A systematic review. Journal of veterinary internal

922 medicine / American College of Veterinary Internal Medicine 33:1849-1864. DOI:

$923 \quad 10.1111 /$ jvim. 15554.

924 Jha AR, Shmalberg J, Tanprasertsuk J, Perry L, Massey D, Honaker RW. 2020. Characterization

925 of gut microbiomes of household pets in the United States using a direct-to-consumer

926 approach. PloS one 15:e0227289. DOI: 10.1371/journal.pone.0227289.

927 Johnson LN, Linder DE, Heinze CR, Kehs RL, Freeman LM. 2016. Evaluation of owner

928 experiences and adherence to home-cooked diet recipes for dogs. The Journal of small

929 animal practice 57:23-27. DOI: 10.1111/jsap.12412.

930 Johnson AJ, Vangay P, Al-Ghalith GA, Hillmann BM, Ward TL, Shields-Cutler RR, Kim AD,

931 Shmagel AK, Syed AN, Personalized Microbiome Class Students, Walter J, Menon R,

932 Koecher K, Knights D. 2019. Daily sampling reveals personalized diet-microbiome

933 associations in humans. Cell host \& microbe 25:789-802.e5. DOI:

$934 \quad$ 10.1016/j.chom.2019.05.005. 
935 Kanehisa M, Sato Y. 2020. KEGG Mapper for inferring cellular functions from protein 936 sequences. Protein science: a publication of the Protein Society 29:28-35. DOI:

937 $10.1002 /$ pro.3711.

938

939

940

941

942

943

944

945

946

947

948

949

950

951

952

953

954

955

956

957

Khun M. 2014. Caret: Classification and regression training. $R$ package version 6.0-35.

Kim J, An J-U, Kim W, Lee S, Cho S. 2017. Differences in the gut microbiota of dogs (Canis lupus familiaris) fed a natural diet or a commercial feed revealed by the Illumina MiSeq platform. Gut pathogens 9:68. DOI: 10.1186/s13099-017-0218-5.

Kim HW, Chew BP, Wong TS, Park JS, Weng BB, Byrne KM, Hayek MG, Reinhart GA. 2000. Dietary lutein stimulates immune response in the canine. Veterinary immunology and immunopathology 74:315-327. DOI: 10.1016/S0165-2427(00)00180-X.

Kolchin IN, Maksiutina NP, Balanda PP, Luĭk AI, Bulakh VN, Moỉbenko AA. 1991. The cardioprotective action of quercetin in experimental occlusion and reperfusion of the coronary artery in dogs. Farmakologiia i toksikologiia 54:20-23.

Laflamme D. 1997. Development and validation of a body condition score system for dogs. Canine practice 22:10-15.

Lewis SJ, Heaton KW. 1997. Stool form scale as a useful guide to intestinal transit time. Scandinavian journal of gastroenterology 32:920-924. DOI: 10.3109/00365529709011203.

Louis P, Flint HJ. 2009. Diversity, metabolism and microbial ecology of butyrate-producing bacteria from the human large intestine. FEMS microbiology letters 294:1-8. DOI: 10.1111/j.1574-6968.2009.01514.x.

Lyu Y, Wu L, Wang F, Shen X, Lin D. 2018. Carotenoid supplementation and retinoic acid in immunoglobulin A regulation of the gut microbiota dysbiosis. Experimental biology and medicine 243:613-620. DOI: 10.1177/1535370218763760. 
958 Macfarlane S, Macfarlane GT. 2003. Regulation of short-chain fatty acid production. The 959 Proceedings of the Nutrition Society 62:67-72. DOI: 10.1079/PNS2002207.

960 Maechler M, Rousseeuw P, Struyt A, Hubert M. 2015. Cluster: Cluster analysis basics and $961 \quad$ extensions. $R$ package version 2.0.1.

962 Massimino S, Kearns RJ, Loos KM, Burr J, Park JS, Chew B, Adams S, Hayek MG. 2003.

963 Effects of age and dietary $\beta$-carotene on immunological variables in dogs. Journal of 964 veterinary internal medicine / American College of Veterinary Internal Medicine 17:835965842.

966 Middelbos IS, Vester Boler BM, Qu A, White BA, Swanson KS, Fahey GC Jr. 2010.

967 Phylogenetic characterization of fecal microbial communities of dogs fed diets with or 968 without supplemental dietary fiber using 454 pyrosequencing. PloS one 5:e9768. DOI: $969 \quad$ 10.1371/journal.pone.0009768.

970 Mills S, Lane JA, Smith GJ, Grimaldi KA, Ross RP, Stanton C. 2019. Precision nutrition and the 971 microbiome part II: Potential opportunities and pathways to commercialisation. Nutrients 972 11. DOI: $10.3390 /$ nu1 1071468.

973 Moon CD, Young W, Maclean PH, Cookson AL, Bermingham EN. 2018. Metagenomic insights 974 into the roles of Proteobacteria in the gastrointestinal microbiomes of healthy dogs and cats. 975 MicrobiologyOpen 7:e00677. DOI: 10.1002/mbo3.677.

976 Moya A, Ferrer M. 2016. Functional redundancy-induced stability of gut microbiota subjected to 977 disturbance. Trends in microbiology 24:402-413. DOI: 10.1016/j.tim.2016.02.002.

978 Oba PM, Utterback PL, Parsons CM, Swanson KS. 2020. True nutrient and amino acid 979 digestibility of dog foods made with human-grade ingredients using the precision-fed 980 cecectomized rooster assay. Translational Animal Science 4:442-451. DOI: 
981 $10.1093 / \operatorname{tas} / \operatorname{txz} 175$.

982 Oksanen J, Blanchet FG, Kindt R, Legendre P, Minchin PR, O’Hara RB, Simpson GL, Solymos 983 P, Stevens MHH, Wagner H. 2014. Vegan: Community ecology package. R package version $984 \quad 2.2-0$

985 Panasevich MR, Kerr KR, Dilger RN, Fahey GC Jr, Guérin-Deremaux L, Lynch GL, Wils D, 986 Suchodolski JS, Steer JM, Dowd SE, Swanson KS. 2015. Modulation of the faecal 987 microbiome of healthy adult dogs by inclusion of potato fibre in the diet. The British 988 journal of nutrition 113:125-133. DOI: 10.1017/S0007114514003274.

989 Pilla R, Suchodolski JS. 2019. The role of the canine gut microbiome and metabolome in health 990 and gastrointestinal disease. Frontiers in veterinary science 6:498. DOI:

$991 \quad 10.3389 /$ fvets.2019.00498.

992 PRWeb. 2015.Allprovide study shows thirty-three percent of U.S. pet owners are interested in 993 the fresh, natural pet food diet. Available at 994 https://www.prweb.com/releases/2015/06/prweb12787651.htm (accessed September 16, 995 2020).

996 Ranjan R, Rani A, Metwally A, McGee HS, Perkins DL. 2016. Analysis of the microbiome: 997 Advantages of whole genome shotgun versus 16S amplicon sequencing. Biochemical and 998 biophysical research communications 469:967-977. DOI: 10.1016/j.bbrc.2015.12.083.

999 Redfern A, Suchodolski J, Jergens A. 2017. Role of the gastrointestinal microbiota in small 1000 animal health and disease. Vet. Rec. 181:370. DOI: 10.1136/vr.103826.

1001 Reimschuessel R, Grabenstein M, Guag J, Nemser SM, Song K, Qiu J, Clothier KA, Byrne BA, 1002 Marks SL, Cadmus K, Pabilonia K, Sanchez S, Rajeev S, Ensley S, Frana TS, Jergens AE, 1003 Chappell KH, Thakur S, Byrum B, Cui J, Zhang Y, Erdman MM, Rankin SC, Daly R, Das 
1004 S, Ruesch L, Lawhon SD, Zhang S, Baszler T, Diaz-Campos D, Hartmann F, Okwumabua

1005 O. 2017. Multilaboratory survey to evaluate Salmonella prevalence in diarrheic and

1006 nondiarrheic dogs and cats in the United States between 2012 and 2014. Journal of clinical

1007 microbiology 55:1350-1368. DOI: 10.1128/JCM.02137-16.

1008 Salas-Mani A, Jeusette I, Castillo I, Manuelian CL, Lionnet C, Iraculis N, Sanchez N, Fernández

1009 S, Vilaseca L, Torre C. 2018. Fecal microbiota composition changes after a BW loss diet in

1010 Beagle dogs. Journal of animal science 96:3102-3111. DOI: 10.1093/jas/sky193.

1011 Salonen A, Lahti L, Salojärvi J, Holtrop G, Korpela K, Duncan SH, Date P, Farquharson F,

1012 Johnstone AM, Lobley GE, Louis P, Flint HJ, de Vos WM. 2014. Impact of diet and

1013 individual variation on intestinal microbiota composition and fermentation products in

1014 obese men. The ISME journal 8:2218-2230. DOI: 10.1038/ismej.2014.63.

1015 Sandri M, Dal Monego S, Conte G, Sgorlon S, Stefanon B. 2017. Raw meat based diet

1016 influences faecal microbiome and end products of fermentation in healthy dogs. $B M C$

1017 veterinary research 13:65. DOI: 10.1186/s12917-017-0981-z.

1018 Schmidt M, Unterer S, Suchodolski JS, Honneffer JB, Guard BC, Lidbury JA, Steiner JM, Fritz

1019 J, Kölle P. 2018. The fecal microbiome and metabolome differs between dogs fed Bones

1020 and Raw Food (BARF) diets and dogs fed commercial diets. PloS one 13:e0201279. DOI:

$1021 \quad$ 10.1371/journal.pone.0201279.

1022 Sing T, Sander O, Beerenwinkel N, Lengauer T. 2005. ROCR: visualizing classifier performance

1023 in R. Bioinformatics 21:3940-3941. DOI: 10.1093/bioinformatics/bti623.

1024 Tanprasertsuk J, Jha AR, Shmalberg J, Jones RB, Perry LM, Maughan H, Honaker RW. 2021.

1025 The microbiota of healthy dogs demonstrates individualized responses to synbiotic

1026 supplementation in a randomized controlled trial. Animal microbiome 3:36. DOI: 
1028

1029

1030

1031

1032

1033

1034

1035

1036

1037

1038

1039

1040

1041

1042

1043

1044

1045

1046

1047

1048

1049

Tran QD, Hendriks WH, van der Poel AFB. 2008. Effects of extrusion processing on nutrients in dry pet food. Journal of the science of food and agriculture 88:1487-1493. DOI: $10.1002 /$ jsfa. 3247.

Walter J. 2008. Ecological role of lactobacilli in the gastrointestinal tract: Implications for fundamental and biomedical research. Applied and environmental microbiology 74:49854996. DOI: 10.1128/AEM.00753-08.

Wernimont SM, Radosevich J, Jackson MI, Ephraim E, Badri DV, MacLeay JM, Jewell DE, Suchodolski JS. 2020. The effects of nutrition on the gastrointestinal microbiome of cats and dogs: Impact on health and disease. Frontiers in microbiology 11:1266. DOI: 10.3389/fmicb.2020.01266.

Xu H, Zhao F, Hou Q, Huang W, Liu Y, Zhang H, Sun Z. 2019. Metagenomic analysis revealed beneficial effects of probiotics in improving the composition and function of the gut microbiota in dogs with diarrhoea. Food \& function 10:2618-2629. DOI: 10.1039/C9FO00087A.

Yeates J, Main D. 2009. Assessment of companion animal quality of life in veterinary practice and research. The Journal of small animal practice 50:274-281. DOI: 10.1111/j.17485827.2009.00755.x.

Yokota A, Fukiya S, Islam KBMS, Ooka T, Ogura Y, Hayashi T, Hagio M, Ishizuka S. 2012. Is bile acid a determinant of the gut microbiota on a high-fat diet? Gut microbes 3:455-459. DOI: $10.4161 /$ gmic. 21216 .

Zmora N, Zilberman-Schapira G, Suez J, Mor U, Dori-Bachash M, Bashiardes S, Kotler E, Zur M, Regev-Lehavi D, Brik RB-Z, Federici S, Cohen Y, Linevsky R, Rothschild D, Moor AE, 
1050 Ben-Moshe S, Harmelin A, Itzkovitz S, Maharshak N, Shibolet O, Shapiro H, Pevsner-

1051 Fischer M, Sharon I, Halpern Z, Segal E, Elinav E. 2018. Personalized gut mucosal

1052 colonization resistance to empiric probiotics is associated with unique host and microbiome

1053 features. Cell 174:1388-1405.e21. DOI: 10.1016/j.cell.2018.08.041.

1054 
Figure 1

\section{Trial flowchart}

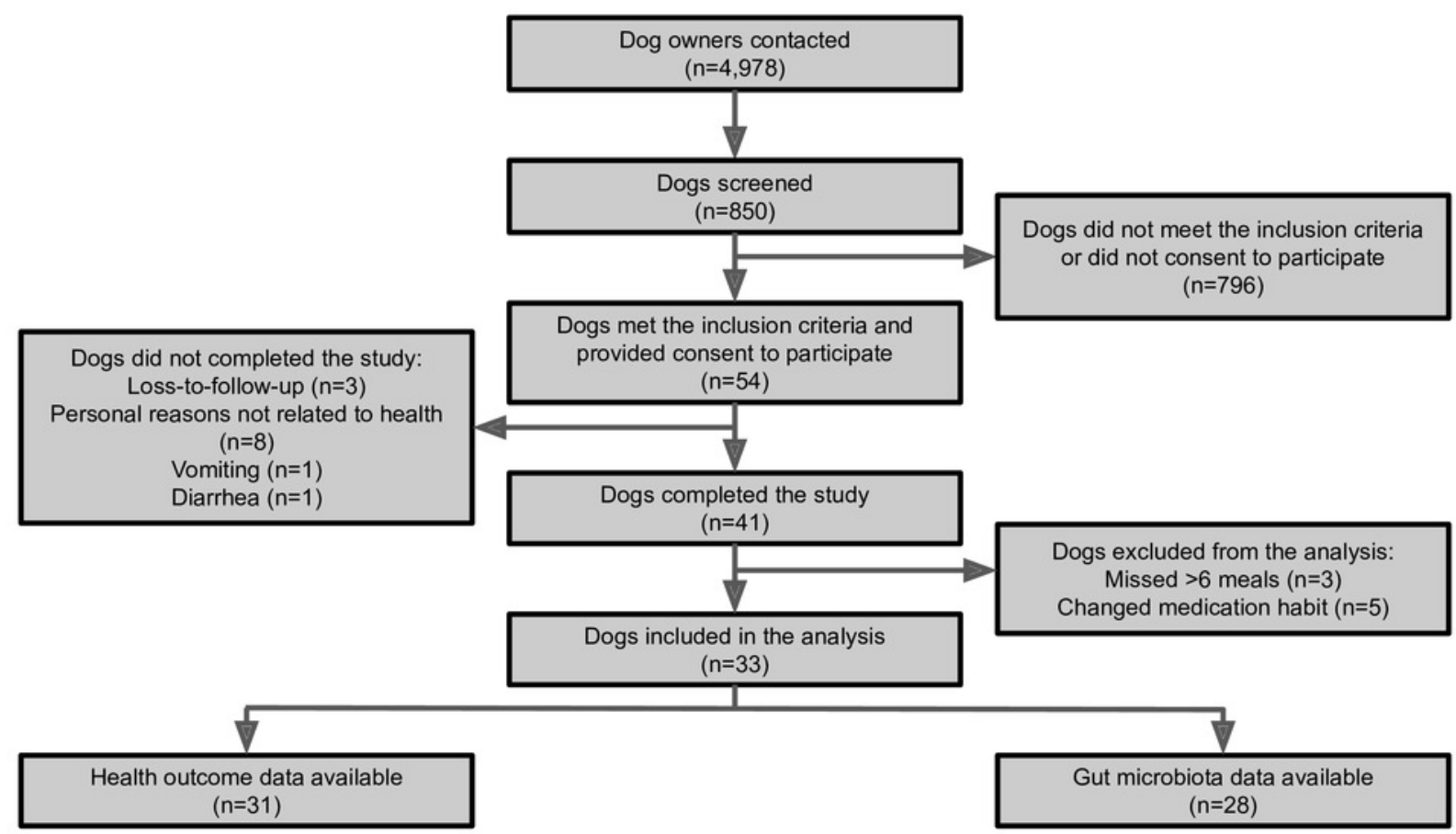




\section{Figure 2}

Species level principal coordinate analysis (PCoA)

(A) PCo1 (Axis 1) and PCo2 (Axis 2) respectively explain $34.2 \%$ and $10.3 \%$ of species abundance variance (56 samples from 28 dogs). PERMANOVA using Bray-Curtis distance shows significant spatial separation between baseline (red) and week 4 (blue) $(p=0.004)$. (B) A significant shift along the PCol axis from baseline (red) to week 4 (blue) is observed ( $p=1.72 \mathrm{E}-04$, Wilcoxon signed rank test). (C) Varying degrees of shift along the PCol axis are observable from baseline to week 4. Subjects were divided into tertiles based on the degree of PCo4 changes between baseline and week 4, with subjects in the first tertile labeled highresponders (HR, maximal PCol score increase, red, $n=9$ ), those in the second tertile midresponders (MR, blue, $n=9$ ), and those in the third tertile low-responders ( $L R$, PCol score decrease or minimal PCol score increase, gray, $n=10$ ). 
A

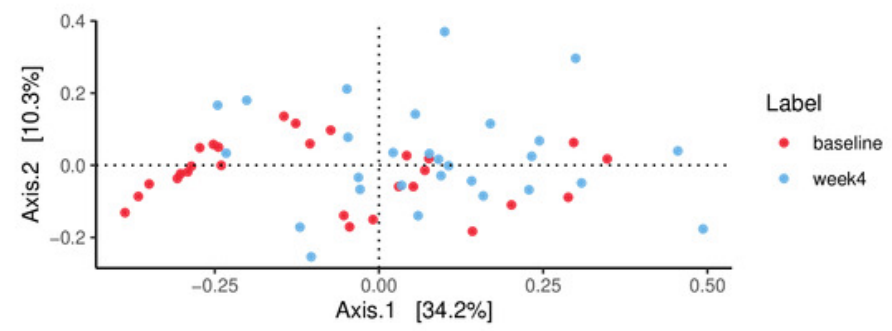

B

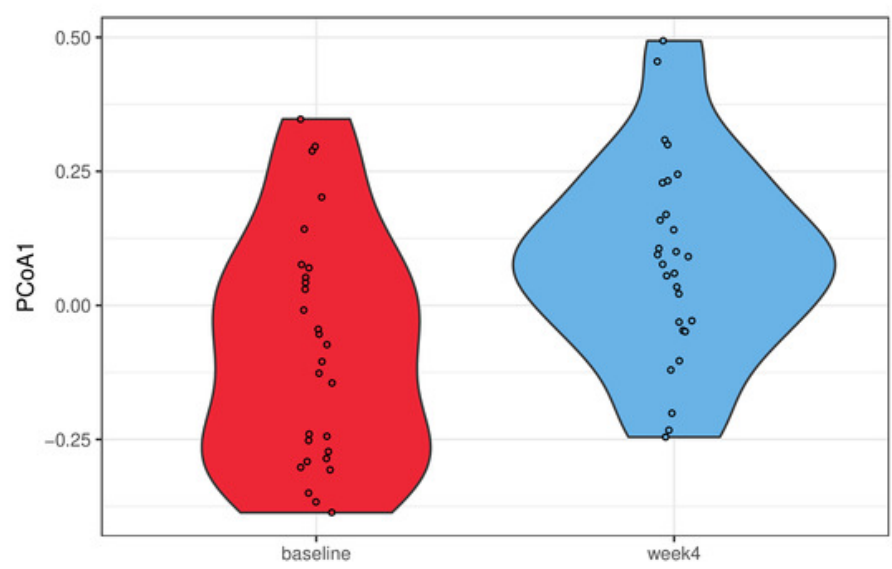

C

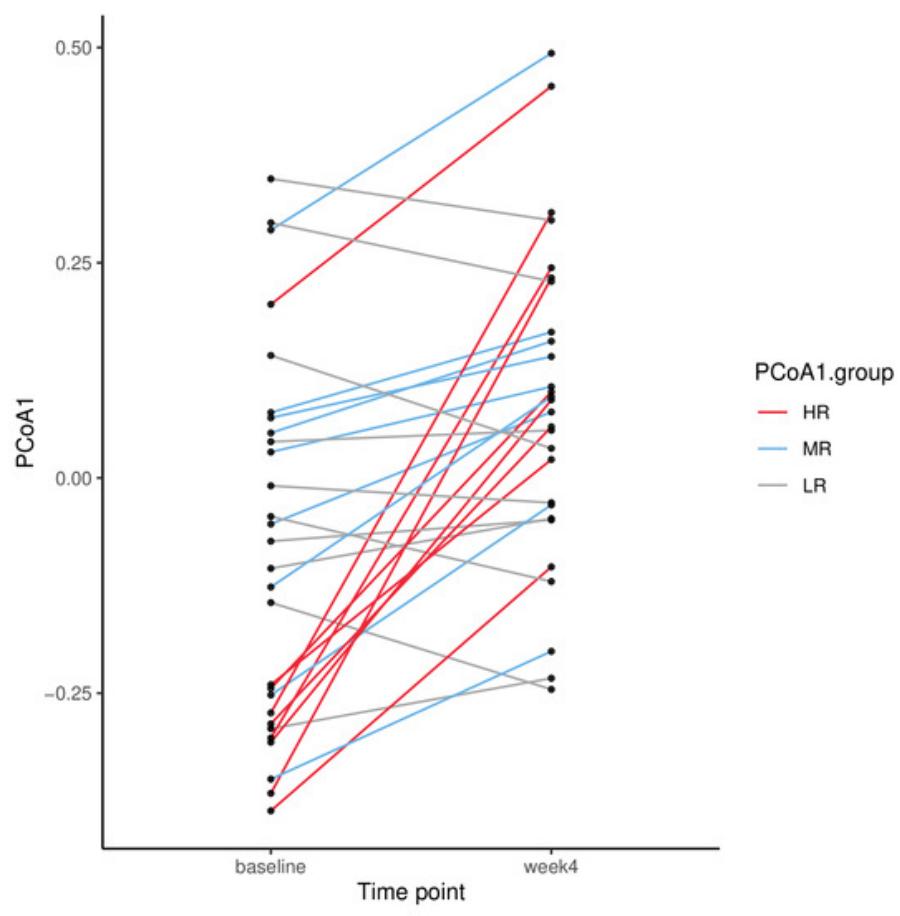




\section{Figure 3}

Relative abundances at phylum level at baseline and week 4 .

The phyla Firmicutes (baseline: 59.18 [36.39 - 77.09]\%, week 4: 49.59 [31.00 - 77.05]\%), Proteobacteria (baseline: 2.12 [0.06 - 46.75]\%, week 4: 33.67 [11.35 - 61.92]\%), Actinobacteria (baseline: 12.59 [0.34 - 19.35]\%, week 4: 1.67 [0.05 - 9.23]\%), and Bacteroidetes (baseline: 0.39 [0.03 - 3.79]\%, week 4: 0.05 [0.00 - 0.88]\%) dominated the GM at baseline and at week 4. Data are displayed separately for high- (HR, $n=9)$, mid- (MR, $n=9)$, and low-responders ( $L R, n=10)$ (see section 3.5.1 for the definition of $H R, M R$, and $L R$ ). 

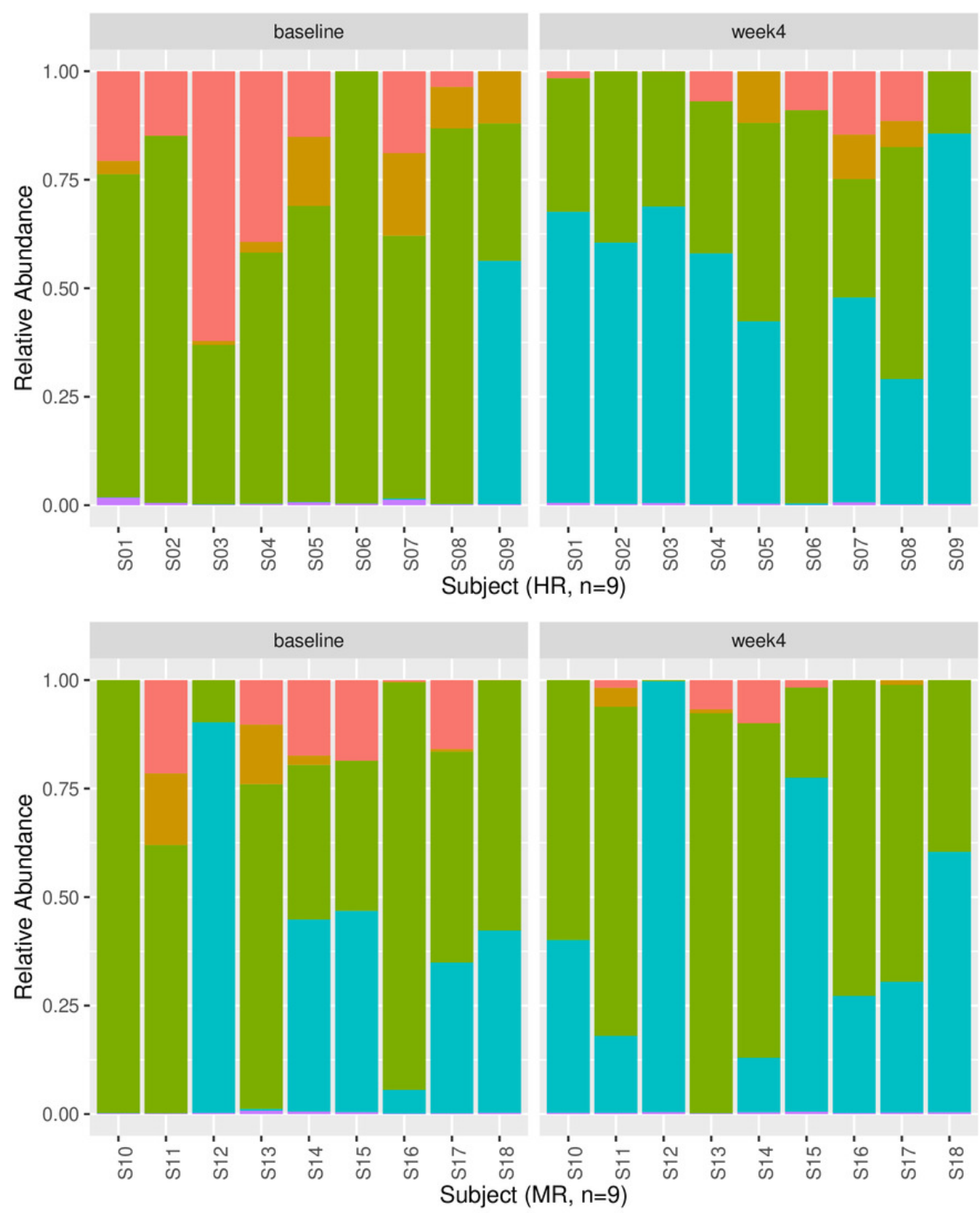

phylum

Actinobacteria
Bacteroidetes
Firmicutes
Fusobacteria
Proteobacteria
Tenericutes
Unknown
Verrucomicrobia

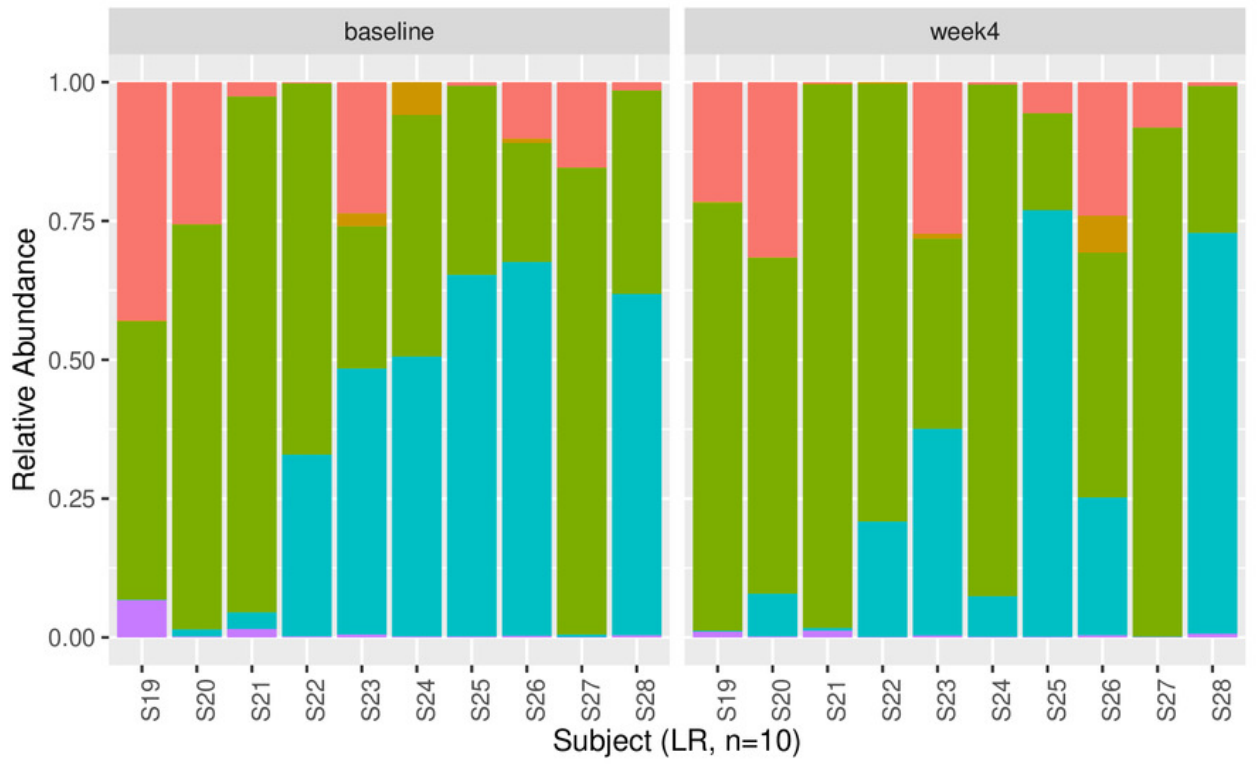


Figure 4

Volcano plot demonstrating fold-change (FC) in species abundance at week 4 compared to baseline.

Vertical dashed lines represent $\log 2 \mathrm{FC}$ at 1 and -1 (i.e. FC at 2 and -2), horizontal dashed line adjusted $p=0.05$. Adjustments of $p$ values were performed with false discovery rate. Points are colored by phylum.

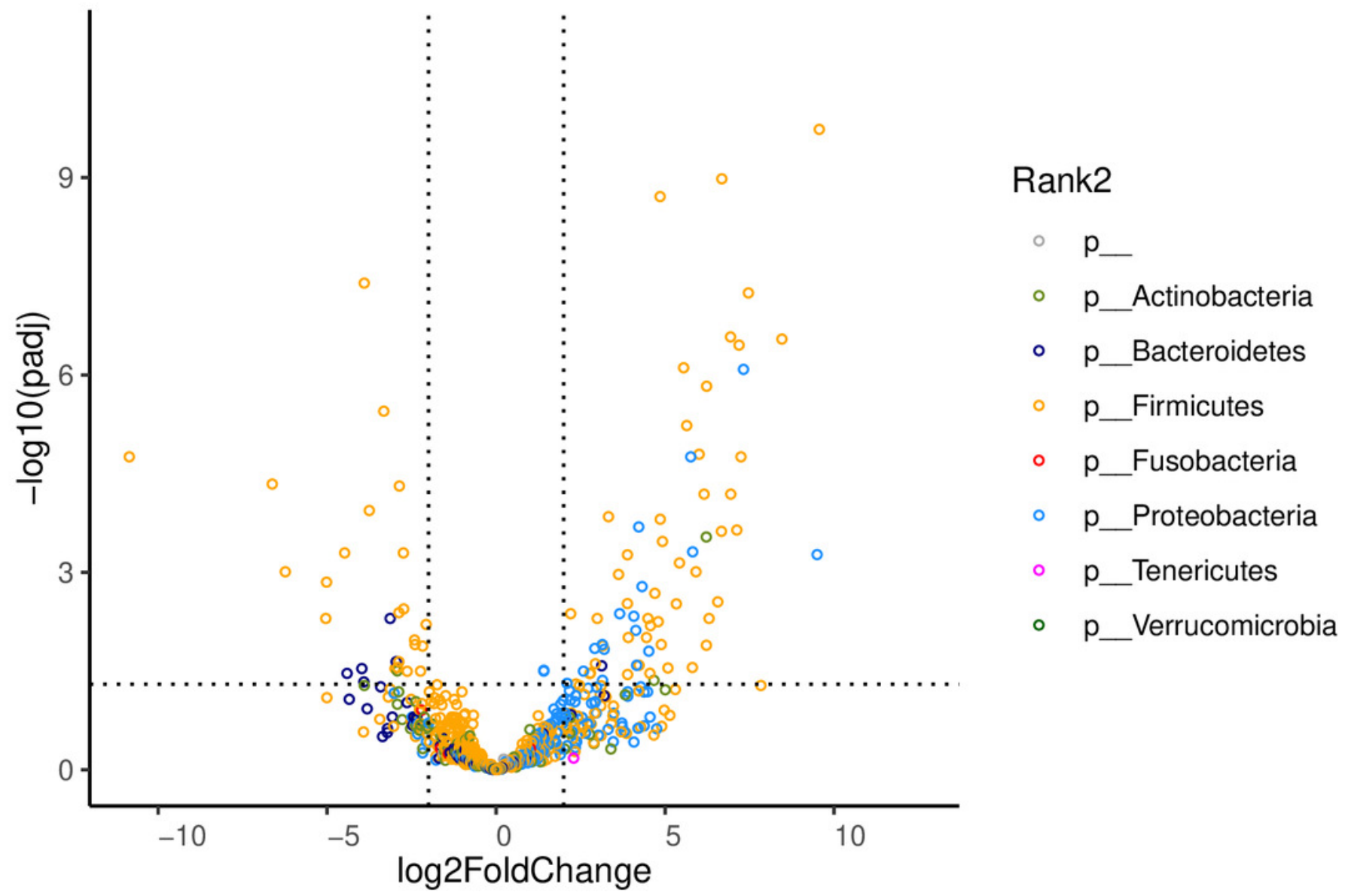




\section{Figure 5}

Principal coordinate analysis (PCOA) of the Kyoto Encyclopedia of Genes and Genomes Orthology (KO) terms

(A) PCo1 (Axis 1) and PCo2 (Axis 2) respectively explain $67.1 \%$ and $11.3 \%$ of abundance variance (56 samples from 28 dogs). PERMANOVA using Bray-Curtis distance shows significant spatial separation between baseline (red) and week 4 (blue) $(p=0.007)$. (B) A significant shift along the PCol axis from baseline (red) to week 4 (blue) is observed $(p=0.013$, Wilcoxon signed rank test $)$. 


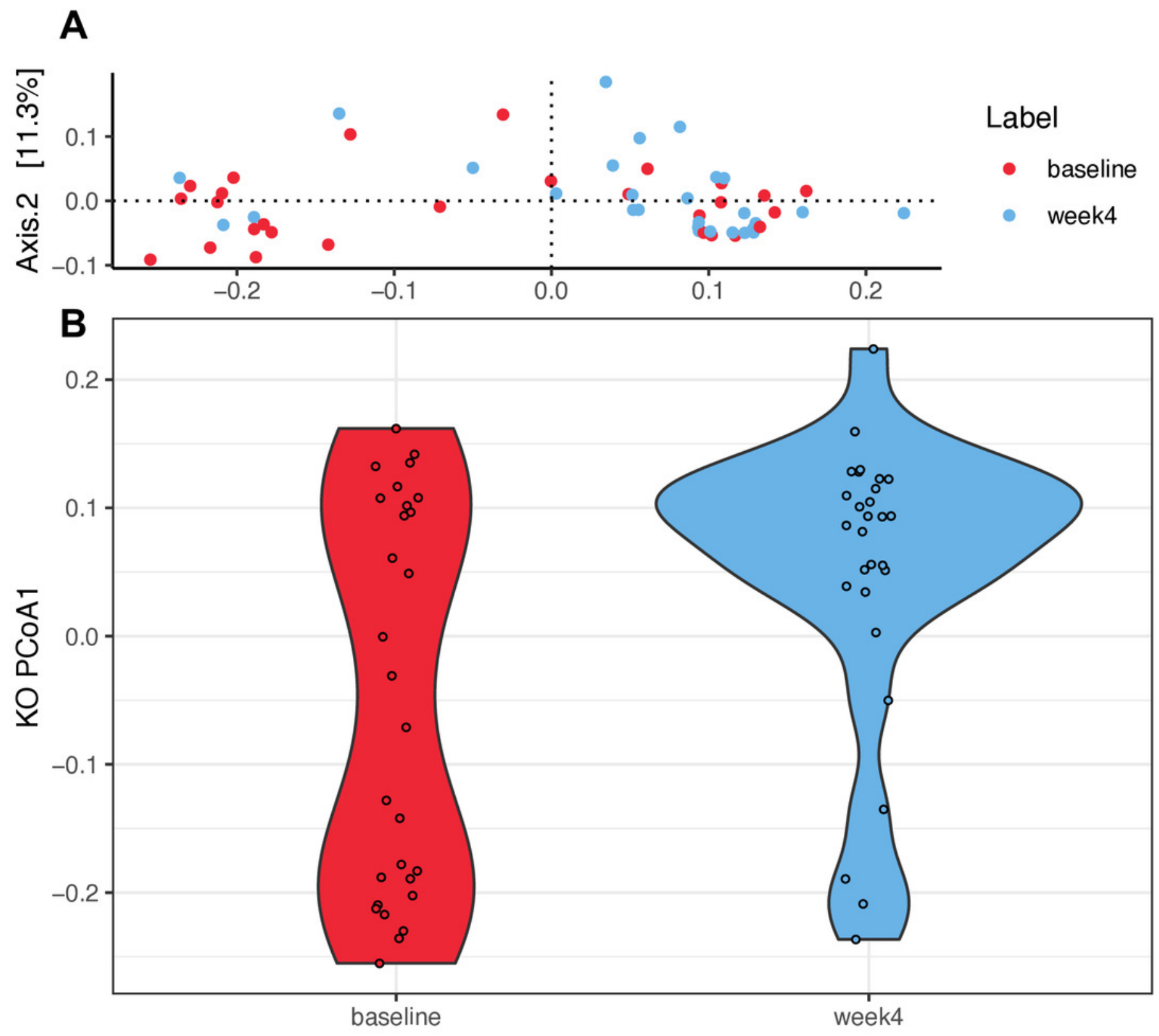




\section{Figure 6}

Volcano plots demonstrating fold-change $(\mathrm{FC})$ of species abundance between highresponders ( $H R, n=9)$ and low-responders $(L R, n=10)$ at $(A)$ baseline and $(B)$ week 4

FC is calculated from HR/LR. Vertical dashed lines show log2FC at 1 and -1 (i.e. FC at 2 and

-2). Horizontal dashed line shows adjusted $p=0.05$. Adjustment of $p$ values is performed with false discovery rate. Points are colored by phylum. 


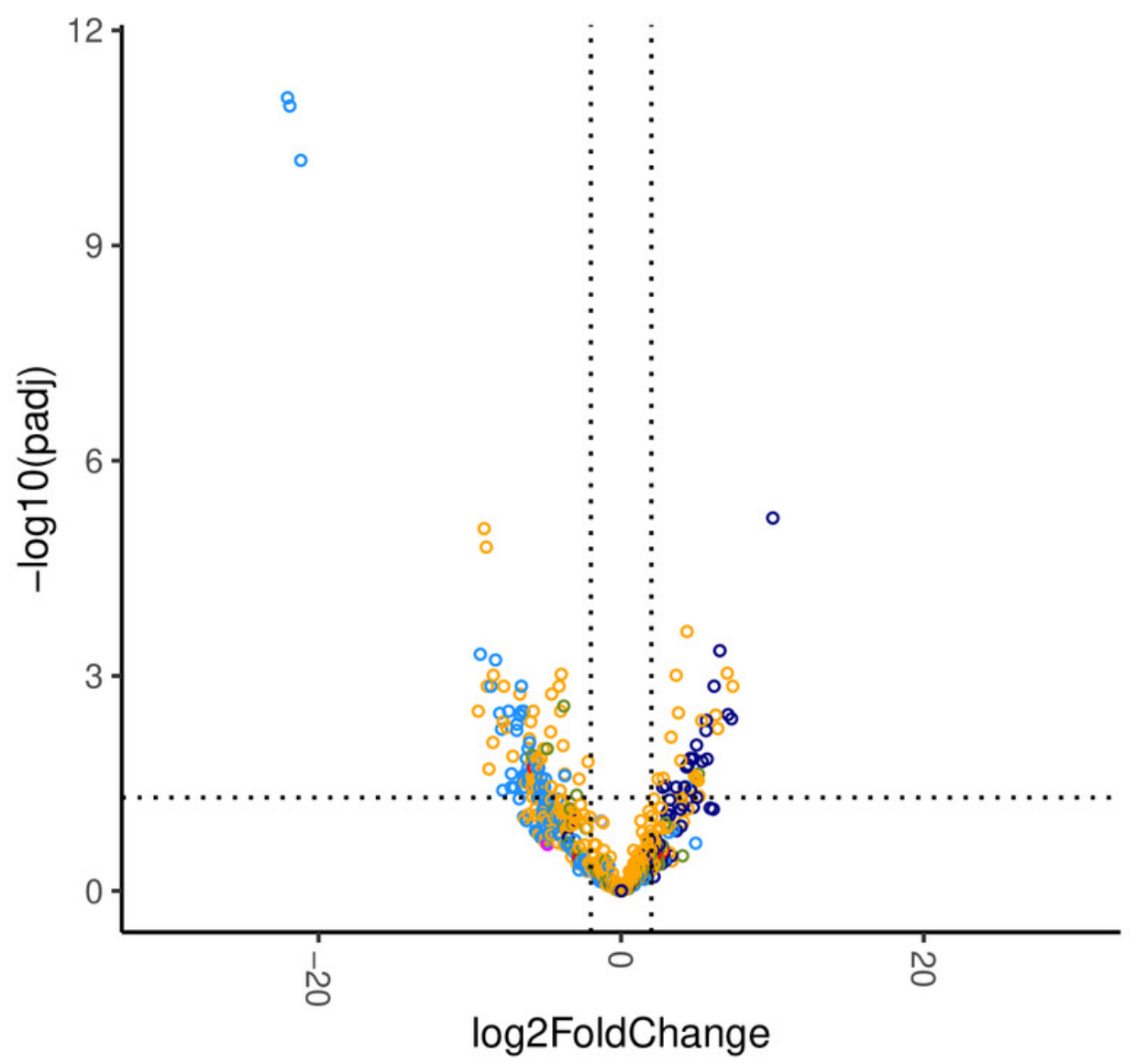
Rank2
- P_
- p_Actinobacteria
- p_Bacteroidetes
- p_Firmicutes
- p_Fusobacteria
- p_Proteobacteria
- p_tenericutes
- p_Verrucomicrobia

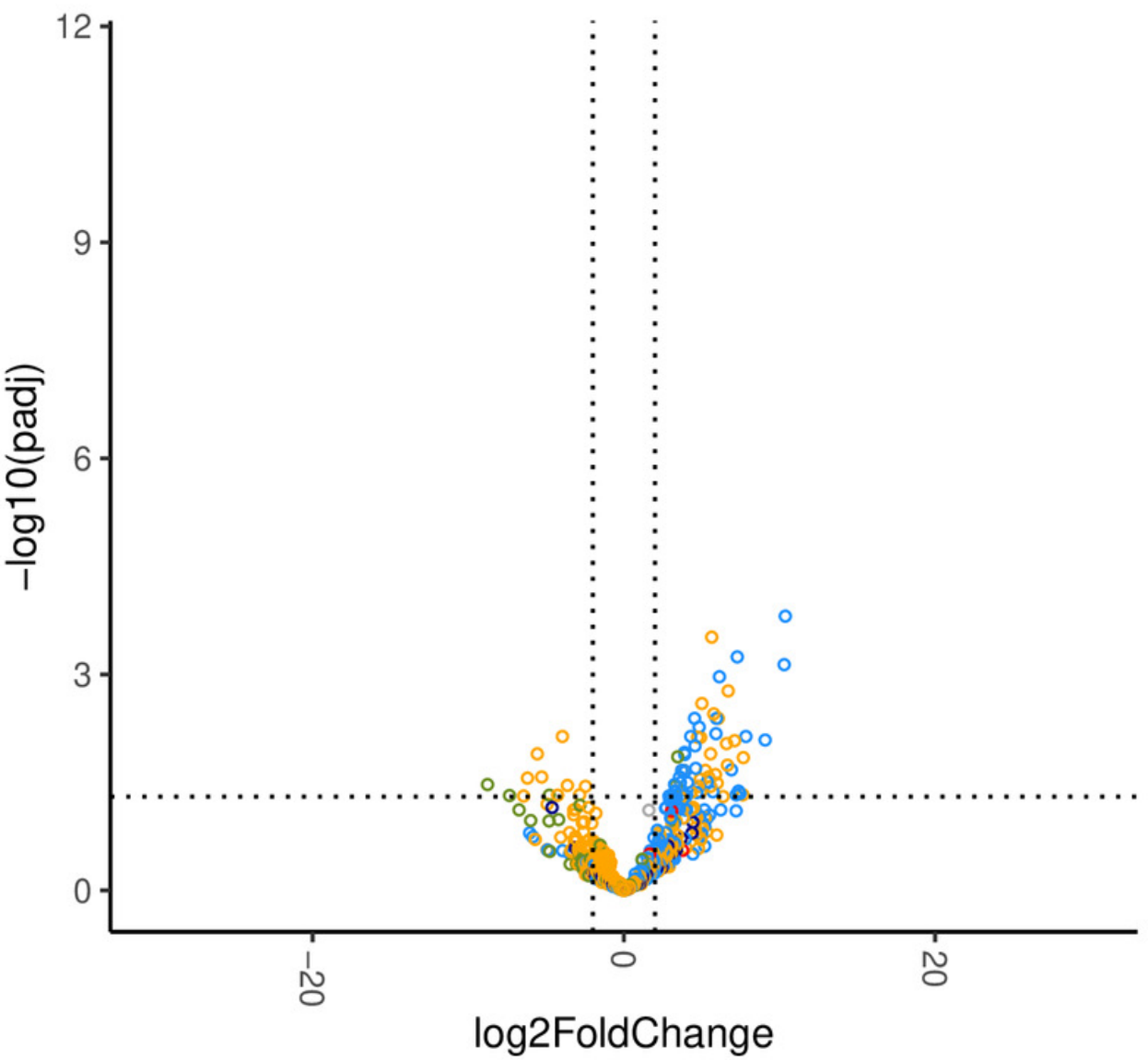

Rank2

$\circ \mathrm{p}$

- p_Actinobacteria

- p_Bacteroidetes

- p_Firmicutes

- p_Fusobacteria

- p_Proteobacteria 


\section{Figure 7}

Volcano plots demonstrating fold-change (FC) of species abundance between week 4 and baseline in (A) high-responders $(n=9)$ and $(B)$ low-responders $(n=10)$

Vertical dashed lines show $\log 2 \mathrm{FC}$ at 1 and -1 (i.e. FC at 2 and -2 ). Horizontal dashed line shows adjusted $p=0.05$. Adjustment of $p$ values is performed with false discovery rate. Points are colored by phylum. 

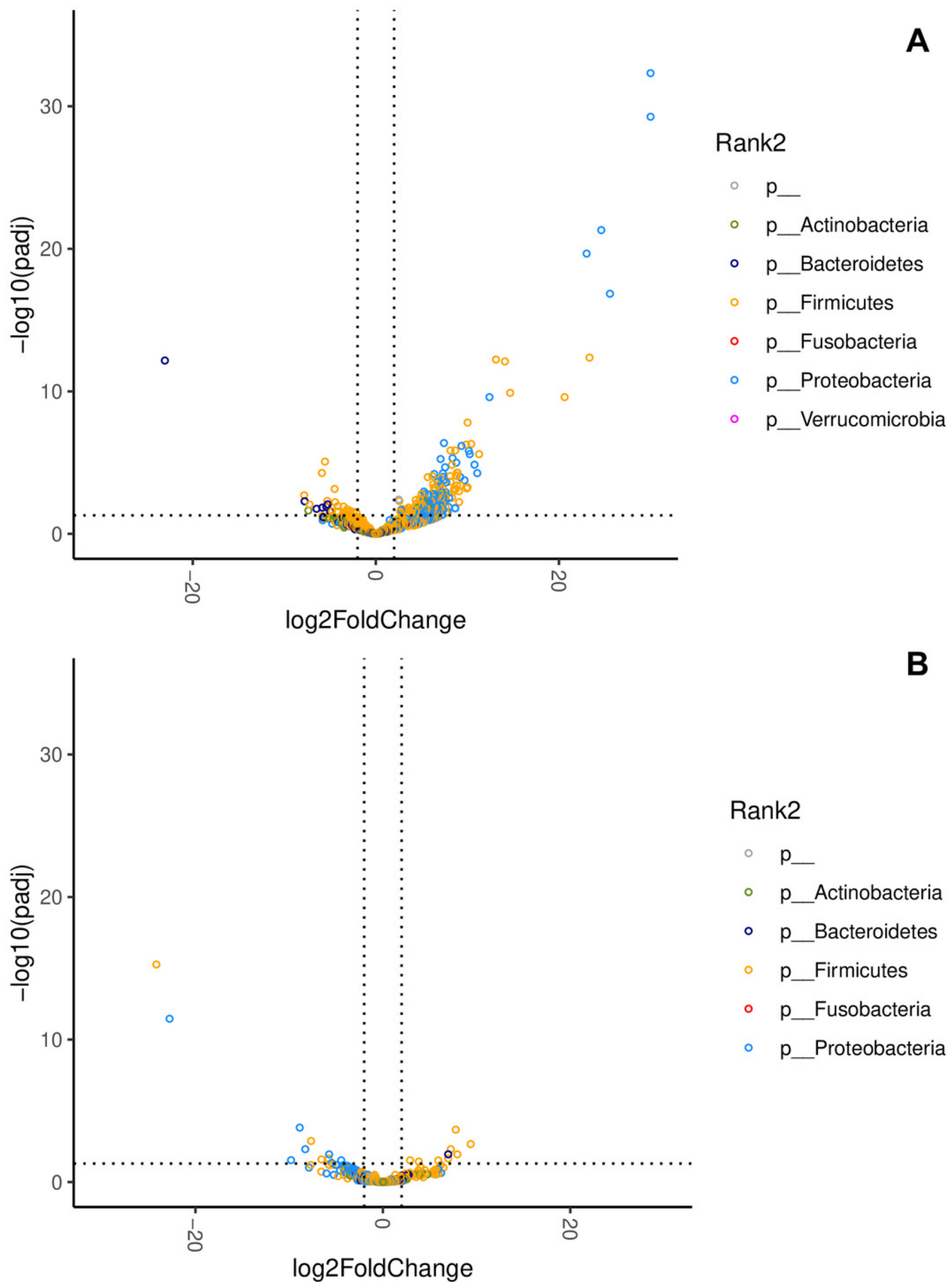
Figure 8

Volcano plot demonstrating fold-change (FC) of species abundance between week 4 and baseline in those reporting better overall health $(n=16)$ compared to those reporting about the same overall health $(n=10)$.

Vertical dashed lines show $\log 2 \mathrm{FC}$ at 1 and -1 (i.e. FC at 2 and -2). Horizontal dashed line shows adjusted $p=0.05$. Adjustment of $p$ values is performed with false discovery rate. Points are colored by phylum.

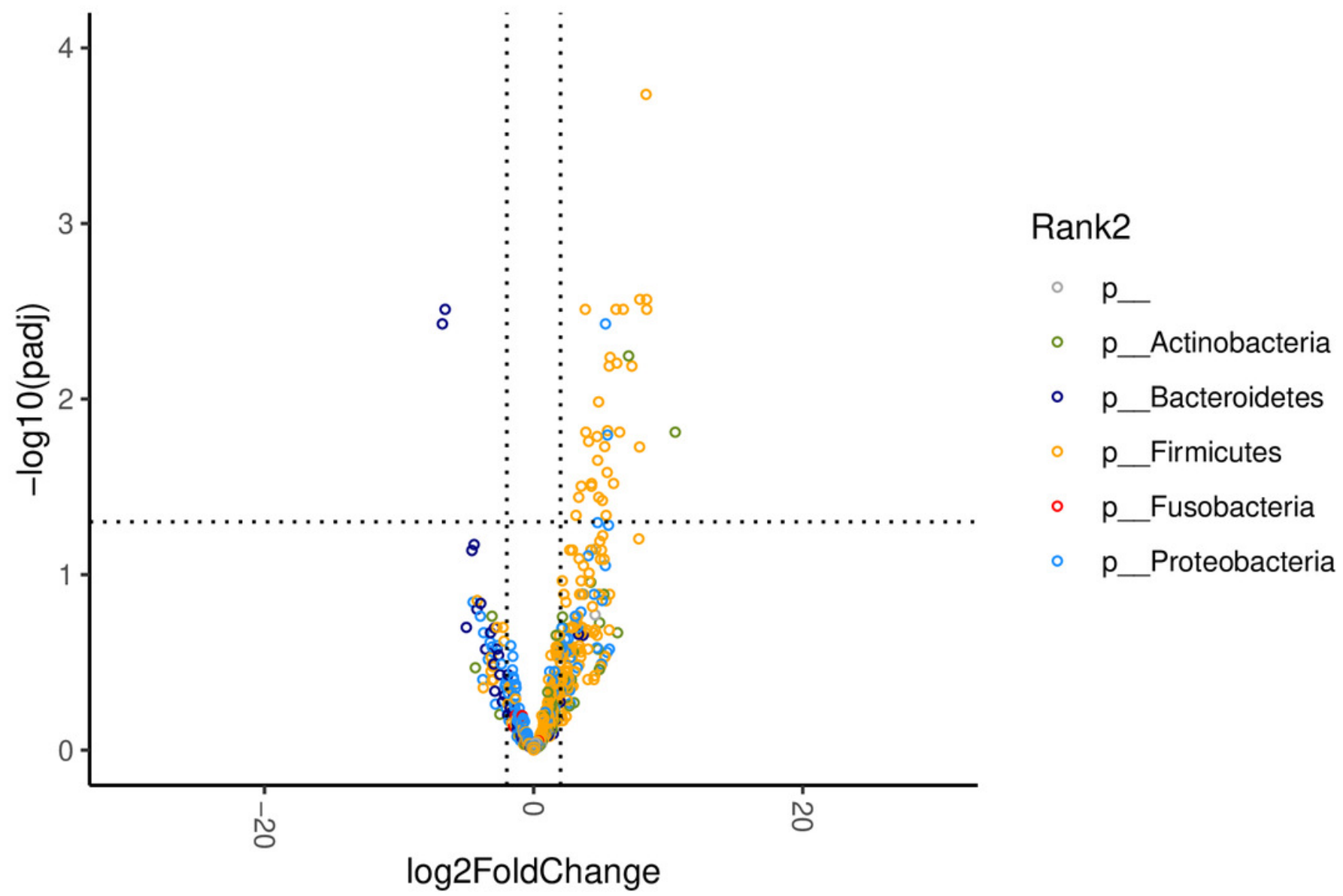




\section{Table 1 (on next page)}

Guaranteed analysis and ingredients of each mildly cooked recipe 
Table 1. Guaranteed analysis and ingredients of each mildly cooked recipe

\begin{tabular}{|c|c|c|c|c|c|}
\hline \multirow[t]{2}{*}{ Recipe } & \multicolumn{5}{|c|}{ Guaranteed analysis } \\
\hline & $\begin{array}{c}\text { Calories, } \\
\text { kcal } / \text { kg FW }\end{array}$ & $\begin{array}{c}\text { Crude } \\
\text { protein, } \\
\text { min \%AF }\end{array}$ & $\begin{array}{l}\text { Crude fat, } \\
\text { min \%AF }\end{array}$ & $\begin{array}{c}\text { Crude fiber, } \\
\max \% \mathrm{AF}\end{array}$ & $\begin{array}{l}\text { Moisture, } \\
\max \% \text { AF }\end{array}$ \\
\hline Beef & 1239 & 10 & 5 & 1 & 73 \\
\hline Chicken & 1255 & 8.5 & 6 & 1 & 77 \\
\hline Pork & 1246 & 8 & 5 & 2 & 75 \\
\hline Turkey & 1479 & 11 & 5 & 1 & 70 \\
\hline Recipe & \multicolumn{5}{|c|}{ Ingredients } \\
\hline Beef & \multicolumn{5}{|c|}{$\begin{array}{l}\text { Ground beef, russet potatoes, eggs, carrots, peas, dicalcium phosphate, } \\
\text { calcium carbonate, salt, fish oil, sunflower oil, vinegar, citric acid } \\
\text { (preservative), taurine, choline bitartrate, zinc gluconate, ferrous sulfate, } \\
\text { vitamin E supplement, copper gluconate, manganese gluconate, thiamine } \\
\text { mononitrate (vitamin B1), selenium yeast, riboflavin (vitamin B2), vitamin } \\
\text { B12 supplement, cholecalciferol (source of vitamin D3), potassium iodide }\end{array}$} \\
\hline Chicken & \multicolumn{5}{|c|}{$\begin{array}{l}\text { Diced chicken, sweet potatoes, yellow squash, spinach, sunflower oil, canola } \\
\text { oil, dicalcium phosphate, calcium carbonate, fish oil, vinegar, citric acid, } \\
\text { taurine, choline bitartrate, zinc gluconate, ferrous sulfate, vitamin E } \\
\text { supplement, copper gluconate, manganese gluconate, thiamine mononitrate } \\
\text { (vitamin B1), selenium yeast, riboflavin (vitamin B2), vitamin B12 } \\
\text { supplement, cholecalciferol (source of vitamin D3), potassium iodide }\end{array}$} \\
\hline Pork & \multicolumn{5}{|c|}{$\begin{array}{l}\text { Ground pork, russet potatoes, green beans, yellow squash, kale, brown } \\
\text { mushrooms, dicalcium phosphate, salt, fish oil, vinegar, citric acid, taurine, } \\
\text { choline bitartrate, zinc gluconate, ferrous sulfate, vitamin E supplement, } \\
\text { copper gluconate, manganese gluconate, thiamine mononitrate (vitamin B1), } \\
\text { selenium yeast, riboflavin (vitamin B2), vitamin B12 supplement, } \\
\text { cholecalciferol (source of vitamin D3), potassium iodide }\end{array}$} \\
\hline Turkey & \multicolumn{5}{|c|}{$\begin{array}{l}\text { Ground turkey, brown rice, eggs, carrots, spinach, dicalcium phosphate, } \\
\text { calcium carbonate, salt, fish oil, vinegar, citric acid, taurine, choline bitartrate, } \\
\text { zinc gluconate, ferrous sulfate, vitamin E supplement, copper gluconate, } \\
\text { manganese gluconate, thiamine mononitrate (vitamin B1), selenium yeast, } \\
\text { riboflavin (vitamin B2), vitamin B12 supplement, cholecalciferol (source of } \\
\text { vitamin D3), potassium iodide }\end{array}$} \\
\hline
\end{tabular}

FW: fresh weight, AF: as fed 


\section{Table 2 (on next page)}

Baseline characteristics of 33 dogs whose owner provided survey data $(n=31)$ or fecal samples $(n=28)$.

Data are expressed as mean \pm SD or $n(\%)$. 
Table 2. Baseline characteristics of 33 dogs whose owner provided survey data $(n=31)$ or fecal samples $(n=28)$. Data are expressed as mean \pm SD or $n(\%)$.

\begin{tabular}{|c|c|c|}
\hline Feature & $\begin{array}{l}\text { Health assessment data } \\
\qquad(n=31)\end{array}$ & $\begin{array}{l}\text { Fecal samples } \\
\qquad(n=28)\end{array}$ \\
\hline Age, in years & $4.8 \pm 3.6$ & $5.2 \pm 3.7$ \\
\hline Male & $16(52 \%)$ & $14(50 \%)$ \\
\hline Spayed or neutered $^{1}$ & $24(83 \%)$ & $24(86 \%)$ \\
\hline Body weight, in kg & $10.2 \pm 8.4$ & $10.7 \pm 8.7$ \\
\hline Ideal body weight, in $\mathrm{kg}$ & $10.0 \pm 8.2$ & $10.5 \pm 8.5$ \\
\hline \multicolumn{3}{|l|}{ Body condition score ${ }^{1}$} \\
\hline $4-5$ & $20(77 \%)$ & $20(74 \%)$ \\
\hline 6 & $6(23 \%)$ & $7(26 \%)$ \\
\hline \multicolumn{3}{|l|}{ Physical activity level $^{1}$} \\
\hline Very active & $2(7 \%)$ & $2(7 \%)$ \\
\hline Active & $8(30 \%)$ & $8(30 \%)$ \\
\hline Average active & $8(30 \%)$ & $6(22 \%)$ \\
\hline Somewhat active & $8(30 \%)$ & $10(37 \%)$ \\
\hline Not active & $1(4 \%)$ & $1(4 \%)$ \\
\hline \multicolumn{3}{|l|}{ Overall health ${ }^{1}$} \\
\hline Excellent & $17(63 \%)$ & $17(63 \%)$ \\
\hline Good & $9(33 \%)$ & $8(30 \%)$ \\
\hline Fair & $1(4 \%)$ & $2(7 \%)$ \\
\hline Poor & $0(0 \%)$ & $0(0 \%)$ \\
\hline Bad & $0(0 \%)$ & $0(0 \%)$ \\
\hline \multicolumn{3}{|l|}{ Food motivation ${ }^{1}$} \\
\hline Very motivated & $12(44 \%)$ & $11(41 \%)$ \\
\hline Somewhat motivated & $11(41 \%)$ & $12(44 \%)$ \\
\hline Average motivated & $1(4 \%)$ & $1(4 \%)$ \\
\hline Mildly motivated & $1(4 \%)$ & $1(4 \%)$ \\
\hline Not at all motivated & $2(7 \%)$ & $2(7 \%)$ \\
\hline Fecal consistency score ${ }^{1}$ & $3.1 \pm 1.3$ & $3.0 \pm 1.2$ \\
\hline \multicolumn{3}{|l|}{ Defecation frequency ${ }^{1}$} \\
\hline$\geq 3$ times/day & $7(26 \%)$ & $8(30 \%)$ \\
\hline 2 times/day & $18(67 \%)$ & $17(63 \%)$ \\
\hline 1 time/day & $2(7 \%)$ & $2(7 \%)$ \\
\hline \multicolumn{3}{|l|}{ Flatulence frequency ${ }^{1}$} \\
\hline Multiple times per day & $1(4 \%)$ & $1(4 \%)$ \\
\hline Daily & $5(19 \%)$ & $5(19 \%)$ \\
\hline Once in a while & $11(41 \%)$ & $11(41 \%)$ \\
\hline Never & $10(37 \%)$ & $10(37 \%)$ \\
\hline
\end{tabular}

${ }^{1}$ Spayed/neutered, body condition, physical activity level, overall health, food motivation, fecal score, defecation frequency, and flatulence frequency data were not available in all dogs. Spayed/neutered was not available in 2 dogs in the first column. Body condition score and fecal 
consistency score were not available in 4 dogs in the first column and 1 dog in the second column. 


\section{Table 3(on next page)}

Health outcomes 28 days after dietary intervention compared to baseline $(n=31)$ 
Table 3. Health outcomes 28 days after dietary intervention compared to baseline $(n=31)$

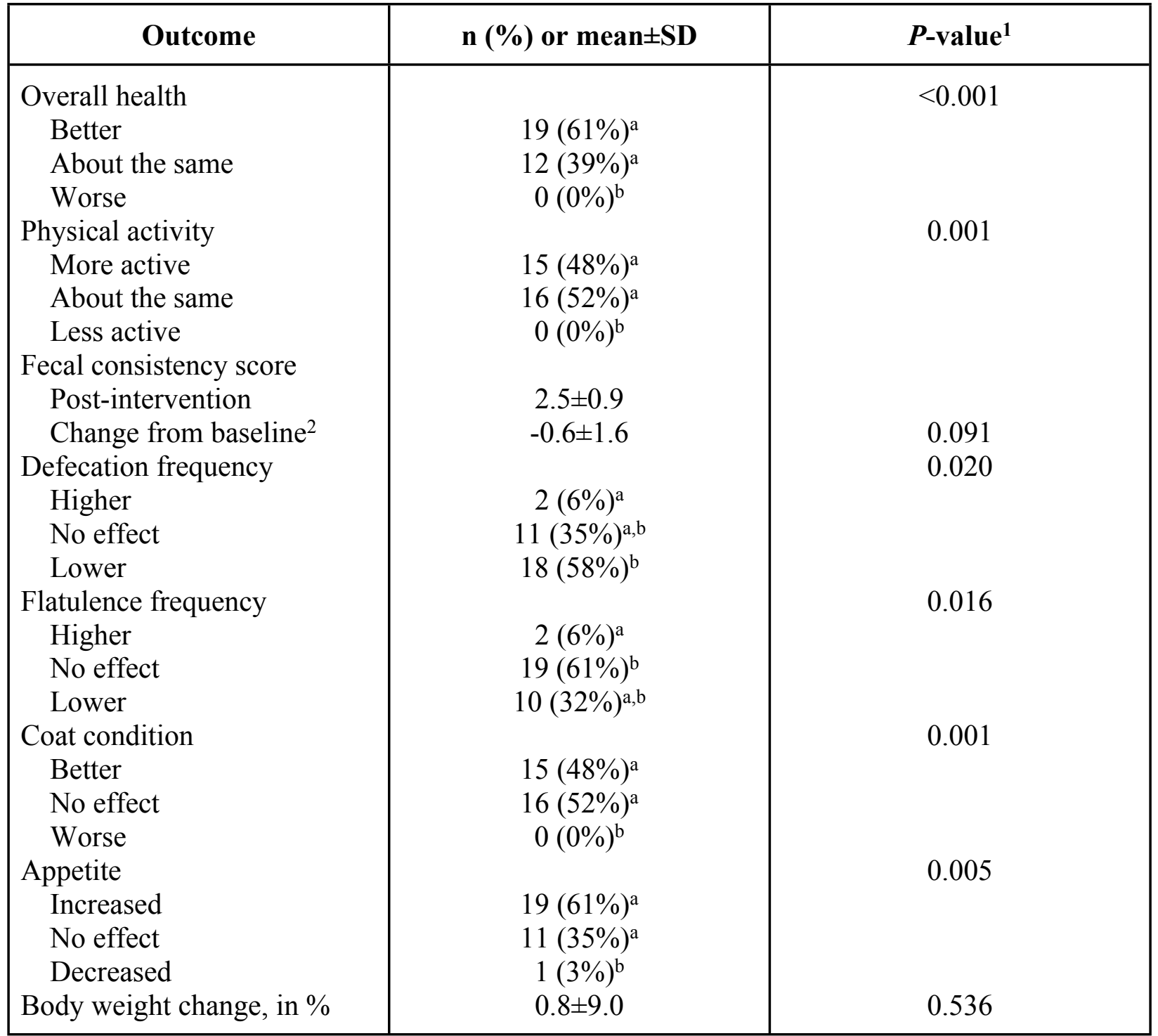

${ }^{1}$ Fisher exact test (categorical variables) and Wilcoxon signed-rank test (continuous variables) were performed to compare the observed data with the expected data under the null hypothesis (equal ratios of subjects in each category for categorical variables and change equal to zero for continuous variables). Those that do not share superscripts are significantly different in pairwise comparisons with false discovery rate (FDR) adjustment.

2 Data not available for 4 subjects. 


\section{Table 4 (on next page)}

Species with differential abundances between baseline and week $4(n=28, \log 2$ |fold change $\mid \geq 2$ and FDR-adjusted $p<0.05$ ) 
Table 4. Species with differential abundances between baseline and week $4\left(n=28, \log _{2} \mid\right.$ fold change $\mid \geq 2$ and FDR-adjusted $\left.p<0.05\right)$

\begin{tabular}{|c|c|c|c|c|c|c|c|c|c|}
\hline \multirow[t]{2}{*}{ Phylum } & \multirow[t]{2}{*}{ Class } & \multirow[t]{2}{*}{ Order } & \multirow[t]{2}{*}{ Family } & \multirow[t]{2}{*}{ Genus } & \multirow[t]{2}{*}{ Species } & \multicolumn{2}{|c|}{$\begin{array}{c}\text { Relative abundance (\%) } \\
\text { Median (IQR) }\end{array}$} & \multicolumn{2}{|c|}{ Week 4 vs Baseline } \\
\hline & & & & & & Baseline & Week 4 & $\begin{array}{c}\log 2 \mathrm{FC} \\
\text { mean } \pm \text { SE }\end{array}$ & $\begin{array}{c}\text { Adjusted } \\
P \text {-value } 1\end{array}$ \\
\hline \multicolumn{10}{|c|}{ Increased at week 4 (70 species) } \\
\hline Firmicutes & Bacilli & Lactobacillales & \begin{tabular}{|l|} 
Lactobacillaceae \\
\end{tabular} & Lactobacillus & algidus & $0.00 \mathrm{E}+00(0.00 \mathrm{E}+00-1.64 \mathrm{E}-04)$ & $3.54 \mathrm{E}-03(1.48 \mathrm{E}-04-1.50 \mathrm{E}-01)$ & $12.53 \pm 1.11$ & $1.12 \mathrm{E}-26$ \\
\hline Firmicutes & Bacilli & Lactobacillales & Leuconostocaceae & Leuconostoc & gelidum & $5.01 \mathrm{E}-05(0.00 \mathrm{E}+00-2.71 \mathrm{E}-04)$ & $8.20 \mathrm{E}-03(3.38 \mathrm{E}-04-1.43 \mathrm{E}+00)$ & $11.90 \pm 1.17$ & $9.78 \mathrm{E}-22$ \\
\hline Firmicutes & Bacilli & Lactobacillales & Lactobacillaceae & Lactobacillus & sakei & $2.62 \mathrm{E}-05(0.00 \mathrm{E}+00-3.44 \mathrm{E}-04)$ & $3.00 \mathrm{E}-03(5.95 \mathrm{E}-05-7.40 \mathrm{E}-02)$ & $11.61 \pm 1.16$ & $3.24 \mathrm{E}-21$ \\
\hline Firmicutes & Bacilli & Lactobacillales & Lactobacillaceae & Lactobacillus & fuchuensis & $0.00 \mathrm{E}+00(0.00 \mathrm{E}+00-5.26 \mathrm{E}-05)$ & $1.12 \mathrm{E}-04(0.00 \mathrm{E}+00-4.20 \mathrm{E}-03)$ & $9.56 \pm 1.34$ & $1.85 \mathrm{E}-10$ \\
\hline Proteobacteria & Gammaproteobacteria & Enterobacterales & Morganellaceae & Proteus & unknown & $0.00 \mathrm{E}+00(0.00 \mathrm{E}+00-0.00 \mathrm{E}+00)$ & $0.00 \mathrm{E}+00(0.00 \mathrm{E}+00-1.06 \mathrm{E}-05)$ & $9.50 \pm 2.25$ & $5.37 \mathrm{E}-04$ \\
\hline Firmicutes & Bacilli & Lactobacillales & Leuconostocaceae & Leuconostoc & carnosum & $0.00 \mathrm{E}+00(0.00 \mathrm{E}+00-1.80 \mathrm{E}-05)$ & $3.22 \mathrm{E}-05(0.00 \mathrm{E}+00-2.10 \mathrm{E}-02)$ & $8.46 \pm 1.43$ & $2.85 \mathrm{E}-07$ \\
\hline Firmicutes & Bacilli & Lactobacillales & Lactobacillaceae & Lactobacillus & curvatus & $0.00 \mathrm{E}+00(0.00 \mathrm{E}+00-2.06 \mathrm{E}-04)$ & $8.89 \mathrm{E}-04(5.95 \mathrm{E}-05-1.83 \mathrm{E}-02)$ & $7.46 \pm 1.21$ & $5.66 \mathrm{E}-08$ \\
\hline Proteobacteria & Gammaproteobacteria & Enterobacterales & Morganellaceae & Proteus & mirabilis & $0.00 \mathrm{E}+00(0.00 \mathrm{E}+00-5.66 \mathrm{E}-05)$ & $7.21 \mathrm{E}-05(0.00 \mathrm{E}+00-1.79 \mathrm{E}-03)$ & $7.32 \pm 1.29$ & $8.23 \mathrm{E}-07$ \\
\hline Firmicutes & Bacilli & Lactobacillales & Lactobacillaceae & \begin{tabular}{|l} 
Lactobacillus \\
\end{tabular} & siliginis & $0.00 \mathrm{E}+00(0.00 \mathrm{E}+00-0.00 \mathrm{E}+00)$ & $0.00 \mathrm{E}+00(0.00 \mathrm{E}+00-1.18 \mathrm{E}-03)$ & $7.24 \pm 1.43$ & $1.76 \mathrm{E}-05$ \\
\hline Firmicutes & Bacilli & Lactobacillales & Leuconostocaceae & Leuconostoc & unknown & $0.00 \mathrm{E}+00(0.00 \mathrm{E}+00-1.11 \mathrm{E}-04)$ & $1.52 \mathrm{E}-03(0.00 \mathrm{E}+00-3.58 \mathrm{E}-02)$ & $7.19 \pm 1.23$ & $3.52 \mathrm{E}-07$ \\
\hline Firmicutes & Bacilli & Lactobacillales & Lactobacillaceae & Lactobacillus & sanfranciscensis & $0.00 \mathrm{E}+00(0.00 \mathrm{E}+00-9.13 \mathrm{E}-05)$ & $1.94 \mathrm{E}-04(0.00 \mathrm{E}+00-6.55 \mathrm{E}-03)$ & $6.94 \pm 1.46$ & $6.48 \mathrm{E}-05$ \\
\hline Firmicutes & Bacilli & Lactobacillales & Leuconostocaceae & Leuconostoc & pseudomesenteroides & $0.00 \mathrm{E}+00(0.00 \mathrm{E}+00-0.00 \mathrm{E}+00)$ & $0.00 \mathrm{E}+00(0.00 \mathrm{E}+00-7.94 \mathrm{E}-04)$ & $6.94 \pm 1.17$ & $2.64 \mathrm{E}-07$ \\
\hline Firmicutes & Bacilli & Lactobacillales & Leuconostocaceae & Leuconostoc & citreum & $2.35 \mathrm{E}-05(0.00 \mathrm{E}+00-2.98 \mathrm{E}-04)$ & 7.62E-04 (2.16E-04 - 2.33E-02) & $6.68 \pm 0.97$ & $1.04 \mathrm{E}-09$ \\
\hline Firmicutes & Bacilli & Lactobacillales & Leuconostocaceae & Leuconostoc & fallax & $0.00 \mathrm{E}+00(0.00 \mathrm{E}+00-0.00 \mathrm{E}+00)$ & $0.00 \mathrm{E}+00(0.00 \mathrm{E}+00-7.02 \mathrm{E}-04)$ & $6.67 \pm 1.50$ & $2.38 \mathrm{E}-04$ \\
\hline Firmicutes & Bacilli & Lactobacillales & Enterococcaceae & Tetragenococcus & halophilus & $0.00 \mathrm{E}+00(0.00 \mathrm{E}+00-0.00 \mathrm{E}+00)$ & $0.00 \mathrm{E}+00(0.00 \mathrm{E}+00-8.40 \mathrm{E}-05)$ & $6.56 \pm 1.74$ & $2.81 \mathrm{E}-03$ \\
\hline Firmicutes & Bacilli & Lactobacillales & Lactobacillaceae & Lactobacillus & saniviri & $0.00 \mathrm{E}+00(0.00 \mathrm{E}+00-0.00 \mathrm{E}+00)$ & $0.00 \mathrm{E}+00(0.00 \mathrm{E}+00-7.28 \mathrm{E}-05)$ & $6.30 \pm 1.77$ & $5.03 \mathrm{E}-03$ \\
\hline Firmicutes & Bacilli & Lactobacillales & Lactobacillaceae & Lactobacillus & plantarum & $4.21 \mathrm{E}-05(0.00 \mathrm{E}+00-2.57 \mathrm{E}-04)$ & $1.37 \mathrm{E}-04(0.00 \mathrm{E}+00-1.90 \mathrm{E}-03)$ & $6.23 \pm 1.12$ & $1.48 \mathrm{E}-06$ \\
\hline Firmicutes & Bacilli & Lactobacillales & Lactobacillaceae & Lactobacillus & paralimentarius & $0.00 \mathrm{E}+00(0.00 \mathrm{E}+00-4.38 \mathrm{E}-05)$ & $1.61 \mathrm{E}-05(0.00 \mathrm{E}+00-1.75 \mathrm{E}-04)$ & $6.22 \pm 1.91$ & $1.28 \mathrm{E}-02$ \\
\hline Actinobacteria & Actinobacteria & Micrococcales & Micrococcaceae & Arthrobacter & unknown & $0.00 \mathrm{E}+00(0.00 \mathrm{E}+00-0.00 \mathrm{E}+00)$ & $0.00 \mathrm{E}+00(0.00 \mathrm{E}+00-2.25 \mathrm{E}-04)$ & $6.22 \pm 1.42$ & $2.90 \mathrm{E}-04$ \\
\hline Firmicutes & Bacilli & Lactobacillales & Leuconostocaceae & Weissella & hellenica & $0.00 \mathrm{E}+00(0.00 \mathrm{E}+00-0.00 \mathrm{E}+00)$ & $0.00 \mathrm{E}+00(0.00 \mathrm{E}+00-6.72 \mathrm{E}-04)$ & $6.15 \pm 1.29$ & $6.48 \mathrm{E}-05$ \\
\hline Firmicutes & Bacilli & Lactobacillales & \begin{tabular}{|l|} 
Leuconostocaceae \\
\end{tabular} & Weissella & cibaria & $0.00 \mathrm{E}+00(0.00 \mathrm{E}+00-6.30 \mathrm{E}-05)$ & $2.25 \mathrm{E}-04(0.00 \mathrm{E}+00-2.10 \mathrm{E}-03)$ & $6.01 \pm 1.18$ & $1.61 \mathrm{E}-05$ \\
\hline Firmicutes & Bacilli & Lactobacillales & Lactobacillaceae & Lactobacillus & coryniformis & $0.00 \mathrm{E}+00(0.00 \mathrm{E}+00-0.00 \mathrm{E}+00)$ & $0.00 \mathrm{E}+00(0.00 \mathrm{E}+00-3.87 \mathrm{E}-04)$ & $5.91 \pm 1.46$ & $9.81 \mathrm{E}-04$ \\
\hline Proteobacteria & Gammaproteobacteria & Enterobacterales & Morganellaceae & Morganella & morganii & $0.00 \mathrm{E}+00(0.00 \mathrm{E}+00-0.00 \mathrm{E}+00)$ & $0.00 \mathrm{E}+00(0.00 \mathrm{E}+00-6.20 \mathrm{E}-05)$ & $5.81 \pm 1.37$ & $4.88 \mathrm{E}-04$ \\
\hline Firmicutes & Bacilli & Lactobacillales & Lactobacillaceae & Lactobacillus & capillatus & $0.00 \mathrm{E}+00(0.00 \mathrm{E}+00-6.65 \mathrm{E}-05)$ & $1.29 \mathrm{E}-05(0.00 \mathrm{E}+00-2.49 \mathrm{E}-03)$ & $5.81 \pm 1.95$ & $2.80 \mathrm{E}-02$ \\
\hline Proteobacteria & Gammaproteobacteria & Enterobacterales & Enterobacteriaceae & Kosakonia & sp S29 & $0.00 \mathrm{E}+00(0.00 \mathrm{E}+00-0.00 \mathrm{E}+00)$ & $2.83 \mathrm{E}-05(0.00 \mathrm{E}+00-1.35 \mathrm{E}-04)$ & $5.76 \pm 1.14$ & $1.76 \mathrm{E}-05$ \\
\hline Firmicutes & Bacilli & Lactobacillales & Leuconostocaceae & Leuconostoc & mesenteroides & $8.43 \mathrm{E}-05(0.00 \mathrm{E}+00-2.37 \mathrm{E}-04)$ & $3.02 \mathrm{E}-04(0.00 \mathrm{E}+00-1.46 \mathrm{E}-02)$ & $5.64 \pm 1.07$ & $5.87 \mathrm{E}-06$ \\
\hline Firmicutes & Bacilli & Lactobacillales & Leuconostocaceae & Weissella & jogaejeotgali & $0.00 \mathrm{E}+00(0.00 \mathrm{E}+00-0.00 \mathrm{E}+00)$ & $0.00 \mathrm{E}+00(0.00 \mathrm{E}+00-1.78 \mathrm{E}-04)$ & $5.33 \pm 1.43$ & $3.02 \mathrm{E}-03$ \\
\hline
\end{tabular}




\begin{tabular}{|c|c|c|c|c|c|c|c|c|c|}
\hline Firmicutes & Bacilli & Lactobacillales & Lactobacillaceae & Pediococcus & inopinatus & $0.00 \mathrm{E}+00(0.00 \mathrm{E}+00-0.00 \mathrm{E}+00)$ & $0.00 \mathrm{E}+00(0.00 \mathrm{E}+00-9.05 \mathrm{E}-05)$ & $5.08 \pm 1.71$ & $2.85 \mathrm{E}-02$ \\
\hline Firmicutes & Bacilli & Lactobacillales & Leuconostocaceae & Weissella & confusa & $0.00 \mathrm{E}+00(0.00 \mathrm{E}+00-1.12 \mathrm{E}-04)$ & $6.25 \mathrm{E}-05(0.00 \mathrm{E}+00-1.90 \mathrm{E}-04)$ & $4.92 \pm 1.13$ & $3.39 \mathrm{E}-04$ \\
\hline Firmicutes & Bacilli & Lactobacillales & Lactobacillaceae & Lactobacillus & oligofermentans & $0.00 \mathrm{E}+00(0.00 \mathrm{E}+00-0.00 \mathrm{E}+00)$ & $0.00 \mathrm{E}+00(0.00 \mathrm{E}+00-4.01 \mathrm{E}-04)$ & $4.89 \pm 1.50$ & $1.25 \mathrm{E}-02$ \\
\hline Firmicutes & Bacilli & Lactobacillales & Leuconostocaceae & Weissella & unknown & $0.00 \mathrm{E}+00(0.00 \mathrm{E}+00-1.11 \mathrm{E}-04)$ & $5.12 \mathrm{E}-05(0.00 \mathrm{E}+00-6.32 \mathrm{E}-04)$ & $4.86 \pm 1.07$ & $1.56 \mathrm{E}-04$ \\
\hline Firmicutes & Bacilli & Lactobacillales & Lactobacillaceae & Lactobacillus & unknown & $1.61 \mathrm{E}-03(4.32 \mathrm{E}-04-4.28 \mathrm{E}-03)$ & $1.57 \mathrm{E}-02(7.43 \mathrm{E}-04-7.92 \mathrm{E}-02)$ & $4.85 \pm 0.72$ & $1.94 \mathrm{E}-09$ \\
\hline Firmicutes & Bacilli & Lactobacillales & Lactobacillaceae & Lactobacillus & paraplantarum & $0.00 \mathrm{E}+00(0.00 \mathrm{E}+00-0.00 \mathrm{E}+00)$ & $0.00 \mathrm{E}+00(0.00 \mathrm{E}+00-2.48 \mathrm{E}-04)$ & $4.80 \pm 1.36$ & $5.63 \mathrm{E}-03$ \\
\hline Firmicutes & Bacilli & Lactobacillales & Leuconostocaceae & Weissella & paramesenteroides & $0.00 \mathrm{E}+00(0.00 \mathrm{E}+00-5.53 \mathrm{E}-05)$ & $0.00 \mathrm{E}+00(0.00 \mathrm{E}+00-2.43 \mathrm{E}-04)$ & $4.70 \pm 1.22$ & $2.08 \mathrm{E}-03$ \\
\hline Actinobacteria & Actinobacteria & Bifidobacteriales & Bifidobacteriaceae & Bifidobacterium & animalis & $0.00 \mathrm{E}+00(0.00 \mathrm{E}+00-1.59 \mathrm{E}-04)$ & $0.00 \mathrm{E}+00(0.00 \mathrm{E}+00-6.60 \mathrm{E}-06)$ & $4.67 \pm 1.68$ & $4.39 \mathrm{E}-02$ \\
\hline Firmicutes & Bacilli & Lactobacillales & Leuconostocaceae & Weissella & koreensis & $0.00 \mathrm{E}+00(0.00 \mathrm{E}+00-0.00 \mathrm{E}+00)$ & $0.00 \mathrm{E}+00(0.00 \mathrm{E}+00-4.02 \mathrm{E}-04)$ & $4.55 \pm 1.59$ & $3.43 \mathrm{E}-02$ \\
\hline Proteobacteria & Gammaproteobacteria & Enterobacterales & Hafniaceae & Hafnia & alvei & $0.00 \mathrm{E}+00(0.00 \mathrm{E}+00-7.61 \mathrm{E}-05)$ & $9.66 \mathrm{E}-05(0.00 \mathrm{E}+00-2.41 \mathrm{E}-03)$ & $4.52 \pm 1.42$ & $1.58 \mathrm{E}-02$ \\
\hline Firmicutes & Bacilli & Lactobacillales & Leuconostocaceae & Leuconostoc & lactis & $0.00 \mathrm{E}+00(0.00 \mathrm{E}+00-2.35 \mathrm{E}-05)$ & $7.59 \mathrm{E}-05(0.00 \mathrm{E}+00-8.90 \mathrm{E}-04)$ & $4.49 \pm 1.26$ & $5.03 \mathrm{E}-03$ \\
\hline Firmicutes & Bacilli & Lactobacillales & Leuconostocaceae & Leuconostoc & garlicum & $0.00 \mathrm{E}+00(0.00 \mathrm{E}+00-0.00 \mathrm{E}+00)$ & $7.89 \mathrm{E}-05(0.00 \mathrm{E}+00-1.36 \mathrm{E}-03)$ & $4.45 \pm 1.33$ & $9.80 \mathrm{E}-03$ \\
\hline Proteobacteria & Gammaproteobacteria & Enterobacterales & Morganellaceae & Proteus & sp HMSC10D02 & $0.00 \mathrm{E}+00(0.00 \mathrm{E}+00-6.23 \mathrm{E}-05)$ & $0.00 \mathrm{E}+00(0.00 \mathrm{E}+00-1.45 \mathrm{E}-04)$ & $4.32 \pm 1.10$ & $1.65 \mathrm{E}-03$ \\
\hline Firmicutes & Bacilli & Lactobacillales & Lactobacillaceae & Lactobacillus & parafarraginis & $0.00 \mathrm{E}+00(0.00 \mathrm{E}+00-0.00 \mathrm{E}+00)$ & $0.00 \mathrm{E}+00(0.00 \mathrm{E}+00-4.81 \mathrm{E}-05)$ & $4.23 \pm 1.40$ & $2.59 \mathrm{E}-02$ \\
\hline Proteobacteria & Gammaproteobacteria & Enterobacterales & Enterobacteriaceae & Raoultella & ornithinolytica & $1.59 \mathrm{E}-05(0.00 \mathrm{E}+00-3.26 \mathrm{E}-04)$ & $1.35 \mathrm{E}-04(0.00 \mathrm{E}+00-1.01 \mathrm{E}-03)$ & $4.22 \pm 0.94$ & $2.04 \mathrm{E}-04$ \\
\hline Proteobacteria & Gammaproteobacteria & Enterobacterales & Enterobacteriaceae & Klebsiella & sp HMSC25G12 & $0.00 \mathrm{E}+00(0.00 \mathrm{E}+00-9.44 \mathrm{E}-06)$ & $0.00 \mathrm{E}+00(0.00 \mathrm{E}+00-1.63 \mathrm{E}-04)$ & $4.16 \pm 1.38$ & $2.59 \mathrm{E}-02$ \\
\hline Proteobacteria & Gammaproteobacteria & Enterobacterales & Enterobacteriaceae & Cronobacter & dublinensis & $0.00 \mathrm{E}+00(0.00 \mathrm{E}+00-1.00 \mathrm{E}-04)$ & $2.29 \mathrm{E}-05(0.00 \mathrm{E}+00-2.66 \mathrm{E}-04)$ & $4.07 \pm 1.13$ & $4.65 \mathrm{E}-03$ \\
\hline Firmicutes & Bacilli & Lactobacillales & Enterococcaceae & Enterococcus & sp kppr-6 & $0.00 \mathrm{E}+00(0.00 \mathrm{E}+00-7.30 \mathrm{E}-05)$ & $3.30 \mathrm{E}-05(0.00 \mathrm{E}+00-8.30 \mathrm{E}-05)$ & $3.91 \pm 1.16$ & $9.79 \mathrm{E}-03$ \\
\hline Firmicutes & Bacilli & Lactobacillales & Lactobacillaceae & Lactobacillus & kefiranofaciens & $8.20 \mathrm{E}-05(0.00 \mathrm{E}+00-2.80 \mathrm{E}-04)$ & $1.43 \mathrm{E}-04(2.66 \mathrm{E}-05-1.52 \mathrm{E}-03)$ & $3.89 \pm 1.37$ & $3.57 \mathrm{E}-02$ \\
\hline Firmicutes & Bacilli & Lactobacillales & Carnobacteriaceae & Carnobacterium & maltaromaticum & $0.00 \mathrm{E}+00(0.00 \mathrm{E}+00-0.00 \mathrm{E}+00)$ & $0.00 \mathrm{E}+00(0.00 \mathrm{E}+00-1.46 \mathrm{E}-04)$ & $3.89 \pm 0.92$ & $5.42 \mathrm{E}-04$ \\
\hline Firmicutes & Bacilli & Lactobacillales & Carnobacteriaceae & Carnobacterium & divergens & $0.00 \mathrm{E}+00(0.00 \mathrm{E}+00-1.58 \mathrm{E}-04)$ & $1.63 \mathrm{E}-04(0.00 \mathrm{E}+00-2.02 \mathrm{E}-03)$ & $3.88 \pm 1.04$ & $2.99 \mathrm{E}-03$ \\
\hline Proteobacteria & Gammaproteobacteria & Enterobacterales & Enterobacteriaceae & Klebsiella & cf. planticola B43 & $0.00 \mathrm{E}+00(0.00 \mathrm{E}+00-3.96 \mathrm{E}-05)$ & $2.68 \mathrm{E}-05(0.00 \mathrm{E}+00-4.17 \mathrm{E}-05)$ & $3.66 \pm 1.01$ & $4.25 \mathrm{E}-03$ \\
\hline Firmicutes & Clostridia & Clostridiales & Clostridiaceae & Clostridium & sp CL-2 & $3.68 \mathrm{E}-05(0.00 \mathrm{E}+00-3.50 \mathrm{E}-04)$ & $6.46 \mathrm{E}-05(0.00 \mathrm{E}+00-6.24 \mathrm{E}-04)$ & $3.62 \pm 0.90$ & $1.08 \mathrm{E}-03$ \\
\hline Firmicutes & Bacilli & Lactobacillales & Streptococcaceae & Lactococcus & piscium & $1.70 \mathrm{E}-04(2.10 \mathrm{E}-05-3.65 \mathrm{E}-04)$ & $3.60 \mathrm{E}-04(8.80 \mathrm{E}-05-4.30 \mathrm{E}-03)$ & $3.32 \pm 0.73$ & $1.43 \mathrm{E}-04$ \\
\hline Proteobacteria & Gammaproteobacteria & Enterobacterales & Enterobacteriaceae & Raoultella & planticola & $0.00 \mathrm{E}+00(0.00 \mathrm{E}+00-7.77 \mathrm{E}-05)$ & $6.66 \mathrm{E}-05(0.00 \mathrm{E}+00-5.63 \mathrm{E}-04)$ & $3.20 \pm 1.00$ & $1.48 \mathrm{E}-02$ \\
\hline Firmicutes & Bacilli & Lactobacillales & Lactobacillaceae & Lactobacillus & fermentum & $4.90 \mathrm{E}-05(0.00 \mathrm{E}+00-2.86 \mathrm{E}-04)$ & $1.73 \mathrm{E}-04(0.00 \mathrm{E}+00-5.50 \mathrm{E}-04)$ & $3.16 \pm 0.97$ & $1.31 \mathrm{E}-02$ \\
\hline Proteobacteria & Gammaproteobacteria & Enterobacterales & Enterobacteriaceae & Lelliottia & jeotgali & $0.00 \mathrm{E}+00(0.00 \mathrm{E}+00-3.33 \mathrm{E}-05)$ & $3.11 \mathrm{E}-05(0.00 \mathrm{E}+00-7.24 \mathrm{E}-05)$ & $3.15 \pm 1.13$ & 4.39E- -02 \\
\hline Proteobacteria & Gammaproteobacteria & Enterobacterales & Enterobacteriaceae & Enterobacter & cloacae complex Hoffmann cluster III & $0.00 \mathrm{E}+00(0.00 \mathrm{E}+00-2.78 \mathrm{E}-04)$ & $1.62 \mathrm{E}-04(0.00 \mathrm{E}+00-8.01 \mathrm{E}-04)$ & $3.14 \pm 0.96$ & $1.25 \mathrm{E}-02$ \\
\hline Bacteroidetes & Bacteroidia & Bacteroidales & Tannerellaceae & Parabacteroides & merdae & $1.54 \mathrm{E}-04(0.00 \mathrm{E}+00-1.50 \mathrm{E}-03)$ & $2.75 \mathrm{E}-05(0.00 \mathrm{E}+00-1.05 \mathrm{E}-03)$ & $3.12 \pm 1.04$ & $2.64 \mathrm{E}-02$ \\
\hline Firmicutes & Bacilli & Lactobacillales & Streptococcaceae & Lactococcus & lactis & $3.81 \mathrm{E}-03(9.03 \mathrm{E}-04-2.35 \mathrm{E}-02)$ & $7.09 \mathrm{E}-03(2.76 \mathrm{E}-03-3.68 \mathrm{E}-02)$ & $2.99 \pm 0.84$ & $5.03 \mathrm{E}-03$ \\
\hline Firmicutes & Bacilli & Lactobacillales & Enterococcaceae & Enterococcus & sp HMSC067C01 & $1.45 \mathrm{E}-04(0.00 \mathrm{E}+00-1.67 \mathrm{E}-03)$ & $5.45 \mathrm{E}-04(9.33 \mathrm{E}-05-1.77 \mathrm{E}-02)$ & $2.93 \pm 0.97$ & $2.45 \mathrm{E}-02$ \\
\hline Proteobacteria & Gammaproteobacteria & Enterobacterales & Enterobacteriaceae & Klebsiella & unknown & $1.44 \mathrm{E}-03(0.00 \mathrm{E}+00-9.01 \mathrm{E}-03)$ & $7.64 \mathrm{E}-03(9.62 \mathrm{E}-04-2.58 \mathrm{E}-02)$ & $2.92 \pm 0.91$ & $1.43 \mathrm{E}-02$ \\
\hline Proteobacteria & Gammaproteobacteria & Enterobacterales & Enterobacteriaceae & Enterobacter & asburiae & $0.00 \mathrm{E}+00(0.00 \mathrm{E}+00-5.62 \mathrm{E}-04)$ & $2.42 \mathrm{E}-04(3.63 \mathrm{E}-05-1.35 \mathrm{E}-03)$ & $2.58 \pm 0.89$ & $3.18 \mathrm{E}-02$ \\
\hline Firmicutes & Bacilli & Lactobacillales & Lactobacillaceae & Lactobacillus & parabuchneri & $8.76 \mathrm{E}-05(0.00 \mathrm{E}+00-2.69 \mathrm{E}-04)$ & $6.09 \mathrm{E}-05(0.00 \mathrm{E}+00-2.71 \mathrm{E}-04)$ & $2.36 \pm 0.87$ & $4.99 \mathrm{E}-02$ \\
\hline
\end{tabular}




\begin{tabular}{|c|c|c|c|c|c|c|c|c|c|}
\hline Firmicutes & Clostridia & Clostridiales & Lachnospiraceae & Tyzzerella & nexilis & 3.93E-02 (1.98E-02 - 5.81E-02) & $2.04 \mathrm{E}-02(4.61 \mathrm{E}-03-6.78 \mathrm{E}-02)$ & $2.21 \pm 0.61$ & $4.25 \mathrm{E}-03$ \\
\hline Proteobacteria & Gammaproteobacteria & Enterobacterales & Enterobacteriaceae & Pseudescherichia & vulneris & $0.00 \mathrm{E}+00(0.00 \mathrm{E}+00-8.89 \mathrm{E}-05)$ & $1.10 \mathrm{E}-04(3.63 \mathrm{E}-05-2.01 \mathrm{E}-04)$ & $2.10 \pm 0.77$ & $4.86 \mathrm{E}-02$ \\
\hline \multicolumn{10}{|c|}{ Decreased at week 4 (28 species) } \\
\hline Firmicutes & Bacilli & Bacillales & Planococcaceae & Rummeliibacillus & stabekisii & $0.00 \mathrm{E}+00(0.00 \mathrm{E}+00-8.97 \mathrm{E}-05)$ & $0.00 \mathrm{E}+00(0.00 \mathrm{E}+00-0.00 \mathrm{E}+00)$ & $-10.85 \pm 2.15$ & $1.76 \mathrm{E}-05$ \\
\hline Firmicutes & Bacilli & Bacillales & Paenibacillaceae & Paenibacillus & ginsengihumi & $0.00 \mathrm{E}+00(0.00 \mathrm{E}+00-1.49 \mathrm{E}-04)$ & $0.00 \mathrm{E}+00(0.00 \mathrm{E}+00-0.00 \mathrm{E}+00)$ & $-6.63 \pm 1.37$ & $4.55 \mathrm{E}-05$ \\
\hline Firmicutes & Bacilli & Bacillales & Paenibacillaceae & Brevibacillus & borstelensis & $0.00 \mathrm{E}+00(0.00 \mathrm{E}+00-9.69 \mathrm{E}-05)$ & $0.00 \mathrm{E}+00(0.00 \mathrm{E}+00-0.00 \mathrm{E}+00)$ & $-6.24 \pm 1.54$ & $9.81 \mathrm{E}-04$ \\
\hline Firmicutes & Bacilli & Bacillales & Paenibacillaceae & Aneurinibacillus & unknown & $0.00 \mathrm{E}+00(0.00 \mathrm{E}+00-1.84 \mathrm{E}-04)$ & $0.00 \mathrm{E}+00(0.00 \mathrm{E}+00-0.00 \mathrm{E}+00)$ & $-5.04 \pm 1.42$ & $5.03 \mathrm{E}-03$ \\
\hline Firmicutes & Bacilli & Lactobacillales & Enterococcaceae & Enterococcus & canintestini & $4.60 \mathrm{E}-05(0.00 \mathrm{E}+00-3.30 \mathrm{E}-03)$ & $1.06 \mathrm{E}-04(0.00 \mathrm{E}+00-4.47 \mathrm{E}-04)$ & $-5.02 \pm 1.27$ & $1.41 \mathrm{E}-03$ \\
\hline Firmicutes & Bacilli & Lactobacillales & Enterococcaceae & Enterococcus & hirae & $2.01 \mathrm{E}-04(2.70 \mathrm{E}-05-5.32 \mathrm{E}-03)$ & $1.40 \mathrm{E}-03(0.00 \mathrm{E}+00-8.16 \mathrm{E}-03)$ & $-4.48 \pm 1.06$ & $5.07 \mathrm{E}-04$ \\
\hline Bacteroidetes & Bacteroidia & Bacteroidales & Prevotellaceae & Prevotella & copri & $5.71 \mathrm{E}-05(0.00 \mathrm{E}+00-1.20 \mathrm{E}-01)$ & $2.94 \mathrm{E}-05(0.00 \mathrm{E}+00-3.01 \mathrm{E}-04)$ & $-4.41 \pm 1.54$ & $3.44 \mathrm{E}-02$ \\
\hline Bacteroidetes & Bacteroidia & Bacteroidales & Prevotellaceae & Prevotella & stercorea & $0.00 \mathrm{E}+00(0.00 \mathrm{E}+00-6.00 \mathrm{E}-04)$ & $0.00 \mathrm{E}+00(0.00 \mathrm{E}+00-0.00 \mathrm{E}+00)$ & $-3.97 \pm 1.35$ & $2.90 \mathrm{E}-02$ \\
\hline Bacteroidetes & Bacteroidia & Bacteroidales & Prevotellaceae & Prevotella & buccalis & $0.00 \mathrm{E}+00(0.00 \mathrm{E}+00-2.28 \mathrm{E}-04)$ & $0.00 \mathrm{E}+00(0.00 \mathrm{E}+00-0.00 \mathrm{E}+00)$ & $-3.91 \pm 1.42$ & $4.63 \mathrm{E}-02$ \\
\hline Firmicutes & Clostridia & Clostridiales & Lachnospiraceae & Blautia & wexlerae & $4.99 \mathrm{E}-02(1.54 \mathrm{E}-02-1.35 \mathrm{E}-01)$ & $2.52 \mathrm{E}-02(5.28 \mathrm{E}-03-3.90 \mathrm{E}-02)$ & $-3.90 \pm 0.62$ & $4.02 \mathrm{E}-08$ \\
\hline Firmicutes & Clostridia & Clostridiales & Lachnospiraceae & Blautia & sp Marseille-P2398 & $1.90 \mathrm{E}-03(7.51 \mathrm{E}-04-4.41 \mathrm{E}-03)$ & $6.13 \mathrm{E}-04(0.00 \mathrm{E}+00-1.33 \mathrm{E}-03)$ & $-3.75 \pm 0.81$ & $1.15 \mathrm{E}-04$ \\
\hline Firmicutes & Clostridia & Clostridiales & Lachnospiraceae & Blautia & unknown & $2.12 \mathrm{E}-01(9.30 \mathrm{E}-02-3.45 \mathrm{E}-01)$ & $6.61 \mathrm{E}-02(8.53 \mathrm{E}-03-2.10 \mathrm{E}-01)$ & $-3.33 \pm 0.62$ & $3.55 \mathrm{E}-06$ \\
\hline Bacteroidetes & Bacteroidia & Bacteroidales & Bacteroidaceae & Bacteroides & thetaiotaomicron & $1.96 \mathrm{E}-04(3.66 \mathrm{E}-05-9.82 \mathrm{E}-04)$ & $0.00 \mathrm{E}+00(0.00 \mathrm{E}+00-1.73 \mathrm{E}-04)$ & $-3.14 \pm 0.88$ & $5.03 \mathrm{E}-03$ \\
\hline Bacteroidetes & Bacteroidia & Bacteroidales & Bacteroidaceae & Bacteroides & coprophilus & $3.78 \mathrm{E}-04(4.00 \mathrm{E}-05-2.33 \mathrm{E}-03)$ & $2.95 \mathrm{E}-05(0.00 \mathrm{E}+00-1.87 \mathrm{E}-04)$ & $-2.96 \pm 0.97$ & $2.28 \mathrm{E}-02$ \\
\hline Actinobacteria & Actinobacteria & Bifidobacteriales & Bifidobacteriaceae & Bifidobacterium & longum & $1.30 \mathrm{E}-04(0.00 \mathrm{E}+00-1.04 \mathrm{E}-03)$ & 7.44E-05 (0.00E+00 - 5.36E-04) & $-2.93 \pm 1.00$ & $3.15 \mathrm{E}-02$ \\
\hline Firmicutes & Clostridia & Clostridiales & Peptostreptococcaceae & Peptostreptococcus & russellii & $1.60 \mathrm{E}-04(0.00 \mathrm{E}+00-5.47 \mathrm{E}-04)$ & $0.00 \mathrm{E}+00(0.00 \mathrm{E}+00-4.79 \mathrm{E}-05)$ & $-2.92 \pm 0.98$ & $2.80 \mathrm{E}-02$ \\
\hline Firmicutes & Erysipelotrichia & Erysipelotrichales & Erysipelotrichaceae & Traorella & massiliensis & $8.35 \mathrm{E}-05(0.00 \mathrm{E}+00-2.42 \mathrm{E}-04)$ & $5.39 \mathrm{E}-05(0.00 \mathrm{E}+00-1.39 \mathrm{E}-04)$ & $-2.88 \pm 0.94$ & $2.28 \mathrm{E}-02$ \\
\hline Firmicutes & Clostridia & Clostridiales & Clostridiaceae & Clostridium & sp L2-50 & $4.28 \mathrm{E}-05(0.00 \mathrm{E}+00-4.24 \mathrm{E}-04)$ & $0.00 \mathrm{E}+00(0.00 \mathrm{E}+00-0.00 \mathrm{E}+00)$ & $-2.88 \pm 0.79$ & $4.10 \mathrm{E}-03$ \\
\hline Firmicutes & Clostridia & Clostridiales & Lachnospiraceae & Blautia & obeum & $2.29 \mathrm{E}-02(9.54 \mathrm{E}-03-5.48 \mathrm{E}-02)$ & $7.10 \mathrm{E}-03(1.23 \mathrm{E}-03-2.10 \mathrm{E}-02)$ & $-2.86 \pm 0.59$ & $4.88 \mathrm{E}-05$ \\
\hline Firmicutes & Clostridia & Clostridiales & Ruminococcaceae & unknown & unknown & $1.04 \mathrm{E}-03(1.82 \mathrm{E}-04-4.44 \mathrm{E}-03)$ & $1.81 \mathrm{E}-04(0.00 \mathrm{E}+00-7.61 \mathrm{E}-04)$ & $-2.75 \pm 0.65$ & $5.07 \mathrm{E}-04$ \\
\hline Firmicutes & Clostridia & Clostridiales & Lachnospiraceae & Roseburia & hominis & $2.63 \mathrm{E}-04(2.39 \mathrm{E}-05-1.91 \mathrm{E}-03)$ & $9.08 \mathrm{E}-05(0.00 \mathrm{E}+00-3.07 \mathrm{E}-04)$ & $-2.74 \pm 0.74$ & $3.60 \mathrm{E}-03$ \\
\hline Firmicutes & Erysipelotrichia & Erysipelotrichales & Erysipelotrichaceae & Faecalitalea & sp Marseille-P3755 & $1.04 \mathrm{E}-04(0.00 \mathrm{E}+00-2.68 \mathrm{E}-04)$ & $0.00 \mathrm{E}+00(0.00 \mathrm{E}+00-5.27 \mathrm{E}-05)$ & $-2.63 \pm 0.91$ & $3.20 \mathrm{E}-02$ \\
\hline Firmicutes & Clostridia & Clostridiales & Lachnospiraceae & unknown & bacterium 28-4 & $5.43 \mathrm{E}-05(2.65 \mathrm{E}-05-1.67 \mathrm{E}-04)$ & $0.00 \mathrm{E}+00(0.00 \mathrm{E}+00-4.85 \mathrm{E}-05)$ & $-2.42 \pm 0.73$ & $1.07 \mathrm{E}-02$ \\
\hline Firmicutes & Bacilli & Bacillales & Bacillaceae & Bacillus & unknown & $4.89 \mathrm{E}-04(1.37 \mathrm{E}-04-1.13 \mathrm{E}-03)$ & $5.78 \mathrm{E}-05(0.00 \mathrm{E}+00-2.96 \mathrm{E}-04)$ & $-2.40 \pm 0.73$ & $1.25 \mathrm{E}-02$ \\
\hline Firmicutes & Clostridia & Clostridiales & Lachnospiraceae & Faecalicatena & contorta & $7.58 \mathrm{E}-04(7.63 \mathrm{E}-05-1.82 \mathrm{E}-03)$ & $9.69 \mathrm{E}-05(0.00 \mathrm{E}+00-4.14 \mathrm{E}-04)$ & $-2.24 \pm 0.77$ & $3.18 \mathrm{E}-02$ \\
\hline Firmicutes & Clostridia & Clostridiales & Lachnospiraceae & unknown & Bacterium 14 56FAA & $2.36 \mathrm{E}-02(8.91 \mathrm{E}-03-7.52 \mathrm{E}-02)$ & $7.29 \mathrm{E}-03(1.38 \mathrm{E}-03-1.72 \mathrm{E}-02)$ & $-2.17 \pm 0.67$ & $1.32 \mathrm{E}-02$ \\
\hline Firmicutes & Clostridia & Clostridiales & Ruminococcaceae & Faecalibacterium & prausnitzii & $9.43 \mathrm{E}-03(3.19 \mathrm{E}-03-2.18 \mathrm{E}-02)$ & 1.46E-03 (1.30E-04 - 8.07E-03) & $-2.07 \pm 0.59$ & $6.19 \mathrm{E}-03$ \\
\hline
\end{tabular}

FC: fold change, SE: standard error, NS: not significant

${ }^{1} \mathrm{p}$ values were adjusted with false discovery rate for multiple comparisons 


\section{Table 5 (on next page)}

Kyoto Encyclopedia of Genes and Genomes Orthology (KO) terms with differential abundances between baseline and week 4 ( $n=28$, |fold change $\geq 2$ and adjusted $p<$ 0.05). 
Table 5. Kyoto Encyclopedia of Genes and Genomes Orthology (KO) terms with differential abundances between baseline and week $4(\mathrm{n}=28, \mid$ fold change $\mid \geq 2$ and adjusted $\mathrm{p}<0.05)$.

\begin{tabular}{|c|c|c|c|}
\hline \multirow[t]{2}{*}{ KO term } & \multirow[t]{2}{*}{ Description } & \multicolumn{2}{|c|}{ Week 4 vs Baseline } \\
\hline & & $\begin{array}{l}\log 2 \text { FC } \\
\operatorname{mean} \pm \text { SE }\end{array}$ & $\begin{array}{l}\text { Adjusted } \\
P \text {-value }\end{array}$ \\
\hline \multicolumn{4}{|c|}{ Increased abundance at week 4} \\
\hline K16323 & purine nucleoside transport protein & $7.2 \pm 1.24$ & $1.80 \mathrm{E}-05$ \\
\hline K13548 & 2-deoxy-scyllo-inosamine dehydrogenase [EC:1.1.1.329] & $6.29 \pm 1.39$ & 0.005 \\
\hline K11628 & mycocerosic acid synthase [EC:2.3.1.111] & $5.99 \pm 1.58$ & 0.034 \\
\hline K20707 & lysine racemase [EC:5.1.1.5] & $5.91 \pm 1.62$ & 0.046 \\
\hline K16959 & L-cystine transport system permease protein & $4.95 \pm 1.15$ & 0.009 \\
\hline K00638 & chloramphenicol O-acetyltransferase type B [EC:2.3.1.28] & $4.45 \pm 1.14$ & 0.025 \\
\hline K16846 & (2R)-sulfolactate sulfo-lyase subunit beta [EC:4.4.1.24] & $3.97 \pm 0.97$ & 0.016 \\
\hline K03457 & nucleobase:cation symporter-1, NCS1 family & $3.32 \pm 0.72$ & 0.004 \\
\hline K12442 & $\begin{array}{l}\text { phthiocerol/phenolphthiocerol synthesis type-I polyketide synthase C } \\
{[\text { EC:2.3.1.292] }}\end{array}$ & $3.13 \pm 0.85$ & 0.045 \\
\hline K12953 & cation-transporting P-type ATPase F [EC:7.2.2.-] & $3.07 \pm 0.79$ & 0.025 \\
\hline K19279 & aminoglycoside 9-adenylyltransferase [EC:2.7.7.-] & $2.66 \pm 0.63$ & 0.009 \\
\hline K18104 & ATP-binding cassette, subfamily B, bacterial AbcA/BmrA [EC:7.6.2.2] & $2.65 \pm 0.68$ & 0.025 \\
\hline K19422 & glycosyltransferase EpsD [EC:2.4.-.-] & $2.32 \pm 0.59$ & 0.025 \\
\hline K15125 & filamentous hemagglutinin & $1.91 \pm 0.53$ & 0.048 \\
\hline
\end{tabular}




\begin{tabular}{|l|l|c|c|}
\hline \multicolumn{2}{|c|}{ Decreased abundance at week 4 } & $-8.43 \pm 1.90$ & 0.006 \\
\hline K13925 & plasmin and fibronectin-binding protein A & $-5.08 \pm 1.03$ & 0.001 \\
\hline K02203 & phosphoserine / homoserine phosphotransferase [EC:3.1.3.3 2.7.1.39] & $-4.17 \pm 1.15$ & 0.047 \\
\hline K13532 & two-component system, sporulation sensor kinase D [EC:2.7.13.3] & $-4.06 \pm 0.78$ & 0.000 \\
\hline K09759 & nondiscriminating aspartyl-tRNA synthetase [EC:6.1.1.23] & $-3.88 \pm 0.95$ & 0.016 \\
\hline K00351 & Na -transporting NADH:ubiquinone oxidoreductase subunit F [EC:7.2.1.1] & $-3.33 \pm 0.87$ & 0.030 \\
\hline K14136 & decaprenyl-phosphate phosphoribosyltransferase [EC:2.4.2.45] & $-2.97 \pm 0.79$ & 0.036 \\
\hline K16165 & fumarylpyruvate hydrolase [EC:3.7.1.20] & $-2.65 \pm 0.63$ & 0.011 \\
\hline K16011 & mannose-1-phosphate guanylyltransferase / mannose-6-phosphate isomerase & $-2.01 \pm 0.54$ & 0.040 \\
\hline K13019 & UDC:2.7.7.13 5.3.1.8] & $-1.72 \pm 0.46$ & $-1.64 \pm 0.38$ \\
\hline K17716 & UDP-glucose 4-epimerase [EC:5.1.3.2] & 0.034 \\
\hline K00385 & anaerobic sulfite reductase subunit C & 0.008 \\
\hline
\end{tabular}

${ }_{1}^{1} \mathrm{p}$ values were adjusted with false discovery rate for multiple comparisons 


\section{Table 6(on next page)}

Bacterial species with differential abundances (|fold change| $\geq 2$ and FDR-adjusted $p<$ $0.05)$ between high-responders ( $H R, n=9)$ and low-responders $(L R, n=10)$ at baseline. 
Table 6. Bacterial species with differential abundances ( $\mid$ fold change $\mid \geq 2$ and FDR-adjusted $\mathrm{p}<0.05$ ) between high-responders (HR, $\mathrm{n}=9$ ) and low-responders ( $\mathrm{LR}, \mathrm{n}=10)$ at baseline.

\begin{tabular}{|c|c|c|c|c|c|c|c|c|c|}
\hline \multirow{2}{*}{ Phylum } & \multirow{2}{*}{ Class } & \multirow{2}{*}{ Order } & \multirow{2}{*}{ Family } & \multirow{2}{*}{ Genus } & \multirow{2}{*}{ Species } & \multicolumn{2}{|c|}{$\begin{array}{c}\text { Relative abundance, in \% } \\
\text { Median (IQR) }\end{array}$} & \multicolumn{2}{|c|}{ Baseline HR vs LR } \\
\hline & & & & & & $\begin{array}{c}\text { HR } \\
(n=9)\end{array}$ & $\begin{array}{c}\text { LR } \\
(\mathrm{n}=10)\end{array}$ & $\begin{array}{c}\log 2 \mathrm{FC} \\
\text { mean } \pm \mathrm{SE}\end{array}$ & $\begin{array}{l}\text { Adjusted } \\
P \text {-value }\end{array}$ \\
\hline \multicolumn{10}{|c|}{ Higher in HR (40 species) } \\
\hline Bacteroidetes & Bacteroidia & Bacteroidales & Bacteroidaceae & Bacteroides & sp 43 47FAA & $3.88 \mathrm{E}-04(5.24 \mathrm{E}-05-1.19 \mathrm{E}-02)$ & $0.00 \mathrm{E}+00(0.00 \mathrm{E}+00-2.96 \mathrm{E}-05)$ & $10.02 \pm 1.89$ & $6.31 \mathrm{E}-06$ \\
\hline Firmicutes & Clostridia & Clostridiales & Ruminococcaceae & Ruminiclostridium & josui & $8.20 \mathrm{E}-04(5.24 \mathrm{E}-05-7.18 \mathrm{E}-03)$ & $0.00 \mathrm{E}+00(0.00 \mathrm{E}+00-0.00 \mathrm{E}+00)$ & $7.37 \pm 1.84$ & $1.40 \mathrm{E}-03$ \\
\hline Bacteroidetes & Bacteroidia & Bacteroidales & Prevotellaceae & Prevotella & bivia & $5.01 \mathrm{E}-04(0.00 \mathrm{E}+00-3.85 \mathrm{E}-03)$ & $0.00 \mathrm{E}+00(0.00 \mathrm{E}+00-0.00 \mathrm{E}+00)$ & $7.29 \pm 2.01$ & $3.97 \mathrm{E}-03$ \\
\hline Bacteroidetes & Bacteroidia & Bacteroidales & Prevotellaceae & Prevotella & copri & $2.09 \mathrm{E}-01(1.01 \mathrm{E}-04-2.07 \mathrm{E}+00)$ & $5.71 \mathrm{E}-05(6.58 \mathrm{E}-06-1.21 \mathrm{E}-02)$ & $7.06 \pm 1.92$ & $3.48 \mathrm{E}-03$ \\
\hline Firmicutes & Negativicutes & Selenomonadales & Selenomonadaceae & Megamonas & sp Calf98-2 & $3.92 \mathrm{E}-01(1.17 \mathrm{E}-02-5.17 \mathrm{E}-01)$ & $8.40 \mathrm{E}-04(0.00 \mathrm{E}+00-4.30 \mathrm{E}-03)$ & $7.01 \pm 1.67$ & $9.19 \mathrm{E}-04$ \\
\hline Bacteroidetes & Bacteroidia & Bacteroidales & Bacteroidaceae & Bacteroides & sp $3133 \mathrm{FAA}$ & $9.99 \mathrm{E}-04(4.56 \mathrm{E}-05-1.46 \mathrm{E}-03)$ & $0.00 \mathrm{E}+00(0.00 \mathrm{E}+00-2.10 \mathrm{E}-05)$ & $6.52 \pm 1.49$ & $4.47 \mathrm{E}-04$ \\
\hline Firmicutes & Negativicutes & Selenomonadales & Selenomonadaceae & Megamonas & no data & $3.38 \mathrm{E}+00(1.43 \mathrm{E}-01-4.20 \mathrm{E}+00)$ & $7.07 \mathrm{E}-03(0.00 \mathrm{E}+00-4.27 \mathrm{E}-02)$ & $6.38 \pm 1.82$ & $5.45 \mathrm{E}-03$ \\
\hline Firmicutes & Negativicutes & Selenomonadales & Selenomonadaceae & Megamonas & funiformis & $5.96 \mathrm{E}-01(3.11 \mathrm{E}-02-7.66 \mathrm{E}-01)$ & $1.25 \mathrm{E}-03(0.00 \mathrm{E}+00-7.41 \mathrm{E}-03)$ & $6.25 \pm 1.71$ & $3.53 \mathrm{E}-03$ \\
\hline Bacteroidetes & Bacteroidia & Bacteroidales & Prevotellaceae & Prevotella & buccalis & $2.28 \mathrm{E}-04(0.00 \mathrm{E}+00-7.57 \mathrm{E}-03)$ & $0.00 \mathrm{E}+00(0.00 \mathrm{E}+00-3.66 \mathrm{E}-05)$ & $6.14 \pm 1.53$ & $1.40 \mathrm{E}-03$ \\
\hline Bacteroidetes & Bacteroidia & Bacteroidales & Bacteroidaceae & Bacteroides & sp $9142 \mathrm{FAA}$ & $1.82 \mathrm{E}-04(6.11 \mathrm{E}-05-2.11 \mathrm{E}-03)$ & $0.00 \mathrm{E}+00(0.00 \mathrm{E}+00-0.00 \mathrm{E}+00)$ & $5.68 \pm 1.81$ & $1.45 \mathrm{E}-02$ \\
\hline Bacteroidetes & Bacteroidia & Bacteroidales & Bacteroidaceae & Bacteroides & vulgatus & $6.41 \mathrm{E}-03(2.69 \mathrm{E}-03-5.92 \mathrm{E}-02)$ & $1.68 \mathrm{E}-04(5.80 \mathrm{E}-05-2.84 \mathrm{E}-03)$ & $5.63 \pm 1.56$ & $4.19 \mathrm{E}-03$ \\
\hline Bacteroidetes & Bacteroidia & Bacteroidales & Bacteroidaceae & Bacteroides & dorei & $1.22 \mathrm{E}-03(1.37 \mathrm{E}-04-1.38 \mathrm{E}-02)$ & 7.04E-05 (0.00E $+00-3.40 \mathrm{E}-04)$ & $5.60 \pm 1.62$ & $5.82 \mathrm{E}-03$ \\
\hline Bacteroidetes & Bacteroidia & Bacteroidales & Prevotellaceae & Prevotella & no data & $2.01 \mathrm{E}-03(2.28 \mathrm{E}-04-7.25 \mathrm{E}-02)$ & $0.00 \mathrm{E}+00(0.00 \mathrm{E}+00-1.08 \mathrm{E}-04)$ & $5.35 \pm 1.73$ & $1.57 \mathrm{E}-02$ \\
\hline Firmicutes & Negativicutes & Selenomonadales & Selenomonadaceae & Megamonas & hypermegale & $4.10 \mathrm{E}-03(1.14 \mathrm{E}-04-8.73 \mathrm{E}-03)$ & $0.00 \mathrm{E}+00(0.00 \mathrm{E}+00-7.09 \mathrm{E}-05)$ & $5.32 \pm 1.48$ & $4.22 \mathrm{E}-03$ \\
\hline Firmicutes & Bacilli & Bacillales & Paenibacillaceae & Brevibacillus & 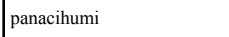 & $4.48 \mathrm{E}-05(0.00 \mathrm{E}+00-7.34 \mathrm{E}-04)$ & $0.00 \mathrm{E}+00(0.00 \mathrm{E}+00-0.00 \mathrm{E}+00)$ & $5.16 \pm 2.02$ & $4.77 \mathrm{E}-02$ \\
\hline Actinobacteria & Actinobacteria & Micrococcales & Cellulomonadaceae & Cellulomonas & carbonis & $1.82 \mathrm{E}-04(0.00 \mathrm{E}+00-1.47 \mathrm{E}-03)$ & $0.00 \mathrm{E}+00(0.00 \mathrm{E}+00-2.96 \mathrm{E}-05)$ & $5.10 \pm 1.75$ & $2.34 \mathrm{E}-02$ \\
\hline Firmicutes & Bacilli & Bacillales & Paenibacillaceae & Brevibacillus & thermoruber & $0.00 \mathrm{E}+00(0.00 \mathrm{E}+00-1.14 \mathrm{E}-03)$ & $0.00 \mathrm{E}+00(0.00 \mathrm{E}+00-2.10 \mathrm{E}-05)$ & $5.10 \pm 1.82$ & $2.88 \mathrm{E}-02$ \\
\hline Bacteroidetes & Bacteroidia & Bacteroidales & Prevotellaceae & Prevotella & bryantii & $4.56 \mathrm{E}-05(0.00 \mathrm{E}+00-9.71 \mathrm{E}-04)$ & $0.00 \mathrm{E}+00(0.00 \mathrm{E}+00-0.00 \mathrm{E}+00)$ & $5.00 \pm 1.98$ & $4.99 \mathrm{E}-02$ \\
\hline Bacteroidetes & Bacteroidia & Bacteroidales & Bacteroidaceae & Mediterranea & massiliensis & $6.29 \mathrm{E}-04(5.04 \mathrm{E}-04-1.95 \mathrm{E}-03)$ & $0.00 \mathrm{E}+00(0.00 \mathrm{E}+00-3.52 \mathrm{E}-05)$ & $4.98 \pm 1.50$ & $9.25 \mathrm{E}-03$ \\
\hline Firmicutes & Bacilli & Bacillales & Paenibacillaceae & Brevibacillus & borstelensis & $1.11 \mathrm{E}-04(0.00 \mathrm{E}+00-4.04 \mathrm{E}-03)$ & $0.00 \mathrm{E}+00(0.00 \mathrm{E}+00-7.20 \mathrm{E}-05)$ & $4.96 \pm 1.74$ & $2.66 \mathrm{E}-02$ \\
\hline Firmicutes & Bacilli & Bacillales & Paenibacillaceae & Paenibacillus & ginsengihumi & $1.11 \mathrm{E}-04(0.00 \mathrm{E}+00-4.84 \mathrm{E}-03)$ & $0.00 \mathrm{E}+00(0.00 \mathrm{E}+00-7.47 \mathrm{E}-05)$ & $4.84 \pm 1.67$ & $2.47 \mathrm{E}-02$ \\
\hline Bacteroidetes & Bacteroidia & Bacteroidales & Prevotellaceae & Prevotella & stercorea & $8.42 \mathrm{E}-04(9.12 \mathrm{E}-05-6.78 \mathrm{E}-03)$ & $0.00 \mathrm{E}+00(0.00 \mathrm{E}+00-3.52 \mathrm{E}-05)$ & $4.78 \pm 1.52$ & $1.42 \mathrm{E}-02$ \\
\hline Firmicutes & Negativicutes & Selenomonadales & Selenomonadaceae & Megamonas & rupellensis & $1.22 \mathrm{E}-01(7.40 \mathrm{E}-03-1.67 \mathrm{E}-01)$ & $2.47 \mathrm{E}-04(0.00 \mathrm{E}+00-1.11 \mathrm{E}-03)$ & $4.61 \pm 1.72$ & $3.58 \mathrm{E}-02$ \\
\hline Bacteroidetes & Bacteroidia & Bacteroidales & Tannerellaceae & Tannerella & sp 61 58FAA CT1 & $9.12 \mathrm{E}-05(0.00 \mathrm{E}+00-5.49 \mathrm{E}-04)$ & $0.00 \mathrm{E}+00(0.00 \mathrm{E}+00-0.00 \mathrm{E}+00)$ & $4.58 \pm 1.75$ & $3.98 \mathrm{E}-02$ \\
\hline Bacteroidetes & Bacteroidia & Bacteroidales & Prevotellaceae & Paraprevotella & clara & $1.66 \mathrm{E}-04(4.21 \mathrm{E}-05-7.94 \mathrm{E}-04)$ & $0.00 \mathrm{E}+00(0.00 \mathrm{E}+00-0.00 \mathrm{E}+00)$ & $4.57 \pm 1.45$ & $1.42 \mathrm{E}-02$ \\
\hline Bacteroidetes & Bacteroidia & Bacteroidales & Bacteroidaceae & Bacteroides & sp Marseille-P3166 & $1.47 \mathrm{E}-03(3.03 \mathrm{E}-04-3.30 \mathrm{E}-03)$ & $0.00 \mathrm{E}+00(0.00 \mathrm{E}+00-2.45 \mathrm{E}-05)$ & $4.42 \pm 1.45$ & $1.74 \mathrm{E}-02$ \\
\hline
\end{tabular}




\begin{tabular}{|c|c|c|c|c|c|c|c|c|c|}
\hline Firmicutes & Clostridia & Clostridiales & Lachnospiraceae & Blautia & wexlerae & $1.05 \mathrm{E}-01(2.46 \mathrm{E}-02-3.83 \mathrm{E}+00)$ & $1.98 \mathrm{E}-02(1.25 \mathrm{E}-02-3.64 \mathrm{E}-02)$ & $4.35 \pm 0.96$ & $2.41 \mathrm{E}-04$ \\
\hline Bacteroidetes & Bacteroidia & Bacteroidales & Odoribacteraceae & Odoribacter & laneus & $8.07 \mathrm{E}-04(0.00 \mathrm{E}+00-2.87 \mathrm{E}-03)$ & $1.40 \mathrm{E}-05(0.00 \mathrm{E}+00-4.98 \mathrm{E}-05)$ & $4.31 \pm 1.43$ & $1.87 \mathrm{E}-02$ \\
\hline Proteobacteria & Betaproteobacteria & Burkholderiales & Sutterellaceae & Sutterella & no data & $1.14 \mathrm{E}-03(0.00 \mathrm{E}+00-1.26 \mathrm{E}-03)$ & $4.21 \mathrm{E}-05(9.86 \mathrm{E}-06-1.87 \mathrm{E}-04)$ & $4.27 \pm 1.57$ & $3.52 \mathrm{E}-02$ \\
\hline Bacteroidetes & Bacteroidia & Bacteroidales & Prevotellaceae & Prevotella & multisaccharivorax & $1.26 \mathrm{E}-04(0.00 \mathrm{E}+00-2.91 \mathrm{E}-04)$ & $0.00 \mathrm{E}+00(0.00 \mathrm{E}+00-0.00 \mathrm{E}+00)$ & $4.18 \pm 1.56$ & $3.58 \mathrm{E}-02$ \\
\hline Firmicutes & Bacilli & Lactobacillales & Streptococcaceae & Streptococcus & minor & $1.27 \mathrm{E}-02(1.85 \mathrm{E}-03-3.57 \mathrm{E}-02)$ & $5.68 \mathrm{E}-04(7.98 \mathrm{E}-05-1.16 \mathrm{E}-03)$ & $3.94 \pm 1.27$ & $1.52 \mathrm{E}-02$ \\
\hline Firmicutes & Erysipelotrichia & Erysipelotrichales & Erysipelotrichaceae & Solobacterium & moorei & $2.33 \mathrm{E}-03(5.01 \mathrm{E}-04-1.45 \mathrm{E}-02)$ & $0.00 \mathrm{E}+00(0.00 \mathrm{E}+00-5.80 \mathrm{E}-05)$ & $3.85 \pm 1.51$ & $4.79 \mathrm{E}-02$ \\
\hline Firmicutes & Clostridia & Clostridiales & Clostridiaceae & Clostridium & sp AT4 & $8.65 \mathrm{E}-02(6.45 \mathrm{E}-03-1.48 \mathrm{E}-01)$ & $4.29 \mathrm{E}-03(1.64 \mathrm{E}-03-8.18 \mathrm{E}-03)$ & $3.78 \pm 1.02$ & $3.29 \mathrm{E}-03$ \\
\hline Bacteroidetes & Bacteroidia & Bacteroidales & Bacteroidaceae & Bacteroides & coprocola & $2.32 \mathrm{E}-02(7.57 \mathrm{E}-03-1.06 \mathrm{E}-01)$ & $5.86 \mathrm{E}-04(1.76 \mathrm{E}-04-2.05 \mathrm{E}-03)$ & $3.64 \pm 1.36$ & $3.58 \mathrm{E}-02$ \\
\hline Firmicutes & Clostridia & Clostridiales & Lachnospiraceae & Blautia & no data & $6.00 \mathrm{E}-01(1.76 \mathrm{E}-01-8.44 \mathrm{E}+00)$ & $1.27 \mathrm{E}-01(4.23 \mathrm{E}-02-2.47 \mathrm{E}-01)$ & $3.63 \pm 0.88$ & $9.84 \mathrm{E}-04$ \\
\hline Firmicutes & Clostridia & Clostridiales & Lachnospiraceae & Blautia & obeum & $5.40 \mathrm{E}-02(1.96 \mathrm{E}-02-5.43 \mathrm{E}-01)$ & $1.08 \mathrm{E}-02(3.61 \mathrm{E}-03-2.24 \mathrm{E}-02)$ & $3.30 \pm 0.97$ & $7.18 \mathrm{E}-03$ \\
\hline Bacteroidetes & Bacteroidia & Bacteroidales & Bacteroidaceae & Bacteroides & mediterraneensis & $1.14 \mathrm{E}-03(3.03 \mathrm{E}-04-2.57 \mathrm{E}-03)$ & $5.38 \mathrm{E}-05(9.01 \mathrm{E}-06-1.01 \mathrm{E}-04)$ & $2.96 \pm 1.08$ & $3.41 \mathrm{E}-02$ \\
\hline Firmicutes & Clostridia & Clostridiales & Lachnospiraceae & Marvinbryantia & formatexigens & $3.58 \mathrm{E}-03(8.07 \mathrm{E}-04-3.87 \mathrm{E}-03)$ & $2.23 \mathrm{E}-04(5.25 \mathrm{E}-05-4.42 \mathrm{E}-04)$ & $2.78 \pm 0.98$ & $2.68 \mathrm{E}-02$ \\
\hline Bacteroidetes & Bacteroidia & Bacteroidales & Bacteroidaceae & Bacteroides & barnesiae & $7.33 \mathrm{E}-04(2.28 \mathrm{E}-04-1.31 \mathrm{E}-03)$ & $2.80 \mathrm{E}-05(0.00 \mathrm{E}+00-7.93 \mathrm{E}-05)$ & $2.75 \pm 1.02$ & $3.58 \mathrm{E}-02$ \\
\hline Firmicutes & Clostridia & Clostridiales & Ruminococcaceae & no data & no data & $3.05 \mathrm{E}-03(7.17 \mathrm{E}-04-1.23 \mathrm{E}-02)$ & $4.25 \mathrm{E}-04(7.09 \mathrm{E}-05-1.13 \mathrm{E}-03)$ & $2.43 \pm 0.86$ & $2.75 \mathrm{E}-02$ \\
\hline
\end{tabular}

\section{Lower in HR (97 species)}

\begin{tabular}{|c|c|c|c|c|c|c|c|c|c|}
\hline Proteobacteria & Gammaproteobacteria & Enterobacterales & Hafniaceae & Hafnia & alvei & $0.00 \mathrm{E}+00(0.00 \mathrm{E}+00-0.00 \mathrm{E}+00)$ & $1.32 \mathrm{E}-05(0.00 \mathrm{E}+00-3.62 \mathrm{E}-04)$ & $-26.49 \pm 2.97$ & $9.00 \mathrm{E}-17$ \\
\hline Proteobacteria & Gammaproteobacteria & Enterobacterales & Enterobacteriaceae & Citrobacter & braakii & $0.00 \mathrm{E}+00(0.00 \mathrm{E}+00-0.00 \mathrm{E}+00)$ & $2.13 \mathrm{E}-03(0.00 \mathrm{E}+00-8.85 \mathrm{E}-03)$ & $-26.22 \pm 2.42$ & $7.87 \mathrm{E}-2.5$ \\
\hline Proteobacteria & Gammaproteobacteria & Enterobacterales & Yersiniaceae & Serratia & marcescens & $0.00 \mathrm{E}+00(0.00 \mathrm{E}+00-0.00 \mathrm{E}+00)$ & $1.51 \mathrm{E}-04(6.58 \mathrm{E}-06-4.23 \mathrm{E}-03)$ & $-25.50 \pm 2.22$ & $9.94 \mathrm{E}-28$ \\
\hline Proteobacteria & Gammaproteobacteria & Pasteurellales & Pasteurellaceae & Haemophilus & sputorum & $0.00 \mathrm{E}+00(0.00 \mathrm{E}+00-0.00 \mathrm{E}+00)$ & $2.80 \mathrm{E}-05(0.00 \mathrm{E}+00-1.38 \mathrm{E}-03)$ & $-24.56 \pm 2.97$ & $1.96 \mathrm{E}-14$ \\
\hline Proteobacteria & Gammaproteobacteria & Enterobacterales & Enterobacteriaceae & Citrobacter & sp MGH99 & $0.00 \mathrm{E}+00(0.00 \mathrm{E}+00-0.00 \mathrm{E}+00)$ & $0.00 \mathrm{E}+00(0.00 \mathrm{E}+00-9.63 \mathrm{E}-04)$ & $-23.88 \pm 2.97$ & $1.05 \mathrm{E}-13$ \\
\hline Proteobacteria & Gammaproteobacteria & Enterobacterales & Hafniaceae & Hafnia & no data & $0.00 \mathrm{E}+00(0.00 \mathrm{E}+00-0.00 \mathrm{E}+00)$ & $0.00 \mathrm{E}+00(0.00 \mathrm{E}+00-1.97 \mathrm{E}-05)$ & $-23.75 \pm 2.97$ & $1.24 \mathrm{E}-13$ \\
\hline Proteobacteria & Gammaproteobacteria & Enterobacterales & Enterobacteriaceae & Citrobacter & portucalensis & $0.00 \mathrm{E}+00(0.00 \mathrm{E}+00-0.00 \mathrm{E}+00)$ & $0.00 \mathrm{E}+00(0.00 \mathrm{E}+00-1.13 \mathrm{E}-04)$ & $-23.27 \pm 2.97$ & $3.96 \mathrm{E}-13$ \\
\hline Proteobacteria & Gammaproteobacteria & Enterobacterales & Enterobacteriaceae & Enterobacter & cloacae complex sp ECNIH7 & $0.00 \mathrm{E}+00(0.00 \mathrm{E}+00-0.00 \mathrm{E}+00)$ & $0.00 \mathrm{E}+00(0.00 \mathrm{E}+00-0.00 \mathrm{E}+00)$ & $-22.05 \pm 2.97$ & $8.72 \mathrm{E}-12$ \\
\hline Proteobacteria & Gammaproteobacteria & Enterobacterales & Hafniaceae & Edwardsiella & piscicida & $0.00 \mathrm{E}+00(0.00 \mathrm{E}+00-0.00 \mathrm{E}+00)$ & $0.00 \mathrm{E}+00(0.00 \mathrm{E}+00-1.97 \mathrm{E}-05)$ & $-21.90 \pm 2.97$ & $1.14 \mathrm{E}-11$ \\
\hline Proteobacteria & Gammaproteobacteria & Enterobacterales & Enterobacteriaceae & Enterobacter & Cloaca complex sp TREC1 & $0.00 \mathrm{E}+00(0.00 \mathrm{E}+00-0.00 \mathrm{E}+00)$ & $0.00 \mathrm{E}+00(0.00 \mathrm{E}+00-4.54 \mathrm{E}-04)$ & $-21.17 \pm 2.97$ & $6.51 \mathrm{E}-11$ \\
\hline Firmicutes & Bacilli & Lactobacillales & Enterococcaceae & Enterococcus & canintestini & $0.00 \mathrm{E}+00(0.00 \mathrm{E}+00-0.00 \mathrm{E}+00)$ & $9.29 \mathrm{E}-03(1.63 \mathrm{E}-05-2.42 \mathrm{E}-01)$ & $-9.45 \pm 2.53$ & $3.12 \mathrm{E}-03$ \\
\hline Proteobacteria & Gammaproteobacteria & Enterobacterales & Enterobacteriaceae & Enterobacter & hormaechei & $0.00 \mathrm{E}+00(0.00 \mathrm{E}+00-0.00 \mathrm{E}+00)$ & $2.04 \mathrm{E}-04(0.00 \mathrm{E}+00-3.08 \mathrm{E}-03)$ & $-9.31 \pm 2.14$ & $5.01 \mathrm{E}-04$ \\
\hline Firmicutes & Bacilli & Lactobacillales & Enterococcaceae & Enterococcus & dispar & $0.00 \mathrm{E}+00(0.00 \mathrm{E}+00-0.00 \mathrm{E}+00)$ & $8.72 \mathrm{E}-04(2.15 \mathrm{E}-04-6.38 \mathrm{E}-03)$ & $-9.06 \pm 1.73$ & $8.87 \mathrm{E}-06$ \\
\hline Firmicutes & Bacilli & Lactobacillales & Enterococcaceae & Enterococcus & thailandicus & $0.00 \mathrm{E}+00(0.00 \mathrm{E}+00-0.00 \mathrm{E}+00)$ & $2.71 \mathrm{E}-04(5.50 \mathrm{E}-05-2.74 \mathrm{E}-03)$ & $-8.92 \pm 1.75$ & $1.61 \mathrm{E}-05$ \\
\hline Firmicutes & Bacilli & Lactobacillales & Enterococcaceae & Enterococcus & sp FDAARGOS 163 & $0.00 \mathrm{E}+00(0.00 \mathrm{E}+00-0.00 \mathrm{E}+00)$ & $1.32 \mathrm{E}-05(0.00 \mathrm{E}+00-7.07 \mathrm{E}-04)$ & $-8.85 \pm 2.20$ & $1.40 \mathrm{E}-03$ \\
\hline Firmicutes & Bacilli & Bacillales & Planococcaceae & Rummeliibacillus & stabekisii & $0.00 \mathrm{E}+00(0.00 \mathrm{E}+00-5.24 \mathrm{E}-05)$ & $0.00 \mathrm{E}+00(0.00 \mathrm{E}+00-4.72 \mathrm{E}-04)$ & $-8.73 \pm 2.93$ & $2.00 \mathrm{E}-02$ \\
\hline Proteobacteria & Gammaproteobacteria & Enterobacterales & Enterobacteriaceae & Enterobacter & asburiae & $0.00 \mathrm{E}+00(0.00 \mathrm{E}+00-0.00 \mathrm{E}+00)$ & $4.31 \mathrm{E}-04(0.00 \mathrm{E}+00-1.06 \mathrm{E}-03)$ & $-8.61 \pm 2.13$ & $1.40 \mathrm{E}-03$ \\
\hline Firmicutes & Bacilli & Lactobacillales & Enterococcaceae & Enterococcus & sp 4E1 DIV0656 & $0.00 \mathrm{E}+00(0.00 \mathrm{E}+00-0.00 \mathrm{E}+00)$ & $1.80 \mathrm{E}-05(0.00 \mathrm{E}+00-1.27 \mathrm{E}-04)$ & $-8.48 \pm 2.54$ & $8.51 \mathrm{E}-03$ \\
\hline Firmicutes & Bacilli & Lactobacillales & Lactobacillaceae & Lactobacillus & sakei & $0.00 \mathrm{E}+00(0.00 \mathrm{E}+00-6.11 \mathrm{E}-05)$ & $9.38 \mathrm{E}-05(0.00 \mathrm{E}+00-3.41 \mathrm{E}-03)$ & $-8.45 \pm 2.03$ & $9.81 \mathrm{E}-04$ \\
\hline Proteobacteria & Gammaproteobacteria & Enterobacterales & Enterobacteriaceae & Enterobacter & cloacae complex Hoffmann cluster III & $0.00 \mathrm{E}+00(0.00 \mathrm{E}+00-0.00 \mathrm{E}+00)$ & $1.15 \mathrm{E}-04(9.01 \mathrm{E}-06-1.22 \mathrm{E}-03)$ & $-8.30 \pm 1.93$ & $6.02 \mathrm{E}-04$ \\
\hline Proteobacteria & Gammaproteobacteria & Enterobacterales & Enterobacteriaceae & Cronobacter & sakazakii & $0.00 \mathrm{E}+00(0.00 \mathrm{E}+00-0.00 \mathrm{E}+00)$ & $1.01 \mathrm{E}-03(3.61 \mathrm{E}-05-3.11 \mathrm{E}-03)$ & $-8.03 \pm 2.17$ & $3.34 \mathrm{E}-03$ \\
\hline Proteobacteria & Gammaproteobacteria & Pseudomonadales & Moraxellaceae & Acinetobacter & indicus & $0.00 \mathrm{E}+00(0.00 \mathrm{E}+00-0.00 \mathrm{E}+00)$ & $5.33 \mathrm{E}-05(0.00 \mathrm{E}+00-8.20 \mathrm{E}-04)$ & $-7.91 \pm 2.27$ & $5.56 \mathrm{E}-03$ \\
\hline
\end{tabular}




\begin{tabular}{|c|c|c|c|c|c|c|c|c|c|}
\hline Proteobacteria & Gammaproteobacteria & Enterobacterales & Enterobacteriaceae & Enterobacter & sp ODB01 & $0.00 \mathrm{E}+00(0.00 \mathrm{E}+00-0.00 \mathrm{E}+00)$ & $0.00 \mathrm{E}+00(0.00 \mathrm{E}+00-0.00 \mathrm{E}+00)$ & $-7.82 \pm 2.97$ & $3.96 \mathrm{E}-02$ \\
\hline Firmicutes & Bacilli & Lactobacillales & Enterococcaceae & Enterococcus & sp HMSC058D07 & $0.00 \mathrm{E}+00(0.00 \mathrm{E}+00-0.00 \mathrm{E}+00)$ & $6.00 \mathrm{E}-05(0.00 \mathrm{E}+00-1.67 \mathrm{E}-03)$ & $-7.80 \pm 2.18$ & $4.39 \mathrm{E}-03$ \\
\hline Firmicutes & Bacilli & Bacillales & Staphylococcaceae & Staphylococcus & epidermidis & $0.00 \mathrm{E}+00(0.00 \mathrm{E}+00-0.00 \mathrm{E}+00)$ & $4.53 \mathrm{E}-04(6.70 \mathrm{E}-05-2.18 \mathrm{E}-03)$ & $-7.76 \pm 1.94$ & $1.40 \mathrm{E}-03$ \\
\hline Firmicutes & Bacilli & Lactobacillales & Enterococcaceae & Enterococcus & faecalis & $0.00 \mathrm{E}+00(0.00 \mathrm{E}+00-2.24 \mathrm{E}-04)$ & $7.52 \mathrm{E}-03(8.40 \mathrm{E}-05-3.24 \mathrm{E}-01)$ & $-7.57 \pm 2.15$ & $5.26 \mathrm{E}-03$ \\
\hline Proteobacteria & Gammaproteobacteria & Enterobacterales & Enterobacteriaceae & Klebsiella & quasipneumoniae & $0.00 \mathrm{E}+00(0.00 \mathrm{E}+00-0.00 \mathrm{E}+00)$ & $1.05 \mathrm{E}-04(3.75 \mathrm{E}-05-9.22 \mathrm{E}-04)$ & $-7.43 \pm 1.99$ & $3.12 \mathrm{E}-03$ \\
\hline Proteobacteria & Gammaproteobacteria & Enterobacterales & Enterobacteriaceae & Citrobacter & sp KTE151 & $0.00 \mathrm{E}+00(0.00 \mathrm{E}+00-0.00 \mathrm{E}+00)$ & $0.00 \mathrm{E}+00(0.00 \mathrm{E}+00-3.29 \mathrm{E}-04)$ & $-7.27 \pm 2.70$ & $3.58 \mathrm{E}-02$ \\
\hline Proteobacteria & Gammaproteobacteria & Enterobacterales & Enterobacteriaceae & Citrobacter & freundii complex s CFNIH3 & $0.00 \mathrm{E}+00(0.00 \mathrm{E}+00-0.00 \mathrm{E}+00)$ & $3.29 \mathrm{E}-05(0.00 \mathrm{E}+00-6.20 \mathrm{E}-04)$ & $-7.25 \pm 2.48$ & $2.32 \mathrm{E}-02$ \\
\hline Firmicutes & Clostridia & Clostridiales & Clostridiaceae & Clostridium & sp CL-2 & $0.00 \mathrm{E}+00(0.00 \mathrm{E}+00-1.01 \mathrm{E}-04)$ & $2.67 \mathrm{E}-05(0.00 \mathrm{E}+00-2.68 \mathrm{E}-04)$ & $-7.16 \pm 2.25$ & $1.32 \mathrm{E}-02$ \\
\hline Proteobacteria & Gammaproteobacteria & Enterobacterales & Enterobacteriaceae & Citrobacter & sp S-77 & $0.00 \mathrm{E}+00(0.00 \mathrm{E}+00-0.00 \mathrm{E}+00)$ & $0.00 \mathrm{E}+00(0.00 \mathrm{E}+00-4.98 \mathrm{E}-04)$ & $-7.14 \pm 2.67$ & $3.58 \mathrm{E}-02$ \\
\hline Proteobacteria & Gammaproteobacteria & Enterobacterales & Erwiniaceae & Pantoea & sesami & $0.00 \mathrm{E}+00(0.00 \mathrm{E}+00-0.00 \mathrm{E}+00)$ & $8.43 \mathrm{E}-05(0.00 \mathrm{E}+00-1.47 \mathrm{E}-03)$ & $-7.05 \pm 2.64$ & $3.58 \mathrm{E}-02$ \\
\hline Proteobacteria & Gammaproteobacteria & Enterobacterales & Enterobacteriaceae & Franconibacter & helveticus & $0.00 \mathrm{E}+00(0.00 \mathrm{E}+00-0.00 \mathrm{E}+00)$ & $2.50 \mathrm{E}-04(9.01 \mathrm{E}-06-4.04 \mathrm{E}-04)$ & $-6.90 \pm 1.99$ & $5.78 \mathrm{E}-03$ \\
\hline Proteobacteria & Gammaproteobacteria & Enterobacterales & Enterobacteriaceae & Citrobacter & freundii complex sp CFNIH2 & $0.00 \mathrm{E}+00(0.00 \mathrm{E}+00-0.00 \mathrm{E}+00)$ & $2.99 \mathrm{E}-04(6.31 \mathrm{E}-05-5.02 \mathrm{E}-04)$ & $-6.88 \pm 1.94$ & $4.73 \mathrm{E}-03$ \\
\hline Proteobacteria & Gammaproteobacteria & Enterobacterales & Enterobacteriaceae & Citrobacter & werkmanii & $0.00 \mathrm{E}+00(0.00 \mathrm{E}+00-0.00 \mathrm{E}+00)$ & $5.38 \mathrm{E}-05(9.01 \mathrm{E}-06-3.96 \mathrm{E}-04)$ & $-6.70 \pm 1.82$ & $3.43 \mathrm{E}-03$ \\
\hline Proteobacteria & Gammaproteobacteria & Enterobacterales & Enterobacteriaceae & Enterobacter & cloacae complex Hoffmann cluster IV & $0.00 \mathrm{E}+00(0.00 \mathrm{E}+00-0.00 \mathrm{E}+00)$ & $3.91 \mathrm{E}-04(4.80 \mathrm{E}-05-8.27 \mathrm{E}-04)$ & $-6.70 \pm 1.83$ & $3.56 \mathrm{E}-03$ \\
\hline Firmicutes & Bacilli & Lactobacillales & Lactobacillaceae & Lactobacillus & curvatus & $1.14 \mathrm{E}-04(0.00 \mathrm{E}+00-1.79 \mathrm{E}-04)$ & $1.64 \mathrm{E}-04(0.00 \mathrm{E}+00-3.71 \mathrm{E}-03)$ & $-6.69 \pm 1.71$ & $1.80 \mathrm{E}-03$ \\
\hline Proteobacteria & Gammaproteobacteria & Enterobacterales & Enterobacteriaceae & Klebsiella & michiganensis & $0.00 \mathrm{E}+00(0.00 \mathrm{E}+00-0.00 \mathrm{E}+00)$ & $6.77 \mathrm{E}-04(1.45 \mathrm{E}-04-2.32 \mathrm{E}-03)$ & $-6.60 \pm 1.65$ & $1.40 \mathrm{E}-03$ \\
\hline Proteobacteria & Gammaproteobacteria & Enterobacterales & Enterobacteriaceae & Pluralibacter & gergoviae & $0.00 \mathrm{E}+00(0.00 \mathrm{E}+00-0.00 \mathrm{E}+00)$ & $6.58 \mathrm{E}-05(8.17 \mathrm{E}-06-5.18 \mathrm{E}-04)$ & $-6.56 \pm 1.75$ & $3.12 \mathrm{E}-03$ \\
\hline Proteobacteria & Gammaproteobacteria & Enterobacterales & Enterobacteriaceae & Shigella & no data & $0.00 \mathrm{E}+00(0.00 \mathrm{E}+00-0.00 \mathrm{E}+00)$ & $1.67 \mathrm{E}-01(1.76 \mathrm{E}-02-1.01 \mathrm{E}+00)$ & $-6.46 \pm 2.31$ & $2.88 \mathrm{E}-02$ \\
\hline Proteobacteria & Gammaproteobacteria & Enterobacterales & Erwiniaceae & Erwinia & teleogrylli & $0.00 \mathrm{E}+00(0.00 \mathrm{E}+00-0.00 \mathrm{E}+00)$ & $9.93 \mathrm{E}-05(8.17 \mathrm{E}-06-6.65 \mathrm{E}-04)$ & $-6.45 \pm 1.71$ & $3.12 \mathrm{E}-03$ \\
\hline Proteobacteria & Gammaproteobacteria & Enterobacterales & Enterobacteriaceae & Escherichia & sp KTE96 & $0.00 \mathrm{E}+00(0.00 \mathrm{E}+00-0.00 \mathrm{E}+00)$ & $4.75 \mathrm{E}-04(9.01 \mathrm{E}-06-3.41 \mathrm{E}-03)$ & $-6.43 \pm 2.21$ & $2.43 \mathrm{E}-02$ \\
\hline Proteobacteria & Gammaproteobacteria & Enterobacterales & Enterobacteriaceae & Escherichia & sp KTE11 & $0.00 \mathrm{E}+00(0.00 \mathrm{E}+00-0.00 \mathrm{E}+00)$ & $1.40 \mathrm{E}-05(0.00 \mathrm{E}+00-2.35 \mathrm{E}-03)$ & $-6.38 \pm 2.38$ & $3.58 \mathrm{E}-02$ \\
\hline Proteobacteria & Gammaproteobacteria & Enterobacterales & Enterobacteriaceae & Shigella & sonnei & $0.00 \mathrm{E}+00(0.00 \mathrm{E}+00-0.00 \mathrm{E}+00)$ & $9.59 \mathrm{E}-02(9.56 \mathrm{E}-03-2.82 \mathrm{E}-01)$ & $-6.38 \pm 2.21$ & $2.52 \mathrm{E}-02$ \\
\hline Firmicutes & Bacilli & Lactobacillales & Enterococcaceae & Enterococcus & sp FDAARGOS 375 & $0.00 \mathrm{E}+00(0.00 \mathrm{E}+00-0.00 \mathrm{E}+00)$ & $6.27 \mathrm{E}-05(0.00 \mathrm{E}+00-4.75 \mathrm{E}-04)$ & $-6.31 \pm 2.28$ & $3.09 \mathrm{E}-02$ \\
\hline Proteobacteria & Gammaproteobacteria & Enterobacterales & Enterobacteriaceae & Cronobacter & malonaticus & $0.00 \mathrm{E}+00(0.00 \mathrm{E}+00-0.00 \mathrm{E}+00)$ & $6.41 \mathrm{E}-05(1.05 \mathrm{E}-05-1.06 \mathrm{E}-03)$ & $-6.27 \pm 1.99$ & $1.42 \mathrm{E}-02$ \\
\hline Proteobacteria & Betaproteobacteria & Burkholderiales & Alcaligenaceae & Achromobacter & sp ATCC35328 & $0.00 \mathrm{E}+00(0.00 \mathrm{E}+00-0.00 \mathrm{E}+00)$ & $9.52 \mathrm{E}-03(1.18 \mathrm{E}-03-1.99 \mathrm{E}-02)$ & $-6.16 \pm 2.04$ & $1.89 \mathrm{E}-02$ \\
\hline Proteobacteria & Gammaproteobacteria & Enterobacterales & Enterobacteriaceae & Klebsiella & oxytoca & $0.00 \mathrm{E}+00(0.00 \mathrm{E}+00-0.00 \mathrm{E}+00)$ & $7.20 \mathrm{E}-04(2.11 \mathrm{E}-05-3.25 \mathrm{E}-03)$ & $-6.16 \pm 1.88$ & $1.04 \mathrm{E}-02$ \\
\hline Proteobacteria & Gammaproteobacteria & Enterobacterales & Enterobacteriaceae & Escherichia & sp KTE159 & $0.00 \mathrm{E}+00(0.00 \mathrm{E}+00-0.00 \mathrm{E}+00)$ & $1.01 \mathrm{E}-02(2.82 \mathrm{E}-04-3.19 \mathrm{E}-02)$ & $-6.16 \pm 2.14$ & $2.54 \mathrm{E}-02$ \\
\hline Proteobacteria & Gammaproteobacteria & Enterobacterales & Enterobacteriaceae & Citrobacter & no data & $0.00 \mathrm{E}+00(0.00 \mathrm{E}+00-0.00 \mathrm{E}+00)$ & $6.56 \mathrm{E}-03(2.91 \mathrm{E}-04-3.21 \mathrm{E}-02)$ & $-6.15 \pm 2.21$ & $3.05 \mathrm{E}-02$ \\
\hline Firmicutes & Bacilli & Lactobacillales & Enterococcaceae & Enterococcus & massiliensis & $0.00 \mathrm{E}+00(0.00 \mathrm{E}+00-9.71 \mathrm{E}-05)$ & $1.97 \mathrm{E}-04(3.94 \mathrm{E}-05-8.56 \mathrm{E}-04)$ & $-6.06 \pm 1.79$ & $7.55 \mathrm{E}-03$ \\
\hline Proteobacteria & Gammaproteobacteria & Enterobacterales & Enterobacteriaceae & no data & no data & $2.28 \mathrm{E}-04(9.71 \mathrm{E}-05-4.19 \mathrm{E}-04)$ & $8.92 \mathrm{E}+00(5.93 \mathrm{E}-01-3.02 \mathrm{E}+01)$ & $-6.05 \pm 1.81$ & $8.53 \mathrm{E}-03$ \\
\hline Firmicutes & Bacilli & Lactobacillales & Enterococcaceae & Enterococcus & hirae & $8.42 \mathrm{E}-05(0.00 \mathrm{E}+00-2.62 \mathrm{E}-04)$ & 3.64E-04 (4.34E-05 - 4.62E-03) & $-5.98 \pm 1.67$ & $4.37 \mathrm{E}-03$ \\
\hline Firmicutes & Bacilli & Lactobacillales & Streptococcaceae & Streptococcus & equinus & $4.55 \mathrm{E}-04(1.94 \mathrm{E}-04-1.50 \mathrm{E}-03)$ & $1.76 \mathrm{E}-03(1.06 \mathrm{E}-04-8.90 \mathrm{E}-01)$ & $-5.94 \pm 1.93$ & $1.61 \mathrm{E}-02$ \\
\hline Firmicutes & Bacilli & Lactobacillales & Enterococcaceae & Enterococcus & raffinosus & $0.00 \mathrm{E}+00(0.00 \mathrm{E}+00-0.00 \mathrm{E}+00)$ & $8.85 \mathrm{E}-05(0.00 \mathrm{E}+00-6.18 \mathrm{E}-04)$ & $-5.90 \pm 2.19$ & $3.58 \mathrm{E}-02$ \\
\hline Proteobacteria & Gammaproteobacteria & Enterobacterales & Enterobacteriaceae & Escherichia & sp KTE52 & $0.00 \mathrm{E}+00(0.00 \mathrm{E}+00-0.00 \mathrm{E}+00)$ & $2.20 \mathrm{E}-03(1.54 \mathrm{E}-04-1.79 \mathrm{E}-02)$ & $-5.90 \pm 1.97$ & $1.94 \mathrm{E}-02$ \\
\hline Actinobacteria & Actinobacteria & Propionibacteriales & Propionibacteriaceae & Propionibacterium & freudenreichii & $1.11 \mathrm{E}-04(0.00 \mathrm{E}+00-2.02 \mathrm{E}-04)$ & $6.80 \mathrm{E}-05(1.05 \mathrm{E}-05-2.17 \mathrm{E}-03)$ & $-5.89 \pm 1.84$ & $1.29 \mathrm{E}-02$ \\
\hline Firmicutes & Bacilli & Bacillales & Paenibacillaceae & Paenibacillus & sp VT-16-81 & $0.00 \mathrm{E}+00(0.00 \mathrm{E}+00-0.00 \mathrm{E}+00)$ & $3.73 \mathrm{E}-05(0.00 \mathrm{E}+00-1.08 \mathrm{E}-04)$ & $-5.87 \pm 2.04$ & $2.54 \mathrm{E}-02$ \\
\hline Proteobacteria & Gammaproteobacteria & Enterobacterales & Enterobacteriaceae & Shigella & boydii & $0.00 \mathrm{E}+00(0.00 \mathrm{E}+00-0.00 \mathrm{E}+00)$ & $8.74 \mathrm{E}-02(7.11 \mathrm{E}-03-2.18 \mathrm{E}-01)$ & $-5.87 \pm 2.18$ & $3.58 \mathrm{E}-02$ \\
\hline Firmicutes & Bacilli & Lactobacillales & Carnobacteriaceae & Carnobacterium & gallinarum & $0.00 \mathrm{E}+00(0.00 \mathrm{E}+00-0.00 \mathrm{E}+00)$ & $3.77 \mathrm{E}-05(0.00 \mathrm{E}+00-7.99 \mathrm{E}-04)$ & $-5.85 \pm 2.17$ & $3.58 \mathrm{E}-02$ \\
\hline
\end{tabular}




\begin{tabular}{|c|c|c|c|c|c|c|c|c|c|}
\hline Firmicutes & Bacilli & Lactobacillales & Streptococcaceae & Streptococcus & lutetiensis & $8.42 \mathrm{E}-05(0.00 \mathrm{E}+00-4.62 \mathrm{E}-03)$ & $1.49 \mathrm{E}-04(6.23 \mathrm{E}-05-3.44 \mathrm{E}+00)$ & $-5.85 \pm 2.30$ & $4.89 \mathrm{E}-02$ \\
\hline Firmicutes & Bacilli & Lactobacillales & Enterococcaceae & Enterococcus & sp HMSC34G12 & $0.00 \mathrm{E}+00(0.00 \mathrm{E}+00-0.00 \mathrm{E}+00)$ & $7.47 \mathrm{E}-05(0.00 \mathrm{E}+00-2.38 \mathrm{E}-04)$ & $-5.83 \pm 2.08$ & $2.88 \mathrm{E}-02$ \\
\hline Firmicutes & Bacilli & Lactobacillales & Streptococcaceae & Streptococcus & no data & $3.68 \mathrm{E}-02(8.00 \mathrm{E}-03-5.84 \mathrm{E}-01)$ & $1.91 \mathrm{E}-01(1.39 \mathrm{E}-02-2.36 \mathrm{E}+01)$ & $-5.81 \pm 1.55$ & $3.12 \mathrm{E}-03$ \\
\hline Fusobacteria & Fusobacteria & Fusobacteriales & Leptotrichiaceae & Streptobacillus & moniliformis & $0.00 \mathrm{E}+00(0.00 \mathrm{E}+00-0.00 \mathrm{E}+00)$ & $3.73 \mathrm{E}-03(6.84 \mathrm{E}-04-1.09 \mathrm{E}-02)$ & $-5.78 \pm 1.92$ & $1.91 \mathrm{E}-02$ \\
\hline Proteobacteria & Gammaproteobacteria & Enterobacterales & Enterobacteriaceae & Escherichia & sp 1143 & $0.00 \mathrm{E}+00(0.00 \mathrm{E}+00-0.00 \mathrm{E}+00)$ & $8.41 \mathrm{E}-03(8.32 \mathrm{E}-04-9.78 \mathrm{E}-03)$ & $-5.68 \pm 1.83$ & $1.52 \mathrm{E}-02$ \\
\hline Firmicutes & Bacilli & Lactobacillales & Streptococcaceae & Streptococcus & infantarius & $8.55 \mathrm{E}-04(0.00 \mathrm{E}+00-1.39 \mathrm{E}-03)$ & $6.33 \mathrm{E}-04(1.34 \mathrm{E}-04-8.77 \mathrm{E}-01)$ & $-5.65 \pm 2.00$ & $2.75 \mathrm{E}-02$ \\
\hline Firmicutes & Bacilli & Lactobacillales & Enterococcaceae & Enterococcus & canis & $0.00 \mathrm{E}+00(0.00 \mathrm{E}+00-0.00 \mathrm{E}+00)$ & $3.32 \mathrm{E}-04(9.01 \mathrm{E}-06-1.50 \mathrm{E}-03)$ & $-5.59 \pm 2.16$ & $4.44 \mathrm{E}-02$ \\
\hline Firmicutes & Bacilli & Lactobacillales & Enterococcaceae & Enterococcus & sp HMSC035C10 & $0.00 \mathrm{E}+00(0.00 \mathrm{E}+00-9.12 \mathrm{E}-05)$ & $5.28 \mathrm{E}-04(4.21 \mathrm{E}-05-9.66 \mathrm{E}-04)$ & $-5.59 \pm 1.77$ & $1.42 \mathrm{E}-02$ \\
\hline Firmicutes & Bacilli & Lactobacillales & Enterococcaceae & Enterococcus & villorum & $0.00 \mathrm{E}+00(0.00 \mathrm{E}+00-8.42 \mathrm{E}-05)$ & $2.35 \mathrm{E}-05(0.00 \mathrm{E}+00-1.47 \mathrm{E}-04)$ & $-5.56 \pm 2.06$ & $3.58 \mathrm{E}-02$ \\
\hline Firmicutes & Bacilli & Lactobacillales & Enterococcaceae & Enterococcus & sp $255 \mathrm{ESPC}$ & $0.00 \mathrm{E}+00(0.00 \mathrm{E}+00-0.00 \mathrm{E}+00)$ & $1.52 \mathrm{E}-04(9.01 \mathrm{E}-06-4.48 \mathrm{E}-03)$ & $-5.54 \pm 1.92$ & $2.47 \mathrm{E}-02$ \\
\hline Proteobacteria & Gammaproteobacteria & Enterobacterales & Enterobacteriaceae & Lelliottia & amnigena & $0.00 \mathrm{E}+00(0.00 \mathrm{E}+00-0.00 \mathrm{E}+00)$ & $9.27 \mathrm{E}-05(1.89 \mathrm{E}-05-3.69 \mathrm{E}-04)$ & $-5.53 \pm 1.84$ & $1.91 \mathrm{E}-02$ \\
\hline Firmicutes & Bacilli & Lactobacillales & Streptococcaceae & Streptococcus & anginosus & $0.00 \mathrm{E}+00(0.00 \mathrm{E}+00-8.42 \mathrm{E}-05)$ & $7.61 \mathrm{E}-04(1.17 \mathrm{E}-05-3.15 \mathrm{E}-03)$ & $-5.46 \pm 1.77$ & $1.58 \mathrm{E}-02$ \\
\hline Proteobacteria & Gammaproteobacteria & Enterobacterales & Erwiniaceae & Erwinia & gerundensis & $0.00 \mathrm{E}+00(0.00 \mathrm{E}+00-0.00 \mathrm{E}+00)$ & $9.82 \mathrm{E}-05(0.00 \mathrm{E}+00-1.26 \mathrm{E}-04)$ & $-5.45 \pm 1.82$ & $1.92 \mathrm{E}-02$ \\
\hline Proteobacteria & Gammaproteobacteria & Enterobacterales & Enterobacteriaceae & Enterobacter & no data & $0.00 \mathrm{E}+00(0.00 \mathrm{E}+00-0.00 \mathrm{E}+00)$ & $3.09 \mathrm{E}-03(3.87 \mathrm{E}-04-1.20 \mathrm{E}-02)$ & $-5.39 \pm 2.00$ & $3.58 \mathrm{E}-02$ \\
\hline Firmicutes & Bacilli & \begin{tabular}{|l} 
Lactobacillales \\
\end{tabular} & Enterococcaceae & Enterococcus & sp HMSC072F02 & $0.00 \mathrm{E}+00(0.00 \mathrm{E}+00-5.05 \mathrm{E}-04)$ & $5.25 \mathrm{E}-04(8.41 \mathrm{E}-05-6.68 \mathrm{E}-03)$ & $-5.29 \pm 1.68$ & $1.42 \mathrm{E}-02$ \\
\hline Proteobacteria & Gammaproteobacteria & Enterobacterales & Enterobacteriaceae & no data & bacterium ENNIH1 & $0.00 \mathrm{E}+00(0.00 \mathrm{E}+00-0.00 \mathrm{E}+00)$ & $5.49 \mathrm{E}-05(0.00 \mathrm{E}+00-1.18 \mathrm{E}-04)$ & $-5.28 \pm 1.85$ & $2.60 \mathrm{E}-02$ \\
\hline Proteobacteria & Gammaproteobacteria & Enterobacterales & Enterobacteriaceae & Raoultella & planticola & $0.00 \mathrm{E}+00(0.00 \mathrm{E}+00-0.00 \mathrm{E}+00)$ & $1.89 \mathrm{E}-05(0.00 \mathrm{E}+00-1.16 \mathrm{E}-04)$ & $-5.17 \pm 2.03$ & $4.79 \mathrm{E}-02$ \\
\hline Firmicutes & Bacilli & Lactobacillales & Enterococcaceae & Enterococcus & gallinarum & $0.00 \mathrm{E}+00(0.00 \mathrm{E}+00-5.55 \mathrm{E}-05)$ & $2.51 \mathrm{E}-03(1.32 \mathrm{E}-03-1.13 \mathrm{E}-02)$ & $-5.12 \pm 1.57$ & $1.04 \mathrm{E}-02$ \\
\hline Proteobacteria & Gammaproteobacteria & Enterobacterales & Yersiniaceae & Yersinia & no data & $0.00 \mathrm{E}+00(0.00 \mathrm{E}+00-0.00 \mathrm{E}+00)$ & $1.41 \mathrm{E}-04(9.01 \mathrm{E}-06-2.87 \mathrm{E}-04)$ & $-5.08 \pm 1.86$ & $3.41 \mathrm{E}-02$ \\
\hline Proteobacteria & Gammaproteobacteria & Enterobacterales & Enterobacteriaceae & Raoultella & ornithinolytica & $0.00 \mathrm{E}+00(0.00 \mathrm{E}+00-0.00 \mathrm{E}+00)$ & $9.13 \mathrm{E}-05(9.44 \mathrm{E}-06-7.79 \mathrm{E}-04)$ & $-5.06 \pm 1.90$ & $3.62 \mathrm{E}-02$ \\
\hline Proteobacteria & Gammaproteobacteria & Enterobacterales & Enterobacteriaceae & Escherichia & no data & $6.11 \mathrm{E}-05(0.00 \mathrm{E}+00-2.10 \mathrm{E}-04)$ & $1.21 \mathrm{E}+00(5.58 \mathrm{E}-01-7.20 \mathrm{E}+00)$ & $-5.02 \pm 1.99$ & $4.99 \mathrm{E}-02$ \\
\hline Proteobacteria & Gammaproteobacteria & Enterobacterales & Enterobacteriaceae & Citrobacter & sp MGH 55 & $0.00 \mathrm{E}+00(0.00 \mathrm{E}+00-0.00 \mathrm{E}+00)$ & $5.88 \mathrm{E}-05(9.01 \mathrm{E}-06-2.40 \mathrm{E}-04)$ & $-5.00 \pm 1.77$ & $2.75 \mathrm{E}-02$ \\
\hline Actinobacteria & Actinobacteria & Corynebacteriales & \begin{tabular}{|l} 
Nocardiaceae \\
\end{tabular} & Rhodococcus & no data & $5.55 \mathrm{E}-05(0.00 \mathrm{E}+00-3.14 \mathrm{E}-04)$ & $2.03 \mathrm{E}-04(0.00 \mathrm{E}+00-7.70 \mathrm{E}-04)$ & $-4.89 \pm 1.50$ & $1.04 \mathrm{E}-02$ \\
\hline Firmicutes & Bacilli & Lactobacillales & Streptococcaceae & Streptococcus & thermophilus & $1.82 \mathrm{E}-04(6.11 \mathrm{E}-05-6.81 \mathrm{E}-04)$ & $1.08 \mathrm{E}-02(5.86 \mathrm{E}-04-2.09 \mathrm{E}-02)$ & $-4.67 \pm 1.35$ & $6.07 \mathrm{E}-03$ \\
\hline Firmicutes & Bacilli & Lactobacillales & Streptococcaceae & Streptococcus & macedonicus & $1.01 \mathrm{E}-04(0.00 \mathrm{E}+00-1.48 \mathrm{E}-02)$ & $2.99 \mathrm{E}-03(4.25 \mathrm{E}-04-6.15 \mathrm{E}-02)$ & $-4.62 \pm 1.70$ & $3.52 \mathrm{E}-02$ \\
\hline Firmicutes & Bacilli & Lactobacillales & Streptococcaceae & Streptococcus & pasteurianus & $8.73 \mathrm{E}-04$ (5.69E-04 - 3.33E-03) & $6.32 \mathrm{E}-03(4.42 \mathrm{E}-04-4.98 \mathrm{E}-02)$ & $-4.60 \pm 1.17$ & $1.80 \mathrm{E}-03$ \\
\hline Firmicutes & Bacilli & Lactobacillales & Streptococcaceae & Streptococcus & suis & $3.88 \mathrm{E}-04(3.19 \mathrm{E}-04-9.27 \mathrm{E}-04)$ & $8.34 \mathrm{E}-04(2.27 \mathrm{E}-04-3.00 \mathrm{E}-03)$ & $-4.10 \pm 1.03$ & $1.40 \mathrm{E}-03$ \\
\hline Firmicutes & Bacilli & Lactobacillales & Enterococcaceae & Enterococcus & durans & $1.26 \mathrm{E}-04(0.00 \mathrm{E}+00-3.19 \mathrm{E}-04)$ & $7.94 \mathrm{E}-04(4.20 \mathrm{E}-05-2.29 \mathrm{E}-03)$ & $-4.04 \pm 1.53$ & $3.96 \mathrm{E}-02$ \\
\hline Firmicutes & Bacilli & Lactobacillales & Lactobacillaceae & Lactobacillus & no data & $5.92 \mathrm{E}-04(2.53 \mathrm{E}-04-1.92 \mathrm{E}-03)$ & $3.83 \mathrm{E}-03(1.86 \mathrm{E}-03-1.66 \mathrm{E}-02)$ & $-4.00 \pm 1.07$ & $3.12 \mathrm{E}-03$ \\
\hline Firmicutes & Bacilli & Lactobacillales & Streptococcaceae & Lactococcus & lactis & $1.26 \mathrm{E}-03(8.88 \mathrm{E}-04-3.54 \mathrm{E}-03)$ & $2.40 \mathrm{E}-02(3.15 \mathrm{E}-03-2.71 \mathrm{E}-02)$ & $-3.96 \pm 0.95$ & $9.52 \mathrm{E}-04$ \\
\hline Firmicutes & Clostridia & Clostridiales & Clostridiales & Emergencia & timonensis & $3.05 \mathrm{E}-04(1.37 \mathrm{E}-04-7.34 \mathrm{E}-04)$ & $4.46 \mathrm{E}-04(2.25 \mathrm{E}-04-1.29 \mathrm{E}-03)$ & $-3.84 \pm 1.16$ & $9.41 \mathrm{E}-03$ \\
\hline Actinobacteria & Actinobacteria & Bifidobacteriales & Bifidobacteriaceae & Bifidobacterium & breve & $3.05 \mathrm{E}-03(1.65 \mathrm{E}-03-3.41 \mathrm{E}-03)$ & $1.63 \mathrm{E}-03(6.32 \mathrm{E}-04-4.35 \mathrm{E}-03)$ & $-3.79 \pm 0.99$ & $2.64 \mathrm{E}-03$ \\
\hline Firmicutes & Bacilli & no data & no data & no data & no data & $8.66 \mathrm{E}-04(1.34 \mathrm{E}-04-4.72 \mathrm{E}-03)$ & $4.48 \mathrm{E}-03(1.65 \mathrm{E}-03-3.28 \mathrm{E}-02)$ & $-3.73 \pm 1.28$ & $2.34 \mathrm{E}-02$ \\
\hline Proteobacteria & Gammaproteobacteria & no data & no data & no data & no data & $5.24 \mathrm{E}-05(4.21 \mathrm{E}-05-1.14 \mathrm{E}-04)$ & $1.39 \mathrm{E}-02(3.37 \mathrm{E}-03-3.15 \mathrm{E}-02)$ & $-3.73 \pm 1.29$ & $2.47 \mathrm{E}-02$ \\
\hline Actinobacteria & Actinobacteria & Micrococcales & Microbacteriaceae & Microbacterium & no data & $5.55 \mathrm{E}-05(0.00 \mathrm{E}+00-2.91 \mathrm{E}-04)$ & $9.61 \mathrm{E}-05(3.85 \mathrm{E}-05-3.39 \mathrm{E}-04)$ & $-2.94 \pm 1.14$ & $4.61 \mathrm{E}-02$ \\
\hline Firmicutes & Clostridia & Clostridiales & Lachnospiraceae & no data & bacterium 31 46FAA & $1.14 \mathrm{E}-02(2.69 \mathrm{E}-03-2.41 \mathrm{E}-02)$ & $1.05 \mathrm{E}-02(1.24 \mathrm{E}-03-6.32 \mathrm{E}-02)$ & $-2.78 \pm 0.99$ & $2.75 \mathrm{E}-02$ \\
\hline Firmicutes & Bacilli & Lactobacillales & Streptococcaceae & Streptococcus & parasanguinis & $7.76 \mathrm{E}-04(6.72 \mathrm{E}-04-1.21 \mathrm{E}-03)$ & $8.33 \mathrm{E}-04(3.19 \mathrm{E}-04-1.59 \mathrm{E}-03)$ & $-2.19 \pm 0.71$ & $1.58 \mathrm{E}-02$ \\
\hline
\end{tabular}

\section{FC: fold change, SE: standard error, NS: not significant}




\section{PeerJ}

${ }^{1} \mathrm{p}$ values were adjusted with false discovery rate for multiple comparisons 


\section{Table 7 (on next page)}

Bacterial species with differential abundances ( $\mid$ fold change $\mid \geq 2$ and $p<0.05$ ) between high-responders $(H R, n=9)$ and low-responders $(L R, n=10)$ at week 4 . 
Table 7. Bacterial species with differential abundances ( $\mid$ fold change $\mid \geq 2$ and $p<0.05)$ between high-responders $($ HR, $n=9)$ and lowresponders $(\mathrm{LR}, \mathrm{n}=10)$ at week 4 .

\begin{tabular}{|c|c|c|c|c|c|c|c|c|c|}
\hline \multirow{2}{*}{ Phylum } & \multirow{2}{*}{ Class } & \multirow{2}{*}{ Order } & \multirow{2}{*}{ Family } & \multirow{2}{*}{ Genus } & \multirow{2}{*}{ Species } & \multicolumn{2}{|c|}{$\begin{array}{c}\text { Relative abundance, in \% } \\
\text { Median (IQR) }\end{array}$} & \multicolumn{2}{|c|}{ Week 4 HR vs LR } \\
\hline & & & & & & $\begin{array}{c}\text { HR } \\
(n=9)\end{array}$ & $\begin{array}{c}\text { LR } \\
(n=10)\end{array}$ & $\begin{array}{c}\log 2 \text { FC } \\
\text { mean } \pm \text { SE }\end{array}$ & $\begin{array}{c}\text { Adjusted } \\
P \text {-value } 1\end{array}$ \\
\hline \multicolumn{10}{|c|}{ Higher in HR (68 species) } \\
\hline Proteobacteria & Gammaproteobacteria & Enterobacterales & Hafniaceae & Hafnia & alvei & $1.88 \mathrm{E}-03(1.47 \mathrm{E}-03-1.06 \mathrm{E}+00)$ & $4.81 \mathrm{E}-05(0.00 \mathrm{E}+00-6.65 \mathrm{E}-05)$ & $10.37 \pm 2.02$ & $1.56 \mathrm{E}-04$ \\
\hline Proteobacteria & Gammaproteobacteria & Enterobacterales & Hafniaceae & Hafnia & no data & $3.57 \mathrm{E}-04(1.66 \mathrm{E}-04-1.54 \mathrm{E}-01)$ & $0.00 \mathrm{E}+00(0.00 \mathrm{E}+00-3.58 \mathrm{E}-05)$ & $10.30 \pm 2.26$ & $7.33 \mathrm{E}-04$ \\
\hline Proteobacteria & Gammaproteobacteria & Enterobacterales & Morganellaceae & Morganella & sp HMSC11D09 & $0.00 \mathrm{E}+00(0.00 \mathrm{E}+00-4.86 \mathrm{E}-03)$ & $0.00 \mathrm{E}+00(0.00 \mathrm{E}+00-0.00 \mathrm{E}+00)$ & $9.07 \pm 2.50$ & $8.16 \mathrm{E}-03$ \\
\hline Proteobacteria & Gammaproteobacteria & Enterobacterales & Hafniaceae & Hafnia & sp HMSC23F03 & $3.96 \mathrm{E}-03(2.77 \mathrm{E}-05-2.24 \mathrm{E}-02)$ & $0.00 \mathrm{E}+00(0.00 \mathrm{E}+00-1.06 \mathrm{E}-04)$ & $7.84 \pm 2.12$ & $7.29 \mathrm{E}-03$ \\
\hline Firmicutes & Bacilli & Bacillales & Listeriaceae & Listeria & monocytogenes & $3.24 \mathrm{E}-05(0.00 \mathrm{E}+00-2.65 \mathrm{E}-04)$ & $0.00 \mathrm{E}+00(0.00 \mathrm{E}+00-5.61 \mathrm{E}-05)$ & $7.67 \pm 2.27$ & $1.43 \mathrm{E}-02$ \\
\hline Firmicutes & Erysipelotrichia & Erysipelotrichales & Erysipelotrichaceae & Solobacterium & moorei & $0.00 \mathrm{E}+00(0.00 \mathrm{E}+00-1.95 \mathrm{E}-04)$ & $0.00 \mathrm{E}+00(0.00 \mathrm{E}+00-0.00 \mathrm{E}+00)$ & $7.64 \pm 2.77$ & $4.71 \mathrm{E}-02$ \\
\hline Proteobacteria & Gammaproteobacteria & Enterobacterales & Enterobacteriaceae & Enterobacter & sp MGH 7 & $0.00 \mathrm{E}+00(0.00 \mathrm{E}+00-5.95 \mathrm{E}-04)$ & $0.00 \mathrm{E}+00(0.00 \mathrm{E}+00-0.00 \mathrm{E}+00)$ & $7.46 \pm 2.68$ & $4.51 \mathrm{E}-02$ \\
\hline Proteobacteria & Gammaproteobacteria & Enterobacterales & Enterobacteriaceae & Klebsiella & sp AA405 & $0.00 \mathrm{E}+00(0.00 \mathrm{E}+00-1.33 \mathrm{E}-04)$ & $0.00 \mathrm{E}+00(0.00 \mathrm{E}+00-0.00 \mathrm{E}+00)$ & $7.36 \pm 2.59$ & $4.18 \mathrm{E}-02$ \\
\hline Proteobacteria & Gammaproteobacteria & Enterobacterales & Enterobacteriaceae & Cronobacter & dublinensis & $1.94 \mathrm{E}-04(1.47 \mathrm{E}-04-9.28 \mathrm{E}-04)$ & $0.00 \mathrm{E}+00(0.00 \mathrm{E}+00-0.00 \mathrm{E}+00)$ & $7.28 \pm 1.56$ & $5.73 \mathrm{E}-04$ \\
\hline Proteobacteria & Gammaproteobacteria & Pseudomonadales & Pseudomonadaceae & Pseudomonas & sp Ep R1 & $0.00 \mathrm{E}+00(0.00 \mathrm{E}+00-6.63 \mathrm{E}-04)$ & $0.00 \mathrm{E}+00(0.00 \mathrm{E}+00-0.00 \mathrm{E}+00)$ & $7.22 \pm 2.61$ & $4.71 \mathrm{E}-02$ \\
\hline Firmicutes & Bacilli & Bacillales & Paenibacillaceae & Paenibacillus & sp VT-16-81 & $1.19 \mathrm{E}-04(0.00 \mathrm{E}+00-3.01 \mathrm{E}-03)$ & $0.00 \mathrm{E}+00(0.00 \mathrm{E}+00-4.34 \mathrm{E}-05)$ & $7.11 \pm 1.97$ & $8.34 \mathrm{E}-03$ \\
\hline Proteobacteria & Gammaproteobacteria & Enterobacterales & Hafniaceae & Edwardsiella & hoshinae & $2.08 \mathrm{E}-05(0.00 \mathrm{E}+00-5.27 \mathrm{E}-04)$ & $0.00 \mathrm{E}+00(0.00 \mathrm{E}+00-0.00 \mathrm{E}+00)$ & $6.91 \pm 2.13$ & $2.12 \mathrm{E}-02$ \\
\hline Firmicutes & Clostridia & Clostridiales & Clostridiaceae & Clostridium & sp CL-2 & $3.97 \mathrm{E}-04(5.54 \mathrm{E}-05-1.66 \mathrm{E}-03)$ & $0.00 \mathrm{E}+00(0.00 \mathrm{E}+00-0.00 \mathrm{E}+00)$ & $6.70 \pm 1.56$ & $1.70 \mathrm{E}-03$ \\
\hline Firmicutes & Clostridia & Clostridiales & Clostridiaceae & Clostridium & tertium & $6.77 \mathrm{E}-05(0.00 \mathrm{E}+00-7.83 \mathrm{E}-04)$ & $0.00 \mathrm{E}+00(0.00 \mathrm{E}+00-0.00 \mathrm{E}+00)$ & $6.65 \pm 2.01$ & $1.83 \mathrm{E}-02$ \\
\hline Firmicutes & Bacilli & Lactobacillales & Enterococcaceae & Enterococcus & sp HMSC072H05 & $2.65 \mathrm{E}-04(0.00 \mathrm{E}+00-7.83 \mathrm{E}-04)$ & $0.00 \mathrm{E}+00(0.00 \mathrm{E}+00-0.00 \mathrm{E}+00)$ & $6.59 \pm 1.84$ & $9.15 \mathrm{E}-03$ \\
\hline Firmicutes & Clostridia & Clostridiales & Ruminococcaceae & Ruminiclostridium & josui & $0.00 \mathrm{E}+00(0.00 \mathrm{E}+00-1.81 \mathrm{E}-03)$ & $0.00 \mathrm{E}+00(0.00 \mathrm{E}+00-0.00 \mathrm{E}+00)$ & $6.37 \pm 2.37$ & $4.97 \mathrm{E}-02$ \\
\hline Proteobacteria & Gammaproteobacteria & Enterobacterales & Enterobacteriaceae & Klebsiella & no data & $1.06 \mathrm{E}-02(7.68 \mathrm{E}-03-1.80 \mathrm{E}-01)$ & $1.36 \mathrm{E}-03(3.94 \mathrm{E}-04-6.31 \mathrm{E}-03)$ & $6.14 \pm 1.39$ & $1.08 \mathrm{E}-03$ \\
\hline Firmicutes & Bacilli & Lactobacillales & Carnobacteriaceae & Carnobacterium & maltaromaticum & $1.08 \mathrm{E}-03(2.66 \mathrm{E}-05-3.65 \mathrm{E}-03)$ & $1.31 \mathrm{E}-04(5.01 \mathrm{E}-05-4.23 \mathrm{E}-04)$ & $6.06 \pm 1.54$ & $4.09 \mathrm{E}-03$ \\
\hline Firmicutes & Bacilli & Lactobacillales & Enterococcaceae & Enterococcus & avium & $1.77 \mathrm{E}-04(0.00 \mathrm{E}+00-2.88 \mathrm{E}-02)$ & $0.00 \mathrm{E}+00(0.00 \mathrm{E}+00-4.11 \mathrm{E}-04)$ & $5.99 \pm 2.00$ & $3.24 \mathrm{E}-02$ \\
\hline Proteobacteria & Gammaproteobacteria & Enterobacterales & Enterobacteriaceae & Escherichia & sp KTE11 & $2.54 \mathrm{E}-03(1.06 \mathrm{E}-03-6.28 \mathrm{E}-03)$ & $0.00 \mathrm{E}+00(0.00 \mathrm{E}+00-6.79 \mathrm{E}-05)$ & $5.94 \pm 1.50$ & $4.09 \mathrm{E}-03$ \\
\hline Proteobacteria & Gammaproteobacteria & Enterobacterales & Erwiniaceae & Pantoea & ananatis & $4.52 \mathrm{E}-04(2.28 \mathrm{E}-04-6.10 \mathrm{E}-04)$ & $0.00 \mathrm{E}+00(0.00 \mathrm{E}+00-0.00 \mathrm{E}+00)$ & $5.91 \pm 1.56$ & $6.66 \mathrm{E}-03$ \\
\hline Firmicutes & Clostridia & Clostridiales & Clostridiaceae & Clostridium & sp $7243 \mathrm{FAA}$ & $1.62 \mathrm{E}-04(0.00 \mathrm{E}+00-7.34 \mathrm{E}-04)$ & $0.00 \mathrm{E}+00(0.00 \mathrm{E}+00-3.58 \mathrm{E}-05)$ & $5.88 \pm 1.87$ & $2.46 \mathrm{E}-02$ \\
\hline Firmicutes & Bacilli & Lactobacillales & Streptococcaceae & Streptococcus & minor & $3.48 \mathrm{E}-03(5.75 \mathrm{E}-04-6.97 \mathrm{E}-03)$ & $9.53 \mathrm{E}-04(1.21 \mathrm{E}-04-3.04 \mathrm{E}-03)$ & $5.77 \pm 1.43$ & $3.54 \mathrm{E}-03$ \\
\hline Proteobacteria & Gammaproteobacteria & Enterobacterales & Enterobacteriaceae & Klebsiella & sp MS 92-3 & $3.97 \mathrm{E}-05(0.00 \mathrm{E}+00-2.21 \mathrm{E}-04)$ & $0.00 \mathrm{E}+00(0.00 \mathrm{E}+00-0.00 \mathrm{E}+00)$ & $5.72 \pm 2.03$ & $4.28 \mathrm{E}-02$ \\
\hline Firmicutes & Clostridia & Clostridiales & Clostridiaceae & Clostridium & no data & $6.10 \mathrm{E}-03(5.07 \mathrm{E}-03-1.04 \mathrm{E}-02)$ & $1.36 \mathrm{E}-03(3.72 \mathrm{E}-04-3.53 \mathrm{E}-03)$ & $5.64 \pm 1.16$ & $3.04 \mathrm{E}-04$ \\
\hline Firmicutes & Clostridia & Clostridiales & Peptostreptococcaceae & Terrisporobacter & glycolicus & $1.22 \mathrm{E}-03(0.00 \mathrm{E}+00-3.90 \mathrm{E}-03)$ & $0.00 \mathrm{E}+00(0.00 \mathrm{E}+00-4.39 \mathrm{E}-05)$ & $5.57 \pm 1.90$ & $3.59 \mathrm{E}-02$ \\
\hline
\end{tabular}




\begin{tabular}{|c|c|c|c|c|c|c|c|c|c|}
\hline Firmicutes & Erysipelotrichia & Erysipelotrichales & Erysipelotrichaceae & Erysipelatoclostridium & ramosum & $4.70 \mathrm{E}-03(1.30 \mathrm{E}-04-2.69 \mathrm{E}-02)$ & $8.23 \mathrm{E}-05(1.32 \mathrm{E}-05-1.54 \mathrm{E}-03)$ & $5.57 \pm 1.62$ & $1.27 \mathrm{E}-02$ \\
\hline Firmicutes & Clostridia & Clostridiales & Clostridiaceae & Clostridium & sartagoforme & $9.73 \mathrm{E}-05(0.00 \mathrm{E}+00-9.12 \mathrm{E}-04)$ & $0.00 \mathrm{E}+00(0.00 \mathrm{E}+00-2.42 \mathrm{E}-05)$ & $5.44 \pm 1.75$ & $2.66 \mathrm{E}-02$ \\
\hline Proteobacteria & Gammaproteobacteria & Enterobacterales & Enterobacteriaceae & Raoultella & no data & $2.66 \mathrm{E}-05(0.00 \mathrm{E}+00-3.72 \mathrm{E}-04)$ & $0.00 \mathrm{E}+00(0.00 \mathrm{E}+00-5.18 \mathrm{E}-05)$ & $5.35 \pm 1.77$ & $3.10 \mathrm{E}-02$ \\
\hline Firmicutes & Clostridia & Clostridiales & Clostridiaceae & Clostridium & celatum & $2.41 \mathrm{E}-04(1.45 \mathrm{E}-04-4.40 \mathrm{E}-04)$ & $0.00 \mathrm{E}+00(0.00 \mathrm{E}+00-0.00 \mathrm{E}+00)$ & $5.22 \pm 1.63$ & $2.16 \mathrm{E}-02$ \\
\hline Firmicutes & Clostridia & Clostridiales & Clostridiaceae & Clostridium & paraputrificum & $7.33 \mathrm{E}-03(1.55 \mathrm{E}-03-3.41 \mathrm{E}-02)$ & $2.06 \mathrm{E}-03(5.15 \mathrm{E}-04-9.22 \mathrm{E}-03)$ & $5.01 \pm 1.20$ & $2.54 \mathrm{E}-03$ \\
\hline Firmicutes & Erysipelotrichia & Erysipelotrichales & Erysipelotrichaceae & Coprobacillus & sp 33 56FAA & $3.47 \mathrm{E}-03(1.95 \mathrm{E}-04-4.56 \mathrm{E}-02)$ & $1.39 \mathrm{E}-03(2.32 \mathrm{E}-04-4.99 \mathrm{E}-03)$ & $4.92 \pm 1.34$ & $7.51 \mathrm{E}-03$ \\
\hline Firmicutes & Bacilli & Lactobacillales & Leuconostocaceae & Leuconostoc & mesenteroides & $2.21 \mathrm{E}-03(2.70 \mathrm{E}-04-1.31 \mathrm{E}-01)$ & $2.38 \mathrm{E}-04(4.92 \mathrm{E}-05-1.15 \mathrm{E}-02)$ & $4.92 \pm 1.75$ & $4.28 \mathrm{E}-02$ \\
\hline Firmicutes & Erysipelotrichia & Erysipelotrichales & Erysipelotrichaceae & Coprobacillus & no data & $1.54 \mathrm{E}-02(1.10 \mathrm{E}-03-4.62 \mathrm{E}-02)$ & $5.15 \mathrm{E}-04(1.98 \mathrm{E}-05-7.03 \mathrm{E}-03)$ & $4.91 \pm 1.60$ & $2.85 \mathrm{E}-02$ \\
\hline Proteobacteria & Gammaproteobacteria & Enterobacterales & Enterobacteriaceae & Klebsiella & quasipneumoniae & $3.91 \mathrm{E}-04(3.45 \mathrm{E}-04-4.74 \mathrm{E}-03)$ & $9.33 \mathrm{E}-05(0.00 \mathrm{E}+00-2.56 \mathrm{E}-04)$ & $4.83 \pm 1.65$ & $3.59 \mathrm{E}-02$ \\
\hline Proteobacteria & Gammaproteobacteria & Enterobacterales & Erwiniaceae & Erwinia & gerundensis & $1.77 \mathrm{E}-04(1.11 \mathrm{E}-04-2.71 \mathrm{E}-04)$ & $0.00 \mathrm{E}+00(0.00 \mathrm{E}+00-4.76 \mathrm{E}-05)$ & $4.83 \pm 1.25$ & $5.40 \mathrm{E}-03$ \\
\hline Firmicutes & Erysipelotrichia & Erysipelotrichales & Erysipelotrichaceae & Turicibacter & sanguinis & $8.27 \mathrm{E}-04(5.54 \mathrm{E}-05-1.52 \mathrm{E}-03)$ & $2.39 \mathrm{E}-05(0.00 \mathrm{E}+00-2.95 \mathrm{E}-04)$ & $4.76 \pm 1.63$ & $3.59 \mathrm{E}-02$ \\
\hline Firmicutes & Erysipelotrichia & Erysipelotrichales & Erysipelotrichaceae & no data & no data & $3.08 \mathrm{E}-01(1.35 \mathrm{E}-02-2.33 \mathrm{E}+00)$ & $1.07 \mathrm{E}-01(1.37 \mathrm{E}-02-1.31 \mathrm{E}-01)$ & $4.73 \pm 1.28$ & $7.46 \mathrm{E}-03$ \\
\hline Proteobacteria & Gammaproteobacteria & Enterobacterales & Enterobacteriaceae & Raoultella & ornithinolytica & $1.86 \mathrm{E}-04(4.89 \mathrm{E}-05-3.96 \mathrm{E}-03)$ & $3.45 \mathrm{E}-05(0.00 \mathrm{E}+00-1.38 \mathrm{E}-04)$ & $4.68 \pm 1.67$ & $4.40 \mathrm{E}-02$ \\
\hline Proteobacteria & Gammaproteobacteria & Enterobacterales & Enterobacteriaceae & Citrobacter & no data & $9.48 \mathrm{E}-03(8.22 \mathrm{E}-03-7.28 \mathrm{E}-02)$ & $1.61 \mathrm{E}-03(2.52 \mathrm{E}-04-8.19 \mathrm{E}-03)$ & $4.61 \pm 1.41$ & 2.02E-02 \\
\hline Proteobacteria & Gammaproteobacteria & Enterobacterales & Enterobacteriaceae & Escherichia & sp KTE172 & $1.67 \mathrm{E}-02(9.42 \mathrm{E}-03-1.64 \mathrm{E}-01)$ & $4.98 \mathrm{E}-03(8.28 \mathrm{E}-04-1.45 \mathrm{E}-02)$ & $4.57 \pm 1.29$ & $9.85 \mathrm{E}-03$ \\
\hline Proteobacteria & Gammaproteobacteria & Enterobacterales & Enterobacteriaceae & Escherichia & sp 1143 & $1.57 \mathrm{E}-02(5.90 \mathrm{E}-03-2.83 \mathrm{E}-02)$ & $1.07 \mathrm{E}-03(3.16 \mathrm{E}-04-5.30 \mathrm{E}-03)$ & $4.54 \pm 1.15$ & $4.09 \mathrm{E}-03$ \\
\hline Firmicutes & Erysipelotrichia & Erysipelotrichales & Erysipelotrichaceae & Turicibacter & no data & $1.03 \mathrm{E}-03(3.09 \mathrm{E}-04-2.31 \mathrm{E}-03)$ & $2.11 \mathrm{E}-04(0.00 \mathrm{E}+00-1.64 \mathrm{E}-03)$ & $4.32 \pm 1.54$ & $4.35 \mathrm{E}-02$ \\
\hline Proteobacteria & Gammaproteobacteria & Enterobacterales & Enterobacteriaceae & Shigella & no data & $9.74 \mathrm{E}-01(2.15 \mathrm{E}-01-1.97 \mathrm{E}+00)$ & $4.37 \mathrm{E}-02(1.42 \mathrm{E}-02-1.51 \mathrm{E}-01)$ & $4.29 \pm 1.15$ & $7.29 \mathrm{E}-03$ \\
\hline Proteobacteria & Gammaproteobacteria & Enterobacterales & Enterobacteriaceae & Klebsiella & pneumoniae & $2.68 \mathrm{E}-03(9.12 \mathrm{E}-04-1.63 \mathrm{E}-02)$ & $5.40 \mathrm{E}-04(8.12 \mathrm{E}-05-1.14 \mathrm{E}-03)$ & $4.09 \pm 1.36$ & $3.19 \mathrm{E}-02$ \\
\hline Proteobacteria & Gammaproteobacteria & Pseudomonadales & Moraxellaceae & Acinetobacter & indicus & $1.14 \mathrm{E}-03(1.33 \mathrm{E}-04-1.81 \mathrm{E}-03)$ & $0.00 \mathrm{E}+00(0.00 \mathrm{E}+00-1.26 \mathrm{E}-04)$ & $3.99 \pm 1.48$ & $4.97 \mathrm{E}-02$ \\
\hline Proteobacteria & Gammaproteobacteria & Enterobacterales & Enterobacteriaceae & Escherichia & sp KTE96 & $1.83 \mathrm{E}-03(4.83 \mathrm{E}-04-3.30 \mathrm{E}-03)$ & $9.68 \mathrm{E}-05(0.00 \mathrm{E}+00-7.69 \mathrm{E}-04)$ & $3.98 \pm 1.45$ & $4.76 \mathrm{E}-02$ \\
\hline Proteobacteria & Gammaproteobacteria & Enterobacterales & Enterobacteriaceae & Citrobacter & freundii complex sp $\mathrm{CFN}$ IH2 & $2.13 \mathrm{E}-04(1.66 \mathrm{E}-04-7.21 \mathrm{E}-04)$ & $4.00 \mathrm{E}-05(0.00 \mathrm{E}+00-9.02 \mathrm{E}-05)$ & $3.94 \pm 1.45$ & $4.81 \mathrm{E}-02$ \\
\hline Proteobacteria & Gammaproteobacteria & Enterobacterales & Enterobacteriaceae & Enterobacter & cloacae & $1.49 \mathrm{E}-03(3.42 \mathrm{E}-04-1.95 \mathrm{E}-03)$ & $1.08 \mathrm{E}-04(0.00 \mathrm{E}+00-3.00 \mathrm{E}-04)$ & $3.92 \pm 1.23$ & $2.26 \mathrm{E}-02$ \\
\hline Proteobacteria & Gammaproteobacteria & Enterobacterales & Enterobacteriaceae & Shigella & flexneri & $3.42 \mathrm{E}-01(2.39 \mathrm{E}-01-7.99 \mathrm{E}-01)$ & $4.10 \mathrm{E}-02(7.24 \mathrm{E}-03-1.49 \mathrm{E}-01)$ & $3.90 \pm 1.14$ & $1.30 \mathrm{E}-02$ \\
\hline Proteobacteria & Gammaproteobacteria & Enterobacterales & Enterobacteriaceae & Siccibacter & turicensis & $1.96 \mathrm{E}-04(1.33 \mathrm{E}-04-2.08 \mathrm{E}-04)$ & $4.84 \mathrm{E}-05(0.00 \mathrm{E}+00-1.21 \mathrm{E}-04)$ & $3.89 \pm 1.12$ & $1.21 \mathrm{E}-02$ \\
\hline Proteobacteria & Gammaproteobacteria & Enterobacterales & Enterobacteriaceae & no data & bacterium strain FGI 57 & 3.05E-03 (9.31E-04 - 8.49E-03) & $7.14 \mathrm{E}-04(1.58 \mathrm{E}-04-1.31 \mathrm{E}-03)$ & $3.86 \pm 1.20$ & $2.15 \mathrm{E}-02$ \\
\hline Proteobacteria & Gammaproteobacteria & Enterobacterales & Enterobacteriaceae & Citrobacter & freundii & $5.34 \mathrm{E}-03(9.58 \mathrm{E}-04-2.11 \mathrm{E}-02)$ & $6.44 \mathrm{E}-04(2.16 \mathrm{E}-04-1.19 \mathrm{E}-03)$ & $3.83 \pm 1.42$ & $4.97 \mathrm{E}-02$ \\
\hline Firmicutes & Erysipelotrichia & Erysipelotrichales & Erysipelotrichaceae & Coprobacillus & sp $8254 \mathrm{BFAA}$ & $5.63 \mathrm{E}-03(5.86 \mathrm{E}-04-2.25 \mathrm{E}-02)$ & $2.28 \mathrm{E}-03(2.22 \mathrm{E}-04-5.50 \mathrm{E}-03)$ & $3.72 \pm 1.15$ & $2.15 \mathrm{E}-02$ \\
\hline Proteobacteria & Gammaproteobacteria & Enterobacterales & Enterobacteriaceae & Yokenella & regensburgei & $5.32 \mathrm{E}-04(3.33 \mathrm{E}-04-9.28 \mathrm{E}-04)$ & $9.74 \mathrm{E}-05(4.14 \mathrm{E}-05-2.38 \mathrm{E}-04)$ & $3.71 \pm 1.16$ & $2.16 \mathrm{E}-02$ \\
\hline Proteobacteria & Gammaproteobacteria & no data & no data & no data & no data & $2.66 \mathrm{E}-02(6.47 \mathrm{E}-03-1.03 \mathrm{E}-01)$ & $2.62 \mathrm{E}-03(7.30 \mathrm{E}-04-9.95 \mathrm{E}-03)$ & $3.70 \pm 1.29$ & $4.11 \mathrm{E}-02$ \\
\hline Proteobacteria & Gammaproteobacteria & Enterobacterales & Enterobacteriaceae & Citrobacter & werkmanii & $3.72 \mathrm{E}-04(5.32 \mathrm{E}-05-2.93 \mathrm{E}-03)$ & $5.87 \mathrm{E}-05(3.61 \mathrm{E}-05-2.19 \mathrm{E}-04)$ & $3.63 \pm 1.20$ & $3.19 \mathrm{E}-02$ \\
\hline Proteobacteria & Gammaproteobacteria & Enterobacterales & Enterobacteriaceae & Shigella & sonnei & $2.11 \mathrm{E}-01(1.90 \mathrm{E}-01-4.21 \mathrm{E}-01)$ & $2.15 \mathrm{E}-02(5.35 \mathrm{E}-03-1.19 \mathrm{E}-01)$ & $3.58 \pm 1.15$ & $2.66 \mathrm{E}-02$ \\
\hline Actinobacteria & Actinobacteria & Corynebacteriales & Corynebacteriaceae & Corynebacterium & striatum & $5.55 \mathrm{E}-04(4.42 \mathrm{E}-04-6.65 \mathrm{E}-04)$ & $1.20 \mathrm{E}-04(1.73 \mathrm{E}-05-2.52 \mathrm{E}-04)$ & $3.46 \pm 1.02$ & $1.40 \mathrm{E}-02$ \\
\hline Proteobacteria & Gammaproteobacteria & Enterobacterales & Enterobacteriaceae & no data & no data & $2.40 \mathrm{E}+01(1.57 \mathrm{E}+01-3.93 \mathrm{E}+01)$ & $3.26 \mathrm{E}+00(3.15 \mathrm{E}-01-1.05 \mathrm{E}+01)$ & $3.34 \pm 1.17$ & $4.11 \mathrm{E}-02$ \\
\hline Actinobacteria & Actinobacteria & Corynebacteriales & Nocardiaceae & Rhodococcus & opacus & $6.19 \mathrm{E}-04(4.44 \mathrm{E}-04-7.18 \mathrm{E}-04)$ & 7.17E-05 (0.00E $+00-3.01 \mathrm{E}-04)$ & $3.32 \pm 1.13$ & $3.53 \mathrm{E}-02$ \\
\hline Firmicutes & Erysipelotrichia & Erysipelotrichales & Erysipelotrichaceae & Coprobacillus & sp D7 & $3.57 \mathrm{E}-03(4.86 \mathrm{E}-04-1.51 \mathrm{E}-02)$ & $2.00 \mathrm{E}-03(4.98 \mathrm{E}-04-5.34 \mathrm{E}-03)$ & $3.29 \pm 1.15$ & $4.11 \mathrm{E}-02$ \\
\hline Proteobacteria & Gammaproteobacteria & Enterobacterales & Enterobacteriaceae & Escherichia & albertii & $3.53 \mathrm{E}-01(1.71 \mathrm{E}-01-5.09 \mathrm{E}-01)$ & $6.62 \mathrm{E}-02(1.44 \mathrm{E}-02-1.43 \mathrm{E}-01)$ & $3.29 \pm 1.15$ & $4.16 \mathrm{E}-02$ \\
\hline Proteobacteria & Gammaproteobacteria & Enterobacterales & Enterobacteriaceae & Citrobacter & sp MGH110 & $1.66 \mathrm{E}-04(1.45 \mathrm{E}-04-6.09 \mathrm{E}-04)$ & $6.33 \mathrm{E}-05(0.00 \mathrm{E}+00-1.34 \mathrm{E}-04)$ & $3.26 \pm 1.15$ & $4.28 \mathrm{E}-02$ \\
\hline
\end{tabular}




\begin{tabular}{|l|l|l|l|l|l|l|l|l|l|}
\hline Proteobacteria & Gammaproteobacteria & Enterobacterales & Enterobacteriaceae & Kluyvera & cryocrescens & $1.04 \mathrm{E}-03(7.06 \mathrm{E}-04-1.46 \mathrm{E}-03)$ & $1.46 \mathrm{E}-04(8.05 \mathrm{E}-06-5.91 \mathrm{E}-04)$ & \multicolumn{1}{|c|}{$3.25 \pm 1.09$} & \multicolumn{1}{|c|}{$3.39 \mathrm{E}-02$} \\
\hline Proteobacteria & Gammaproteobacteria & Enterobacterales & Enterobacteriaceae & Enterobacter & no data & $5.65 \mathrm{E}-03(4.07 \mathrm{E}-03-8.89 \mathrm{E}-03)$ & $7.39 \mathrm{E}-04(1.65 \mathrm{E}-04-2.59 \mathrm{E}-03)$ & $3.09 \pm 1.13$ & $4.81 \mathrm{E}-02$ \\
\hline Proteobacteria & Gammaproteobacteria & Enterobacterales & Enterobacteriaceae & Kosakonia & cowanii & $4.42 \mathrm{E}-04(3.17 \mathrm{E}-04-4.79 \mathrm{E}-04)$ & $5.90 \mathrm{E}-05(0.00 \mathrm{E}+00-3.21 \mathrm{E}-04)$ & $2.99 \pm 1.10$ & $4.90 \mathrm{E}-02$ \\
\hline Proteobacteria & Gammaproteobacteria & Enterobacterales & Enterobacteriaceae & Shigella & boydii & $2.11 \mathrm{E}-01(7.81 \mathrm{E}-02-3.71 \mathrm{E}-01)$ & $2.20 \mathrm{E}-02(6.29 \mathrm{E}-03-7.84 \mathrm{E}-02)$ & $2.90 \pm 1.07$ & $4.90 \mathrm{E}-02$ \\
\hline
\end{tabular}

Lower in HR (12 species)

\begin{tabular}{|c|c|c|c|c|c|c|c|c|c|}
\hline Actinobacteria & Coriobacteriia & Eggerthellales & Eggerthellaceae & Eggerthella & no data & $0.00 \mathrm{E}+00(0.00 \mathrm{E}+00-0.00 \mathrm{E}+00)$ & $0.00 \mathrm{E}+00(0.00 \mathrm{E}+00-9.63 \mathrm{E}-05)$ & $-8.77 \pm 2.94$ & $3.39 \mathrm{E}-02$ \\
\hline Actinobacteria & Actinobacteria & Bifidobacteriales & Bifidobacteriaceae & Bifidobacterium & gallinarum & $0.00 \mathrm{E}+00(0.00 \mathrm{E}+00-1.47 \mathrm{E}-04)$ & $0.00 \mathrm{E}+00(0.00 \mathrm{E}+00-1.97 \mathrm{E}-02)$ & $-7.36 \pm 2.70$ & $4.81 \mathrm{E}-02$ \\
\hline Firmicutes & Clostridia & Clostridiales & Lachnospiraceae & Anaerostipes & caccae & $0.00 \mathrm{E}+00(0.00 \mathrm{E}+00-0.00 \mathrm{E}+00)$ & $2.42 \mathrm{E}-05(0.00 \mathrm{E}+00-4.28 \mathrm{E}-03)$ & $-6.45 \pm 2.38$ & $4.90 \mathrm{E}-02$ \\
\hline Firmicutes & Clostridia & Clostridiales & Lachnospiraceae & Anaerostipes & no data & $2.08 \mathrm{E}-05(0.00 \mathrm{E}+00-1.33 \mathrm{E}-04)$ & $1.23 \mathrm{E}-04(8.06 \mathrm{E}-06-4.72 \mathrm{E}-02)$ & $-6.20 \pm 2.01$ & $2.76 \mathrm{E}-02$ \\
\hline Firmicutes & Bacilli & Lactobacillales & Enterococcaceae & Enterococcus & canintestini & $7.98 \mathrm{E}-05(0.00 \mathrm{E}+00-2.92 \mathrm{E}-04)$ & $3.40 \mathrm{E}-04(3.54 \mathrm{E}-05-1.04 \mathrm{E}-02)$ & $-5.57 \pm 1.62$ & $1.27 \mathrm{E}-02$ \\
\hline Firmicutes & Erysipelotrichia & Erysipelotrichales & Erysipelotrichaceae & Catenibacterium & mitsuokai & $8.32 \mathrm{E}-05(0.00 \mathrm{E}+00-7.59 \mathrm{E}-04)$ & $2.97 \mathrm{E}-02(1.35 \mathrm{E}-03-5.00 \mathrm{E}-01)$ & $-5.29 \pm 1.71$ & $2.66 \mathrm{E}-02$ \\
\hline Actinobacteria & Actinobacteria & Bifidobacteriales & Bifidobacteriaceae & Bifidobacterium & no data & $0.00 \mathrm{E}+00(0.00 \mathrm{E}+00-2.22 \mathrm{E}-04)$ & $3.54 \mathrm{E}-04(3.63 \mathrm{E}-05-1.07 \mathrm{E}-02)$ & $-4.80 \pm 1.75$ & $4.76 \mathrm{E}-02$ \\
\hline Firmicutes & Bacilli & Lactobacillales & Streptococcaceae & Streptococcus & pasteurianus & $4.89 \mathrm{E}-04(1.38 \mathrm{E}-04-3.65 \mathrm{E}-03)$ & $6.72 \mathrm{E}-03(1.91 \mathrm{E}-03-2.25 \mathrm{E}-01)$ & $-4.26 \pm 1.55$ & $4.76 \mathrm{E}-02$ \\
\hline Firmicutes & Clostridia & Clostridiales & Lachnospiraceae & Anaerostipes & sp $3256 \mathrm{FAA}$ & $1.55 \mathrm{E}-03(2.92 \mathrm{E}-04-1.01 \mathrm{E}-02)$ & $2.29 \mathrm{E}-02(5.94 \mathrm{E}-03-4.40 \mathrm{E}-02)$ & $-3.96 \pm 1.07$ & $7.29 \mathrm{E}-03$ \\
\hline Firmicutes & Clostridia & Clostridiales & Eubacteriaceae & no data & bacterium CHKCI004 & $0.00 \mathrm{E}+00(0.00 \mathrm{E}+00-3.97 \mathrm{E}-05)$ & $1.54 \mathrm{E}-04(5.61 \mathrm{E}-05-5.19 \mathrm{E}-04)$ & $-3.63 \pm 1.23$ & $3.48 \mathrm{E}-02$ \\
\hline Firmicutes & Clostridia & Clostridiales & Lachnospiraceae & no data & bacterium 31 46FAA & $5.06 \mathrm{E}-04(1.35 \mathrm{E}-04-3.67 \mathrm{E}-03)$ & $5.23 \mathrm{E}-03(2.61 \mathrm{E}-03-3.45 \mathrm{E}-02)$ & $-2.85 \pm 1.03$ & $4.71 \mathrm{E}-02$ \\
\hline Firmicutes & Clostridia & Clostridiales & Clostridiaceae & Clostridium & sp SS2/1 & $2.93 \mathrm{E}-04(6.49 \mathrm{E}-05-6.85 \mathrm{E}-04)$ & $1.51 \mathrm{E}-03(7.01 \mathrm{E}-04-4.71 \mathrm{E}-03)$ & $-2.47 \pm 0.85$ & $3.59 \mathrm{E}-02$ \\
\hline
\end{tabular}

FC: fold change, SE: standard error, NS: not significant

${ }^{1} \mathrm{p}$ values were adjusted with false discovery rate for multiple comparisons 


\section{Table 8(on next page)}

Summary of the differential abundances of Bacteroidales, Clostridiales, Lactobacillales, and Enterobacterales at baseline and week 4 in all dogs $(n=28)$, high- $(n=9)$, and lowresponders $(n=10)$

Data expressed as numbers of species and percentages of all species being compared in each order. 
Table 8. Summary of the differential abundances of Bacteroidales, Clostridiales, Lactobacillales, and Enterobacterales at baseline and week 4 in all dogs $(n=28)$, high- $(n=9)$, and low-responders $(n=10)$. Data expressed as numbers of species and percentages of all species being compared in each order.

\begin{tabular}{|c|c|c|c|c|}
\hline Bacteria (Order) & Subjects & Baseline & Change in the abundance & Week 4 \\
\hline \multirow[t]{3}{*}{$\begin{array}{l}\text { Bacteroidales } \\
96 \text { species compared }\end{array}$} & All & - & $\begin{array}{l}\uparrow 1 \text { species }(1.0 \%) \\
\downarrow 5 \text { species }(5.2 \%)\end{array}$ & - \\
\hline & HR & \multirow{2}{*}{$\begin{array}{l}\text { HR>LR: } 20 \text { species }(20.8 \%) \\
\text { HR <LR: } 0 \text { species }(0 \%)\end{array}$} & $\downarrow 7$ species $(7.3 \%)$ & \multirow{2}{*}{$\begin{array}{l}\text { HR>LR: } 0 \text { species }(0 \%) \\
\text { HR<LR: } 0 \text { species }(0 \%)\end{array}$} \\
\hline & LR & & $\uparrow 1$ species $(1.0 \%)$ & \\
\hline \multirow[t]{3}{*}{$\begin{array}{l}\text { Clostridiales } \\
205 \text { species compared }\end{array}$} & All & - & $\begin{array}{c}\uparrow 3 \text { species }(1.5 \%) \\
\downarrow 13 \text { species }(6.3 \%)\end{array}$ & - \\
\hline & HR & \multirow{2}{*}{$\begin{array}{l}\text { HR>LR: } 7 \text { species }(3.4 \%) \\
\text { HR<LR: } 3 \text { species }(1.5 \%)\end{array}$} & $\begin{array}{l}\uparrow 5 \text { species }(2.4 \%) \\
\downarrow 17 \text { species }(8.3 \%)\end{array}$ & \multirow{2}{*}{$\begin{array}{l}\text { HR>LR: } 9 \text { species }(4.4 \%) \\
\text { HR<LR: } 6 \text { species }(2.9 \%)\end{array}$} \\
\hline & LR & & $\begin{array}{l}\uparrow 3 \text { species }(1.5 \%) \\
\downarrow 1 \text { species }(0.5 \%)\end{array}$ & \\
\hline \multirow[t]{3}{*}{$\begin{array}{l}\text { Lactobacillales } \\
205 \text { species compared }\end{array}$} & All & - & $\begin{array}{c}\uparrow 47 \text { species }(22.9 \%) \\
\downarrow 2 \text { species }(1.0 \%)\end{array}$ & - \\
\hline & HR & \multirow[b]{2}{*}{$\begin{array}{l}\text { HR<LR: } 34 \text { species }(16.6 \%) \\
\text { HR>LR: } 1 \text { species }(0.5 \%)\end{array}$} & $\uparrow 77$ species $(37.6 \%)$ & \multirow[b]{2}{*}{$\begin{array}{l}\text { HR>LR: } 5 \text { species }(2.4 \%) \\
\text { HR<LR: } 2 \text { species }(1.0 \%)\end{array}$} \\
\hline & LR & & $\begin{array}{l}\uparrow 5 \text { species }(2.4 \%) \\
\downarrow 1 \text { species }(0.5 \%)\end{array}$ & \\
\hline $\begin{array}{l}\text { Enterobacteriales } \\
205 \text { species compared }\end{array}$ & All & - & $\uparrow 17$ species $(8.3 \%)$ & - \\
\hline
\end{tabular}




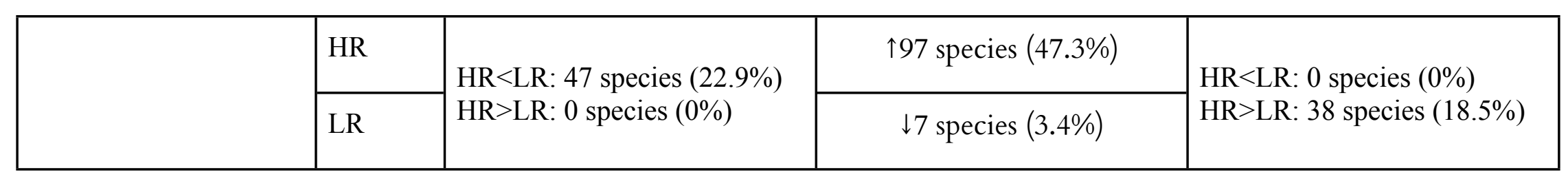


Table 9 (on next page)

Bacterial species whose abundance at week 4 was significantly different (|fold change| $\geq 2$ and FDR-adjusted $p<0.05)$ between those reporting "better" $(n=16)$ and "about the same" overall health $(n=10)$ after diet change. 
1 Table 9. Bacterial species whose abundance at week 4 was significantly different (|fold change $\mid \geq 2$ and FDR-adjusted $p<0.05$ )

2 between those reporting "better" $(\mathrm{n}=16)$ and "about the same" overall health $(\mathrm{n}=10)$ after diet change.

\begin{tabular}{|c|c|c|c|c|c|c|c|c|c|}
\hline \multirow[t]{2}{*}{ Phylum } & \multirow[t]{2}{*}{ Class } & \multirow[t]{2}{*}{ Order } & \multirow[t]{2}{*}{ Family } & \multirow[t]{2}{*}{ Genus } & \multirow[t]{2}{*}{ Species } & \multicolumn{2}{|c|}{$\begin{array}{c}\text { Relative abundance, in \% } \\
\text { Median (IQR) }\end{array}$} & \multicolumn{2}{|c|}{$\begin{array}{c}\text { Better vs About the same health } \\
\text { Week } 4\end{array}$} \\
\hline & & & & & & $\begin{array}{c}\text { Better overall health } \\
(n=16)\end{array}$ & $\begin{array}{l}\text { About the same overall health } \\
\qquad(\mathrm{n}=10)\end{array}$ & $\begin{array}{c}\log 2 \mathrm{FC} \\
\text { mean } \pm \mathrm{SE}\end{array}$ & $\begin{array}{l}\text { Adjusted } \\
P \text {-value }\end{array}$ \\
\hline \multicolumn{10}{|c|}{ Higher in "better overall health" (35 species) } \\
\hline Firmicutes & Bacilli & Bacillales & Bacillaceae & Lysinibacillus & sphaericus & $0.00 \mathrm{E}+00(0.00 \mathrm{E}+00-0.00 \mathrm{E}+00)$ & $0.00 \mathrm{E}+00(0.00 \mathrm{E}+00-0.00 \mathrm{E}+00)$ & $25.39 \pm 3.04$ & $3.41 \mathrm{E}-14$ \\
\hline Actinobacteria & Actinobacteria & Bifidobacteriales & Bifidobacteriaceae & Bifidobacterium & animalis & $0.00 \mathrm{E}+00(0.00 \mathrm{E}+00-2.94 \mathrm{E}-05)$ & $0.00 \mathrm{E}+00(0.00 \mathrm{E}+00-0.00 \mathrm{E}+00)$ & $10.52 \pm 3.04$ & $1.54 \mathrm{E}-02$ \\
\hline Firmicutes & Bacilli & Lactobacillales & Enterococcaceae & Enterococcus & avium & $1.85 \mathrm{E}-04(0.00 \mathrm{E}+00-9.98 \mathrm{E}-04)$ & $0.00 \mathrm{E}+00(0.00 \mathrm{E}+00-3.11 \mathrm{E}-05)$ & $8.40 \pm 2.03$ & $3.09 \mathrm{E}-03$ \\
\hline Firmicutes & Bacilli & Lactobacillales & Enterococcaceae & Enterococcus & sp 3C7 DIV0644 & $6.49 \mathrm{E}-05(0.00 \mathrm{E}+00-2.20 \mathrm{E}-03)$ & $0.00 \mathrm{E}+00(0.00 \mathrm{E}+00-0.00 \mathrm{E}+00)$ & $8.39 \pm 1.94$ & $2.71 \mathrm{E}-03$ \\
\hline Firmicutes & Bacilli & Lactobacillales & Lactobacillaceae & Lactobacillus & plantarum & $3.25 \mathrm{E}-04(8.20 \mathrm{E}-05-1.99 \mathrm{E}-03)$ & $1.18 \mathrm{E}-04(0.00 \mathrm{E}+00-1.64 \mathrm{E}-03)$ & $8.35 \pm 1.68$ & $1.84 \mathrm{E}-04$ \\
\hline Firmicutes & Bacilli & Lactobacillales & Enterococcaceae & Enterococcus & sp 3G6 DIV0642 & $8.56 \mathrm{E}-04(0.00 \mathrm{E}+00-6.13 \mathrm{E}-03)$ & $0.00 \mathrm{E}+00(0.00 \mathrm{E}+00-0.00 \mathrm{E}+00)$ & $7.89 \pm 1.84$ & $2.71 \mathrm{E}-03$ \\
\hline Firmicutes & Bacilli & Lactobacillales & Enterococcaceae & Enterococcus & sp HMSC072H05 & $1.33 \mathrm{E}-05(0.00 \mathrm{E}+00-2.88 \mathrm{E}-04)$ & $0.00 \mathrm{E}+00(0.00 \mathrm{E}+00-0.00 \mathrm{E}+00)$ & $7.87 \pm 2.36$ & $1.88 \mathrm{E}-02$ \\
\hline Firmicutes & Bacilli & Lactobacillales & Enterococcaceae & Enterococcus & sp FDAARGOOS 163 & $1.35 \mathrm{E}-04(0.00 \mathrm{E}+00-3.44 \mathrm{E}-03)$ & $0.00 \mathrm{E}+00(0.00 \mathrm{E}+00-0.00 \mathrm{E}+00)$ & $7.30 \pm 1.95$ & $6.49 \mathrm{E}-03$ \\
\hline Actinobacteria & Actinobacteria & Micrococcales & Micrococcaceae & Arthrobacter & no data & $8.09 \mathrm{E}-05(0.00 \mathrm{E}+00-3.75 \mathrm{E}-04)$ & $0.00 \mathrm{E}+00(0.00 \mathrm{E}+00-3.29 \mathrm{E}-05)$ & $7.05 \pm 1.83$ & $5.68 \mathrm{E}-03$ \\
\hline Firmicutes & Bacilli & Lactobacillales & Enterococcaceae & Enterococcus & sp 5B3 DIV0040 & $4.23 \mathrm{E}-04(0.00 \mathrm{E}+00-5.17 \mathrm{E}-03)$ & $0.00 \mathrm{E}+00(0.00 \mathrm{E}+00-2.42 \mathrm{E}-05)$ & $6.66 \pm 1.64$ & $3.09 \mathrm{E}-03$ \\
\hline Firmicutes & Bacilli & Lactobacillales & Enterococcaceae & Enterococcus & sp CR-Ec1 & $7.63 \mathrm{E}-05(0.00 \mathrm{E}+00-1.59 \mathrm{E}-03)$ & $0.00 \mathrm{E}+00(0.00 \mathrm{E}+00-0.00 \mathrm{E}+00)$ & $6.39 \pm 1.85$ & $1.54 \mathrm{E}-02$ \\
\hline Firmicutes & Bacilli & Lactobacillales & Enterococcaceae & Enterococcus & sp kppr-6 & $5.33 \mathrm{E}-05(0.00 \mathrm{E}+00-4.47 \mathrm{E}-03)$ & $0.00 \mathrm{E}+00(0.00 \mathrm{E}+00-2.42 \mathrm{E}-05)$ & $6.17 \pm 1.63$ & $6.25 \mathrm{E}-03$ \\
\hline Firmicutes & Bacilli & Lactobacillales & Enterococcaceae & Enterococcus & sp FDAARGGOS 375 & $9.02 \mathrm{E}-04(2.08 \mathrm{E}-05-1.91 \mathrm{E}-02)$ & $4.83 \mathrm{E}-05(0.00 \mathrm{E}+00-2.76 \mathrm{E}-04)$ & $6.12 \pm 1.50$ & $3.09 \mathrm{E}-03$ \\
\hline Firmicutes & Bacilli & Lactobacillales & Streptococcaceae & Streptococcus & orisratti & $1.02 \mathrm{E}-04(0.00 \mathrm{E}+00-7.83 \mathrm{E}-04)$ & $0.00 \mathrm{E}+00(0.00 \mathrm{E}+00-0.00 \mathrm{E}+00)$ & $5.94 \pm 1.88$ & $3.03 \mathrm{E}-02$ \\
\hline Firmicutes & Bacilli & Lactobacillales & Enterococcaceae & Enterococcus & casseliflavus & $4.22 \mathrm{E}-03(3.18 \mathrm{E}-04-5.93 \mathrm{E}-02)$ & $5.53 \mathrm{E}-05(6.27 \mathrm{E}-06-4.45 \mathrm{E}-04)$ & $5.68 \pm 1.49$ & $5.79 \mathrm{E}-03$ \\
\hline Firmicutes & Bacilli & Lactobacillales & Lactobacillaceae & Lactobacillus & brevis & $2.64 \mathrm{E}-04(0.00 \mathrm{E}+00-8.82 \mathrm{E}-04)$ & $5.09 \mathrm{E}-05(3.45 \mathrm{E}-05-5.27 \mathrm{E}-04)$ & $5.61 \pm 1.49$ & $6.49 \mathrm{E}-03$ \\
\hline Firmicutes & Bacilli & Lactobacillales & Enterococcaceae & Enterococcus & pseudoavium & $7.17 \mathrm{E}-05(0.00 \mathrm{E}+00-3.14 \mathrm{E}-04)$ & $0.00 \mathrm{E}+00(0.00 \mathrm{E}+00-0.00 \mathrm{E}+00)$ & $5.49 \pm 1.57$ & $1.51 \mathrm{E}-02$ \\
\hline Proteobacteria & Gammaproteobacteria & Enterobacterales & Hafniaceae & Hafnia & alvei & $8.40 \mathrm{E}-04(5.64 \mathrm{E}-05-1.16 \mathrm{E}-01)$ & $3.45 \mathrm{E}-05(0.00 \mathrm{E}+00-4.21 \mathrm{E}-04)$ & $5.48 \pm 1.60$ & $1.60 \mathrm{E}-02$ \\
\hline Firmicutes & Erysipelotrichia & Erysipelotrichales & Erysipelotrichaceae & Catenibacterium & mitsuokai & 4.69E-03 (3.99E-05 - 7.00E-01) & $7.95 \mathrm{E}-04(1.71 \mathrm{E}-04-2.00 \mathrm{E}-02)$ & $5.46 \pm 1.69$ & $2.62 \mathrm{E}-02$ \\
\hline Firmicutes & Bacilli & Lactobacillales & Enterococcaceae & Enterococcus & sp 6D12 DIV0197 & $2.71 \mathrm{E}-04(0.00 \mathrm{E}+00-9.29 \mathrm{E}-03)$ & $0.00 \mathrm{E}+00(0.00 \mathrm{E}+00-6.22 \mathrm{E}-05)$ & $5.38 \pm 1.81$ & $4.60 \mathrm{E}-02$ \\
\hline Proteobacteria & Gammaproteobacteria & Enterobacterales & Enterobacteriaceae & Raoultella & ornithinolytica & $1.96 \mathrm{E}-04(0.00 \mathrm{E}+00-3.51 \mathrm{E}-03)$ & $5.90 \mathrm{E}-05(8.27 \mathrm{E}-06-1.22 \mathrm{E}-04)$ & $5.34 \pm 1.34$ & $3.73 \mathrm{E}-03$ \\
\hline Firmicutes & Bacilli & Lactobacillales & Enterococcaceae & Enterococcus & sp $\mathrm{HMSC} 05 \mathrm{C} 03$ & $1.11 \mathrm{E}-04(0.00 \mathrm{E}+00-8.99 \mathrm{E}-04)$ & $0.00 \mathrm{E}+00(0.00 \mathrm{E}+00-0.00 \mathrm{E}+00)$ & $5.28 \pm 1.58$ & $1.87 \mathrm{E}-02$ \\
\hline Firmicutes & Bacilli & Lactobacillales & Streptococcaceae & Streptococcus & canis & $1.46 \mathrm{E}-04(0.00 \mathrm{E}+00-1.36 \mathrm{E}-03)$ & $3.45 \mathrm{E}-05(0.00 \mathrm{E}+00-1.93 \mathrm{E}-04)$ & $5.11 \pm 1.67$ & $3.78 \mathrm{E}-02$ \\
\hline Firmicutes & Clostridia & Clostridiales & Lachnospiraceae & Anaerostipes & no data & $1.82 \mathrm{E}-04(0.00 \mathrm{E}+00-2.27 \mathrm{E}-02)$ & $4.25 \mathrm{E}-05(5.19 \mathrm{E}-06-3.35 \mathrm{E}-03)$ & $4.83 \pm 1.57$ & $3.63 \mathrm{E}-02$ \\
\hline Firmicutes & Bacilli & Lactobacillales & Enterococcaceae & Enterococcus & gallinarum & $1.84 \mathrm{E}-03(2.06 \mathrm{E}-04-8.66 \mathrm{E}-03)$ & $8.58 \mathrm{E}-05(0.00 \mathrm{E}+00-1.66 \mathrm{E}-03)$ & $4.82 \pm 1.34$ & $1.04 \mathrm{E}-02$ \\
\hline Firmicutes & Bacilli & Lactobacillales & Enterococcaceae & Enterococcus & dispar & $7.80 \mathrm{E}-05(0.00 \mathrm{E}+00-1.00 \mathrm{E}-03)$ & $0.00 \mathrm{E}+00(0.00 \mathrm{E}+00-6.09 \mathrm{E}-05)$ & $4.75 \pm 1.45$ & $2.23 \mathrm{E}-02$ \\
\hline Firmicutes & Bacilli & Lactobacillales & Enterococcaceae & Enterococcus & malodoratus & $1.66 \mathrm{E}-04(3.32 \mathrm{E}-05-5.32 \mathrm{E}-04)$ & $0.00 \mathrm{E}+00(0.00 \mathrm{E}+00-3.67 \mathrm{E}-05)$ & $4.72 \pm 1.38$ & $1.64 \mathrm{E}-02$ \\
\hline Firmicutes & Bacilli & Lactobacillales & Carnobacteriaceae & Carnobacterium & maltaromaticum & $2.01 \mathrm{E}-04$ (9.79E-05 - 3.96E-03) & $2.93 \mathrm{E}-05(0.00 \mathrm{E}+00-9.28 \mathrm{E}-04)$ & $4.30 \pm 1.36$ & $3.03 \mathrm{E}-02$ \\
\hline Firmicutes & Bacilli & Lactobacillales & Lactobacillaceae & Lactobacillus & fermentum & $3.96 \mathrm{E}-04(0.00 \mathrm{E}+00-1.01 \mathrm{E}-03)$ & $6.09 \mathrm{E}-05(0.00 \mathrm{E}+00-2.59 \mathrm{E}-04)$ & $4.29 \pm 1.37$ & $3.14 \mathrm{E}-02$ \\
\hline
\end{tabular}




\begin{tabular}{|c|c|c|c|c|c|c|c|c|c|}
\hline Firmicutes & Bacilli & Lactobacillales & Streptococcaceae & Lactococcus & garvieae & $4.12 \mathrm{E}-04(1.69 \mathrm{E}-04-1.80 \mathrm{E}-03)$ & $1.88 \mathrm{E}-04(0.00 \mathrm{E}+00-4.24 \mathrm{E}-04)$ & $4.09 \pm 1.21$ & $1.74 \mathrm{E}-02$ \\
\hline Firmicutes & Bacilli & Lactobacillales & Streptococcaceae & Lactococcus & lactis & $2.18 \mathrm{E}-02(2.76 \mathrm{E}-03-1.32 \mathrm{E}-01)$ & $6.68 \mathrm{E}-03(3.89 \mathrm{E}-03-2.35 \mathrm{E}-02)$ & $3.88 \pm 1.12$ & $1.54 \mathrm{E}-02$ \\
\hline Firmicutes & Erysipelotrichia & Erysipelotrichales & Erysipelotrichaceae & Erysipelatoclostridium & innocuum & $6.12 \mathrm{E}-04(2.26 \mathrm{E}-04-3.63 \mathrm{E}-03)$ & $1.46 \mathrm{E}-04(3.54 \mathrm{E}-05-2.50 \mathrm{E}-04)$ & $3.83 \pm 0.94$ & $3.09 \mathrm{E}-03$ \\
\hline Firmicutes & Erysipelotrichia & Erysipelotrichales & Erysipelotrichaceae & Coprobacillus & sp $3356 \mathrm{FAA}$ & $4.90 \mathrm{E}-03(8.45 \mathrm{E}-04-1.62 \mathrm{E}-02)$ & $8.80 \mathrm{E}-04(1.98 \mathrm{E}-05-3.02 \mathrm{E}-03)$ & $3.54 \pm 1.13$ & $3.14 \mathrm{E}-02$ \\
\hline Firmicutes & Erysipelotrichia & Erysipelotrichales & Erysipelotrichaceae & no data & no data & $2.01 \mathrm{E}-01(1.77 \mathrm{E}-02-1.16 \mathrm{E}+00)$ & $2.66 \mathrm{E}-02(4.94 \mathrm{E}-03-2.53 \mathrm{E}-01)$ & $3.35 \pm 1.09$ & $3.63 \mathrm{E}-02$ \\
\hline Firmicutes & Erysipelotrichia & Erysipelotrichales & Erysipelotrichaceae & Coprobacillus & sp 8254 BFAA & $6.89 \mathrm{E}-03(2.25 \mathrm{E}-03-1.77 \mathrm{E}-02)$ & $5.31 \mathrm{E}-04(5.01 \mathrm{E}-05-4.51 \mathrm{E}-03)$ & $3.15 \pm 1.06$ & $4.60 \mathrm{E}-02$ \\
\hline \multicolumn{10}{|c|}{ Lower in "better overall health" (2 species) } \\
\hline Bacteroidetes & Bacteroidia & Bacteroidales & Bacteroidaceae & Bacteroides & stercoris & $7.21 \mathrm{E}-05(0.00 \mathrm{E}+00-1.05 \mathrm{E}-03)$ & $1.43 \mathrm{E}-03(0.00 \mathrm{E}+00-1.59 \mathrm{E}-01)$ & $-6.79 \pm 1.71$ & $3.73 \mathrm{E}-03$ \\
\hline Bacteroidetes & Bacteroidia & Bacteroidales & Bacteroidaceae & Bacteroides & coprocola & $1.50 \mathrm{E}-05(0.00 \mathrm{E}+00-5.17 \mathrm{E}-04)$ & $2.17 \mathrm{E}-04(2.38 \mathrm{E}-05-5.16 \mathrm{E}-02)$ & $-6.58 \pm 1.60$ & 3.09E- -03 \\
\hline
\end{tabular}

3 FC: fold change, SE: standard error, NS: not significant

$4 \quad{ }^{1} \mathrm{p}$ values were adjusted with false discovery rate for multiple comparisons 